Check for updates

Cite this: RSC Adv., 2019, 9, 8515

Received 24th December 2018

Accepted 3rd March 2019

DOI: 10.1039/c8ra10532d

rsc.li/rsc-advances

\title{
Synthesis, anti-mycobacterial and cytotoxic evaluation of substituted isoindoline-1,3-dione-4- aminoquinolines coupled via alkyl/amide linkers $\uparrow$
}

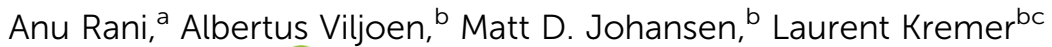 \\ and Vipan Kumar (iD *a
}

A series of secondary amine-substituted isoindoline-1,3-dione-4-aminoquinolines were prepared via microwave heating and assayed for their anti-mycobacterial activities. The compound with a butyl chain as a spacer between the two pharmacophores and piperidine as the secondary amine component on the isoindoline ring was the most potent and non-cytotoxic among the synthesized compounds, exhibiting a minimum inhibitory concentration ( $\mathrm{MIC}_{99}$ ) of $6.25 \mu \mathrm{g} \mathrm{mL} \mathrm{m}^{-1}$ against Mycobacterium tuberculosis.

\section{Introduction}

Tuberculosis (TB) is a global pandemic caused by the single infectious agent Mycobacterium tuberculosis. TB has been a scourge to mankind for thousands of years and roughly more than one third of the world's population is latently infected. ${ }^{1}$ In 2016, there were 10.4 million new cases of TB diagnosed with approximate mortality of 1.3 million among HIV-negative and an additional 374000 deaths among HIV-positive people, mostly in developing countries. ${ }^{2}$ According to the Revised National Tuberculosis Control Program (RNTCP), India accounts for one fourth of the global TB burden with 1.75 million TB patients, including data from both the public and private health sectors, while 33820 drug-resistant TB patients are noted additionally. ${ }^{3}$ Increasing cases of multidrug-resistant (MDR) TB and extensively drug-resistant (XDR) TB all over the world is hindering current TB treatment, ${ }^{4}$ which includes the first-line drugs isoniazid (INH), rifampicin (RIF), pyrazinamide, ethambutol, and streptomycin, and the second line drugs, aminoglycosides, polypeptides, fluoroquinolones, thioamides, cycloserine and terizidone., ${ }^{5,6}$ The emergence of resistant strains warrants the urgent search for faster-acting, less harmful, more efficient drug candidates.

The quinoline core has received recent attention as it is one of the active key building blocks of many drugs. Bedaquiline -

${ }^{a}$ Department of Chemistry, Guru Nanak Dev University, Amritsar-143005, Punjab, India.E-mail: vipan_org@yahoo.com

${ }^{b}$ Institut de Recherche en Infectiologie (IRIM) de Montpellier, CNRS, UMR 9004 Université de Montpellier, France

INSERM, IRIM, 34293 Montpellier, France

$\dagger$ Electronic supplementary information (ESI) available: Scanned ${ }^{1} \mathrm{H}$ and ${ }^{13} \mathrm{C}$ NMR spectra of few representative compounds viz. 4c, 4d, 4f, 4k, 4m, 4o, 4s, 7a, 7c, 7e, $\mathbf{7 i}, \mathbf{7 n}, \mathbf{7 q}, \mathbf{8 a}, \mathbf{8 c}, \mathbf{8 d}, \mathbf{8 j}, \mathbf{8 n}$ and $\mathbf{8 p}$ are provided in the electronic supplementary information. See DOI: $10.1039 / \mathrm{c} 8 \mathrm{ra10532d}$ a diarylquinoline - was recently approved by Food and Drug Administration (FDA) and European Medicine Agency (EMA) for treating MDR-TB patients. ${ }^{-9}$ However, the drug comes with a black-box warning, which includes the risk of cardiac (QT prolongation) and hepatic dysfunction and heightened risk of mortality. ${ }^{10}$ Mefloquine, an orally administered drug, is another quinoline derivative known for potent anti-tubercular activity. ${ }^{11-15}$ Remarkably, numerous derivatives of mefloquine were reported to have good antibacterial and anti-mycobacterial activities. $^{\mathbf{1 6 , 1 7}}$

Isoindoline-1,3-dione and its derivatives were shown to possess interesting biological properties ${ }^{\mathbf{1 8}}$ against a wide panel of diseases and conditions, such as angiogenic disease, ${ }^{19}$ inflammation, ${ }^{20}$ cancer, ${ }^{21,22}$ Parkinson's, ${ }^{23}$ leprosy, AIDS and multiple myeloma (MM); as COX inhibitors; antidepressants and histone deacetylase inhibitors. ${ }^{24}$ Synthesis of conjugates of the isoindoline-1,3-dione subunit with different active moieties afforded active antimicrobials against Mycobacterium leprae and M. tuberculosis. ${ }^{25}$

A recent report from our lab highlighted the antimycobacterial potential of isoindoline-1,3-dione-4aminoquinolines, exhibiting comparable activity with ethionamide and cephalexin (Fig. 1). ${ }^{26}$ In continuation of our efforts, ${ }^{27}$ we present herein the synthesis and anti-mycobacterial

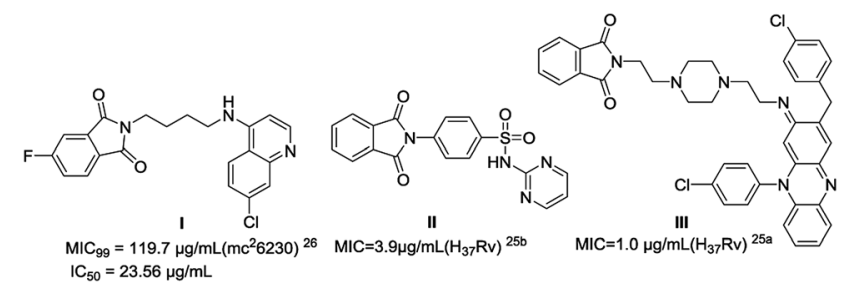

Fig. 1 Isoindoline-1,3-dione based active anti-TB compounds. 
activities of secondary amino-substituted isoindoline-1,3-dione4-aminoquinolines. The spacer length between two pharmacophores as well as the secondary amine functionality at the C4/C5 position of isoindoline-1,3-dione was meticulously altered for analysing the structure-activity relationship (SAR).

\section{Results and discussion}

\section{Synthetic chemistry}

For the synthesis of the desired isoindoline-1,3-dione-4aminoquinolines with the secondary amine functionality at the $\mathrm{C}-4 / \mathrm{C}-5$ position, microwave heating was attempted, as the reactions were sluggish when carried out under conventional heating. The microwave assisted reaction between 3-fluorophthalic anhydride 1a, $N$-(7-chloroquinolin-4-yl)diamine $\mathbf{2 a ^ { 2 8 }}$ and piperidine was chosen as model reaction. Different solvents viz. DMF, DMSO and NMP were screened, both for the singlepot as well as for the step-wise synthesis and the results are provided in Scheme 1. As evident, the single pot synthesis gave the desired scaffold $\mathbf{4 a}$, albeit in moderate yields, when compared to the step-wise process. The solvent choice seems to be crucial and better yields were observed by heating in NMP because of its polar aprotic nature and ease of removal during purification procedure. Best results obtained via either heating in single pot synthesis at $160{ }^{\circ} \mathrm{C}$ for $5 \mathrm{~min}$ (70\% yield) or in stepwise synthesis by heating at $140{ }^{\circ} \mathrm{C}$ for 2 min for step 1 and then at $160{ }^{\circ} \mathrm{C}$ for $2 \mathrm{~min}$ for step 2 ( $89 \%$ yield).

Having optimized the reaction conditions, the scope of the developed strategy was then explored for the synthesis of a series of C-4/C-5 secondary amine linked isoindoline-1,3dione-4-aminoquinolines $\mathbf{4 b}-\mathbf{4 t}$ following the stepwise microwave synthesis (Scheme 2). The structure assignment was done on the basis of spectral data and analytical evidences. For example, the compound $\mathbf{4 s}$ exhibited a molecular ion peak at $\mathrm{m} /$ $z$ 508.2084 $[\mathrm{M}+\mathrm{H}]^{+}$in the High Resolution Mass Spectrum (HRMS). The noteworthy features of its ${ }^{1} \mathrm{H}$ NMR spectrum encompassed the appearance of multiplet at $\delta$ 1.76-1.86, two triplets at $3.34(\mathrm{~J}=6.6 \mathrm{~Hz})$ and $3.73(\mathrm{~J}=6.4 \mathrm{~Hz})$ because of methylenes, two triplets at $2.66(J=4.7 \mathrm{~Hz})$ and $3.40(J=4.6 \mathrm{~Hz})$

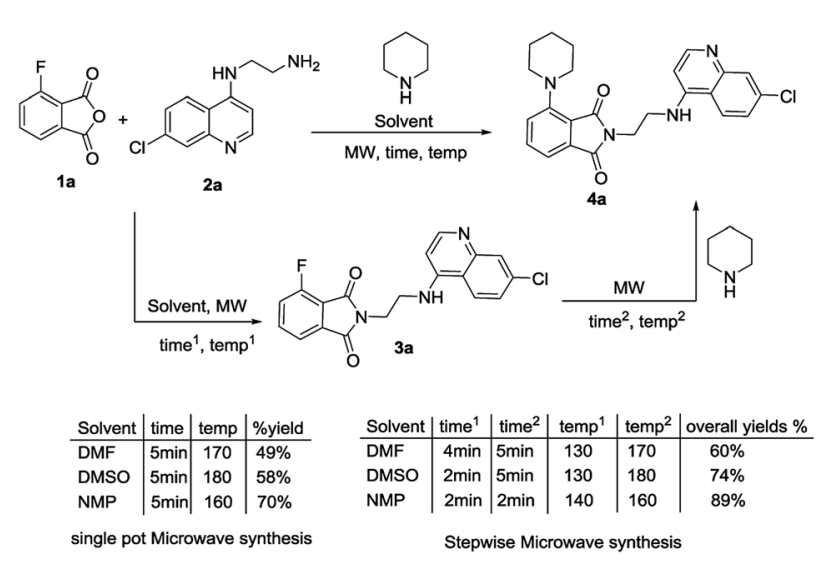

Scheme 1 Optimizing microwave-assisted synthesis of the C-4piperidine ring substituted isoindoline-1,3-dione-4-aminoquinolines $4 a$.

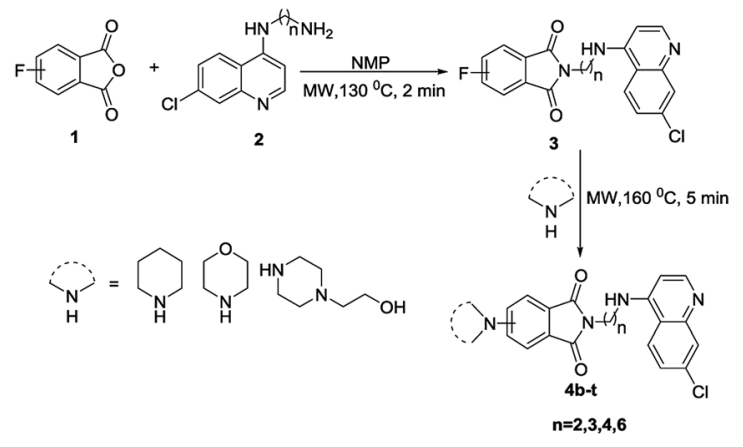

Scheme 2 Microwave-promoted synthesis of C-4/C-5 secondary amine substituted isoindoline-1,3-dione-4-aminoquinolines (4b-t).

because of piperazine ring protons and a doublet at $\delta 7.00(\mathrm{~J}=$ $8.4 \mathrm{~Hz}$ ) because of aromatic ring protons. The presence of absorption peaks at $\delta 169.1$ and 168.7, corresponding to carbonyl carbons in the ${ }^{13} \mathrm{C}$ NMR spectrum along with methylenes at $\delta 25.5,26.5,37.2$ and 42.8 and piperazine carbons at $\delta 47.6$ and 52.4 , as corroborated by the ${ }^{13} \mathrm{C}$ NMR (DEPT) spectrum, validated the assigned structure. For the synthesis of conjugates 7a-r, amide coupling of 6 with $N$-(7-chloroquinolin4-yl)diamine 2 was done using amide coupling reagents EDCHOBt at room temperature. Further, C-5 flouro substituted conjugates $\mathbf{7 m}-\mathbf{r}$ were reacted with different secondary amines under microwave heating resulted in the formation of desired conjugates 8a-r in good to excellent yields (Scheme 3). Spectral data and analytical evidences were used to assign the structure to the synthesized conjugates.

\section{In vitro anti-mycobacterial evaluation}

The synthesized scaffolds were assayed for their antimycobacterial activities against $M$. tuberculosis $\mathrm{mc}^{2} 6230$ and the result are enlisted in Table 1 . As evident, all the synthesized compounds were not as active as isoniazid, but some of them showed promising activities. A closer analysis of Table 1 showed the dependence of activity on the nature of linker between two pharmacophores, the nature of substituent at C-4/C-5 position of isoindoline-1,3-dione as well as the linker used as spacer. Cytotoxic studies of all the synthesized compounds were also carried out against Vero cells so as to confirm whether the observed activities were due to their inherent antimycobacterial efficacy or cytotoxicity (Table 1, Fig. 2).

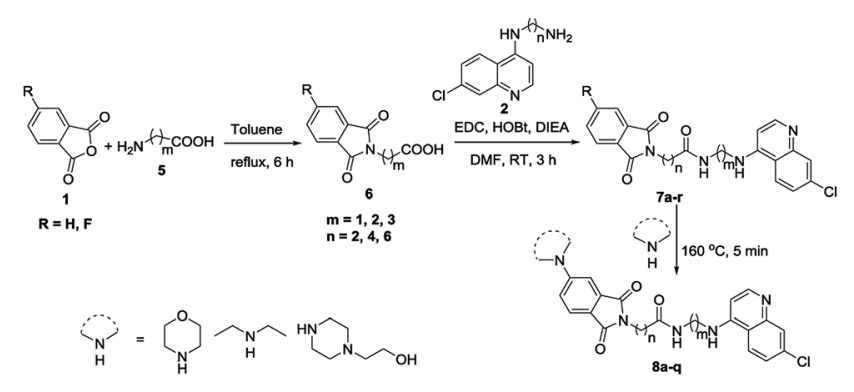

Scheme 3 Synthesis of C-5 substituted isoindoline-1,3-dione linked with 4-aminoquinolines via amide spacer $7 a-r, 8 a-r$. 
Table 1 In vitro anti-mycobacterial activity of synthesized compounds against M. tuberculosis mc ${ }^{2} 6230$ and cytotoxicity against Vero cells

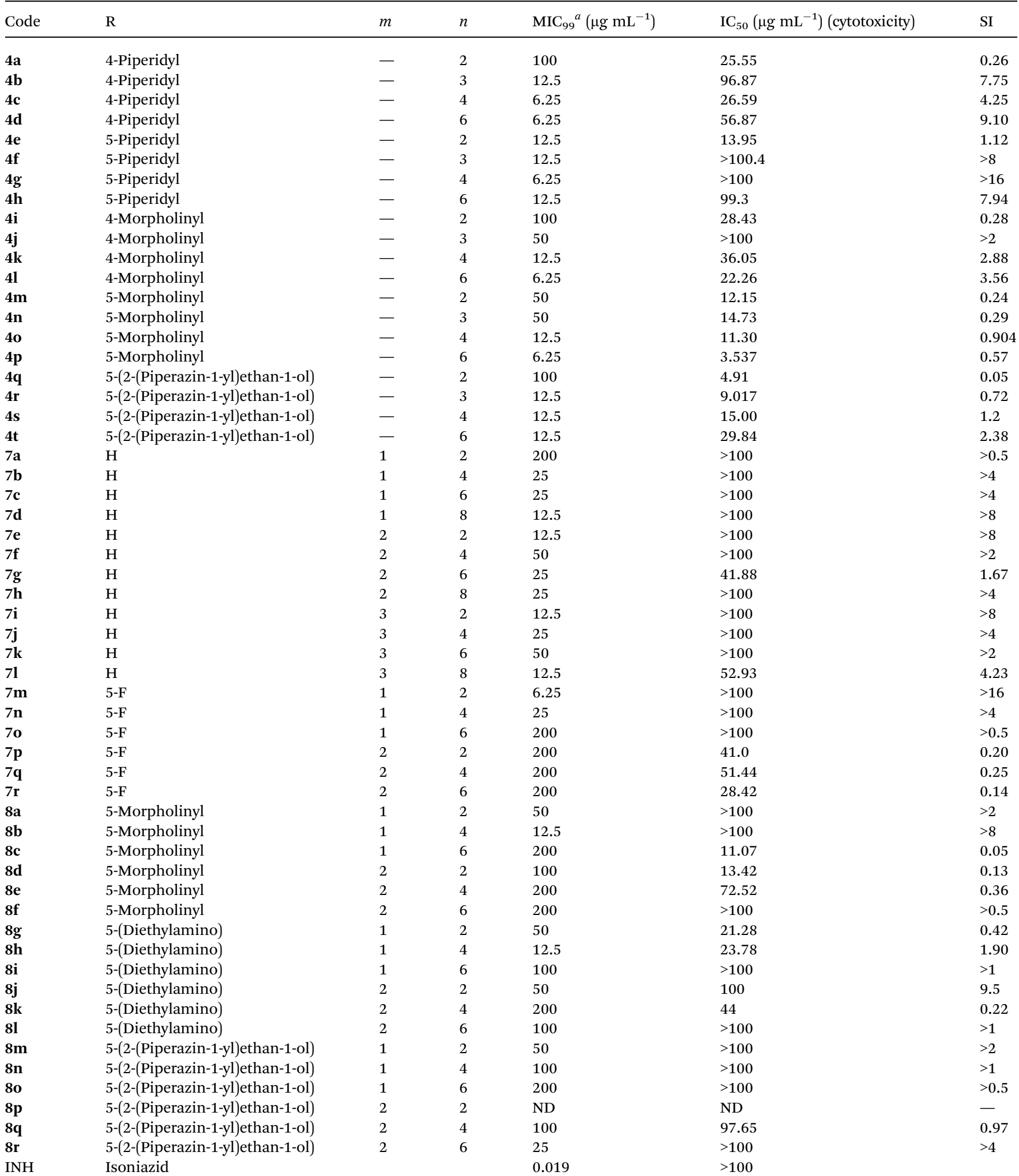

${ }^{a}$ The MIC expressed in $\mu \mathrm{g} \mathrm{mL}^{-1}$ were determined using the microdilution method in broth medium; $m, n$ are alkyl chain length (Schemes 1-3).

Among isoindoline-1,3-dione-4-aminoquinolines linked via alkyl chain $\mathbf{4 a - t}$, the replacement of fluoro-substituent (compound I, Fig. 1) with secondary amine on isoindoline-1,3- dione ring, not only improved the anti-TB activity but also reduced their cytotoxicity, which were in the range of 5.03-20.92 $\mu \mathrm{g} \mathrm{mL}^{-1} .^{26}$ Introduction of a piperidine ring at the $\mathrm{C}-4 / \mathrm{C}-5$ 
position among compounds, $\mathbf{4 a}-\mathbf{4 h}$ revealed an increase in activity with the increase in alkyl chain length as evident by $\mathbf{4 c}(n$ $=4)$, 4d $(n=6)$ and $4 \mathrm{~g}(n=4)$, exhibiting MIC values of 6.25. Similar improvement in anti-TB activities was observed with the induction of morpholine ring. The compounds $4 \mathbf{k}, \mathbf{4 l}, \mathbf{4 0}$ and $4 \mathbf{p}$ exhibited MIC of 12.5, 6.25, 12.5, $6.25 \mu \mathrm{g} \mathrm{mL}{ }^{-1}$ respectively. Introduction of hydroxy-ethyl-piperazine as the secondary amine counterpart considerably enhanced the anti-
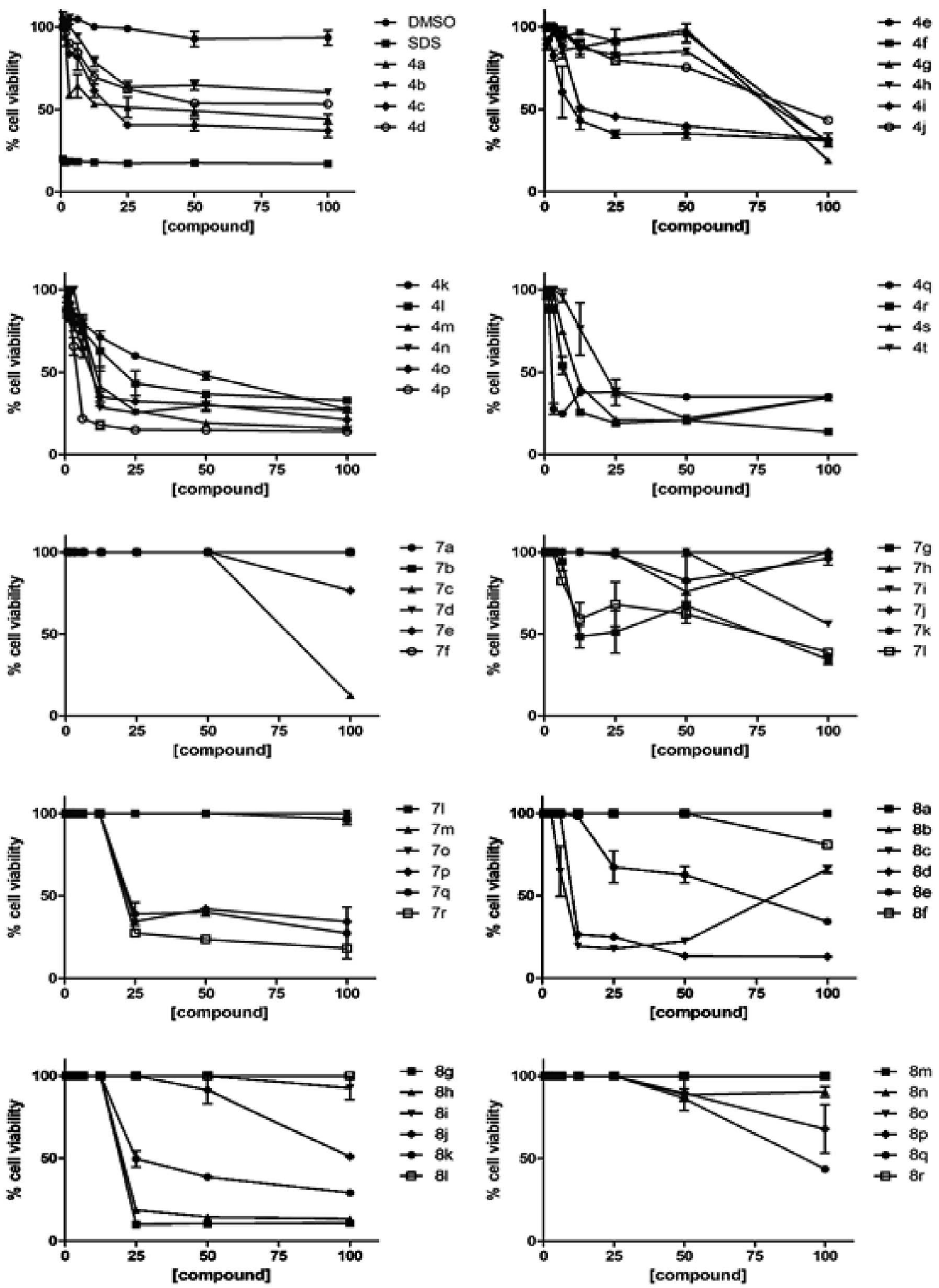

Fig. 2 Cytotoxicity of synthesized compounds (4a-t, 7a-r, 8a-r) on Vero cells. Shown are means and standard deviations calculated from two independent experiments. DMSO is included as a negative control, while SDS was included as a positive control. 


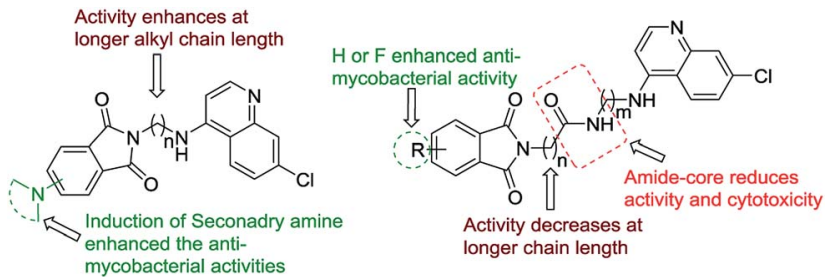

Fig. 3 Generalized SAR of synthesized isoindoline-1,3-dione-4aminoquinolines

mycobacterial activity even at shorter chain lengths. 4r, 4s and 4t having propyl, butyl and hexyl spacer length along with hydroxyl-ethyl-piperazine at C-5 position exhibited MIC values of $12.5 \mu \mathrm{g} \mathrm{mL}{ }^{-1}$, for all three compounds, but also increased their respective cytotoxicity.

Among the amide tethered isoindoline-1,3-dione-4aminoquinoline 7a-r, although a decrease in antimycobacterial activity has been observed in general, the compounds were non-cytotoxic in nature. Among the scaffold having $n=1$ (Glycine), the compound $7 \mathbf{d}(\mathrm{R}=\mathrm{H}, n=8)$ and $7 \mathbf{m}$ $(\mathrm{R}=\mathrm{F}, n=2)$ displayed better activity profiles compared to the other members of the series with MIC of 12.5 and $6.25 \mu \mathrm{g} \mathrm{mL}^{-1}$ respectively. The introduction of $\beta$-alanine and $\gamma$-aminobutyric acid showed more or less similar activity profiles with low cytotoxicity. The introduction of secondary amine functionality among the amide-linked series resulted in considerable loss of anti-mycobacterial activities except for the compound $\mathbf{8 b}$ which was non-cytotoxic and exhibited a MIC of $12.5 \mu \mathrm{g} \mathrm{mL}{ }^{-1}$. The generalized SAR of the synthesized isoindoline-1,3-dione-4aminoquinolines (both the alkyl chain as well as amide-core tethered) for their anti-mycobacterial activity against $\mathrm{mc}^{2} 6230$ strain of $M$. tuberculosis and cytotoxicity against Vero cells is depicted in Fig. 3.

\section{Conclusion}

In conclusion, the present describes the microwave-promoted synthesis of a series of C-4/C-5 secondary amine substituted isoindoline-1,3-dione-4-aminoquinolines coupled via alkyl/ amide core as linker. The synthesized scaffolds were evaluated for their anti-mycobacterial profiles against the M. tuberculosis $\mathrm{mc}^{2} 6230$ strain while cytotoxicity was determined against Vero cells. The compound $\mathbf{4 g}$ with an optimum combination of piperidine as the secondary amine at C-5 position and a butyl chain as spacer proved to be non-cytotoxic with a $\mathrm{MIC}_{99}$ of 6.25 $\mu \mathrm{g} \mathrm{mL}^{-1}$.

\section{Experimental section}

General

Veego Precision Digital Melting Point apparatus (MP-D) was used for the determination of melting points which are uncorrected. ${ }^{1} \mathrm{H}$ NMR spectra were recorded in deuterated chloroform $\left(\mathrm{CDCl}_{3}\right) / \mathrm{DMSO}-\mathrm{d}_{6}$ using Bruker $500(500 \mathrm{MHz})$ and Jeol $400(400$ $\mathrm{MHz}$ ) spectrometers while TMS is used as internal standard. Microwave reactions were performed in a Biotage ${ }^{\circledR}$ Initiator+ instrument using sealed $2-5 \mathrm{~mL}$ process vials. Reaction times refer to irradiation time at the target temperature, not the total irradiation time. The temperature was measured with an IR sensor. Chemical shift values are specified as parts per million (ppm) downfield from TMS, while coupling constant $(J)$ values are in hertz. Patterns of splitting are designated as s: singlet, d: doublet, t: triplet, $\mathrm{m}$ : multiplet, dd: double doublet, ddd: doublet of a doublet of a doublet, and br: broad peak. ${ }^{13} \mathrm{C}$ NMR spectra were recorded on Bruker $125 \mathrm{MHz}$ and Jeol $100 \mathrm{MHz}$ spectrometers in $\mathrm{CDCl}_{3}$ and $\mathrm{DMSO}-\mathrm{d}_{6}$. High Resolution Mass Spectra (HRMS) were recorded on a Bruker-micrOTOF-Q II spectrometer using ESI as the ion source.

General procedure for the preparation of C-4/C-5 secondary amine substituted isoindoline-1,3-dione-4-aminoquinolines $(4 a-t)$

To a microwave reaction vial was added a solution of C-3/C-4 fluoro-phthalic anhydride $(1.0 \mathrm{mmol})$ in $0.5 \mathrm{~mL}$ of NMP $(N$ methylpyrrolidin-2-one) and 4-aminoquinoline-diamines (1.0 mmol). After sealing with a PTFE cap, the vessel was heated to $130{ }^{\circ} \mathrm{C}$ for $2 \mathrm{~min}$ in the microwave reactor. After accomplishment of the first step, as obvious from TLC, secondary amine $(1.2 \mathrm{mmol})$ was added in the same reaction vial. The reaction mixture was again heated at $160{ }^{\circ} \mathrm{C}$ for $5 \mathrm{~min}$ in the microwave reactor and the completion was ascertained using TLC. After completion, the contents were poured in water $(20 \mathrm{~mL})$ resulting in the precipitation of the desired product. The obtained product was filtered and re-crystallized using absolute ethanol.

2-(2-((7-Chloroquinolin-4-yl)amino)ethyl)-4-(piperidin-1-yl) isoindoline-1,3-dione (4a). Yield 89\%; dark yellow solid; mp 140$141{ }^{\circ} \mathrm{C} ;{ }^{1} \mathrm{H}$ NMR (500 MHz, $\left.\mathrm{CDCl}_{3}\right) \delta$ 1.63-1.68 (m, 2H, - $\mathbf{C H}_{2}-$ ); 1.79-1.85 (m, 4H, $\left.2 \times-\mathbf{C H}_{2}-\right)$; $3.36\left(\mathrm{t}, J=5.2 \mathrm{~Hz}, 4 \mathrm{H}, 2 \times-\mathbf{C H}_{2}-\right)$; 3.35-3.47 (m, 2H, $\left.-\mathbf{C H}_{2}-\right) ; 3.78\left(\mathrm{t}, J=6.4 \mathrm{~Hz}, 2 \mathrm{H},-\mathbf{C H}_{2}-\right) ; 5.39(\mathrm{~s}$, $1 \mathrm{H}, \mathrm{NH}$-exchangeable with $\left.\mathrm{D}_{2} \mathrm{O}\right) ; 6.41(\mathrm{~d}, J=5.2 \mathrm{~Hz}, 1 \mathrm{H}, \mathrm{Ar}-\mathrm{H})$; 7.14 (d, $J=8.2 \mathrm{~Hz}, 1 \mathrm{H}, \mathrm{Ar}-\mathrm{H})$; 7.32-7.37 (m, 2H, Ar-H); 7.54-7.58 (m, 1H, Ar-H); 7.82 (d, J = 9.0 Hz, 1H, Ar-H); 7.98 (s, 1H, Ar-H); $8.51(\mathrm{~d}, J=5.2 \mathrm{~Hz}, 1 \mathrm{H}, \mathrm{Ar}-\mathrm{H}) ;{ }^{13} \mathrm{C} \mathrm{NMR}\left(125 \mathrm{MHz} \mathrm{CDCl}_{3}\right) \delta 24.1$, 25.7, 37.3, 43.2, 52.9, 99.1, 114.8, 117.3, 117.5, 121.3, 123.4, 125.3, 128.7, 134.6, 134.9, 135.2, 149.3, 149.9, 150.9, 152.1, 168.2, 168.8. HRMS calcd for $\mathrm{C}_{24} \mathrm{H}_{23} \mathrm{ClN}_{4} \mathrm{O}_{2}[\mathrm{M}+\mathrm{H}]^{+} 435.1543$ found 435.1547.

2-(3-((7-Chloroquinolin-4-yl)amino)propyl)-4-(piperidin-1-yl) isoindoline-1,3-dione (4b). Yield 88\%; dark yellow solid; mp 121-122 ${ }^{\circ} \mathrm{C} ;{ }^{1} \mathrm{H}$ NMR (500 MHz, $\left.\mathrm{CDCl}_{3}\right) \delta 1.62-1.67(\mathrm{~m}, 2 \mathrm{H}$, $\left.-\mathbf{C H}_{2}{ }^{-}\right)$; $1.82-1.88\left(\mathrm{~m}, 4 \mathrm{H}, 2 \times-\mathbf{C H}_{2}{ }^{-}\right) ; 1.98\left(\mathrm{~m}, 2 \mathrm{H},-\mathbf{C H}_{2}{ }^{-}\right), 3.32$ $\left(\mathrm{t}, J=5.1 \mathrm{~Hz}, 4 \mathrm{H}, 2 \times-\mathbf{C H}_{2}{ }^{-}\right) ; 3.35-3.40\left(\mathrm{~m}, 2 \mathrm{H},-\mathbf{C H}_{2}{ }^{-}\right) ; 3.80(\mathrm{t}, J$ $\left.=6.4 \mathrm{~Hz}, 2 \mathrm{H},-\mathbf{C H}_{2}-\right) ; 5.36\left(\mathrm{~s}, 1 \mathrm{H}, \mathrm{NH}\right.$-exchangeable with $\left.\mathrm{D}_{2} \mathrm{O}\right)$; $6.40(\mathrm{~d}, J=5.1 \mathrm{~Hz}, 1 \mathrm{H}, \mathrm{Ar}-\mathrm{H}) ; 7.18$ (d, $J=8.2 \mathrm{~Hz}, 1 \mathrm{H}, \mathrm{Ar}-\mathrm{H})$; 7.32-7.36 (m, 2H, Ar-H); 7.51-7.55 (m, 1H, Ar-H); 7.81 (d, $J=$ $8.8 \mathrm{~Hz}, 1 \mathrm{H}, \mathrm{Ar}-\mathrm{H})$; 7.94 (s, 1H, Ar-H); 8.51 (d, $=5.2 \mathrm{~Hz}, 1 \mathrm{H}, \mathrm{Ar}-$ $\mathrm{H}) ;{ }^{13} \mathrm{C}$ NMR $\left(125 \mathrm{MHz}, \mathrm{CDCl}_{3}\right) \delta 24.0,25.5,26.6,37.2,43.4$, 52.7, 99.0, 114.6, 117.1, 117.4, 121.2, 123.4, 125.2, 128.8, 134.3, $134.8,135.1,149.4,149.9,150.8,152.0,168.1$, 168.9. HRMS calcd for $\mathrm{C}_{25} \mathrm{H}_{25} \mathrm{ClN}_{4} \mathrm{O}_{2}[\mathrm{M}+\mathrm{H}]^{+} 449.1700$ found 449.1708 .

2-(4-((7-Chloroquinolin-4-yl)amino)butyl)-4-(piperidin-1-yl) isoindoline-1,3-dione (4c). Yield 89\%; dark brown solid; mp 110$111{ }^{\circ} \mathrm{C} ;{ }^{1} \mathrm{H}$ NMR (500 MHz, $\mathrm{CDCl}_{3}$ ) $\delta$ 1.64-1.67 (m, 2H, $-\mathbf{C H}_{2}-$ ); 
1.80-1.89 (m, 8H, $\left.4 \times-\mathbf{C H}_{2}-\right)$; $3.30\left(\mathrm{t}, J=5.3 \mathrm{~Hz}, 4 \mathrm{H}, 2 \times-\mathbf{C H}_{2}-\right)$; 3.37-3.41 (m, 2H, $\left.-\mathbf{C H}_{2} \mathbf{2}^{-}\right) ; 3.77\left(\mathrm{t}, J=6.5 \mathrm{~Hz}, 2 \mathrm{H},-\mathbf{C H}_{2}-\right) ; 5.37(\mathrm{~s}$, $1 \mathrm{H}, \mathrm{NH}$-exchangeable with $\left.\mathrm{D}_{2} \mathrm{O}\right) ; 6.41(\mathrm{~d}, J=5.4 \mathrm{~Hz}, 1 \mathrm{H}, \mathrm{Ar}-\mathrm{H})$; 7.16 (d, $J=8.5 \mathrm{~Hz}, 1 \mathrm{H}, \mathrm{Ar}-\mathrm{H}) ; 7.33-7.37$ (m, 2H, Ar-H); 7.53-7.56 (m, 1H, Ar-H); 7.80 (d, J=8.9 Hz, 1H, Ar-H); 7.95 (s, 1H, Ar-H); $8.52(\mathrm{~d}, J=5.4 \mathrm{~Hz}, 1 \mathrm{H}, \mathrm{Ar}-\mathrm{H}) ;{ }^{13} \mathrm{C} \mathrm{NMR}\left(125 \mathrm{MHz}, \mathrm{CDCl}_{3}\right) \delta 24.0$, 25.6, 25.9, 26.5, 37.2, 43.0, 52.7, 99.0, 114.7, 117.2, 117.4, 121.2, 123.2, 125.2, 128.7, 134.4, 134.7, 135.0, 149.1, 149.7, 150.9, 152.0, 168.1, 168.7. HRMS calcd for $\mathrm{C}_{26} \mathrm{H}_{27} \mathrm{ClN}_{4} \mathrm{O}_{2}[\mathrm{M}+\mathrm{H}]^{+} 463.1856$ found 463.1863 .

2-(6-((7-Chloroquinolin-4-yl)amino)hexyl)-4-(piperidin-1-yl) isoindoline-1,3-dione (4d). Yield 90\%; dark brown solid; mp 85$86{ }^{\circ} \mathrm{C} ;{ }^{1} \mathrm{H}$ NMR $\left(500 \mathrm{MHz}, \mathrm{CDCl}_{3}\right) \delta 1.40-1.56\left(\mathrm{~m}, 4 \mathrm{H}, 2 \times-\mathbf{C H}_{2}-\right)$; 1.63-1.67 (m, 2H, $-\mathbf{C H}_{2}^{-}$); 1.70-1.78 (m, 4H, 2×- $\mathbf{C H}_{2}-$ ); 1.80-1.83 $\left(\mathrm{m}, 4 \mathrm{H}, 2 \times-\mathbf{C H}_{2}-\right)$; 3.28-3.33 (m, 6H, 3×- $\left.\mathbf{C H}_{2}-\right) ; 3.68(\mathrm{t}, J=$ $\left.5.5 \mathrm{~Hz}, 2 \mathrm{H},-\mathbf{C H}_{2}-\right)$; 5.21 (s, $1 \mathrm{H}, \mathrm{NH}$-exchangeable with $\mathrm{D}_{2} \mathrm{O}$ ); 6.41 $(\mathrm{d}, J=5.4 \mathrm{~Hz}, 1 \mathrm{H}, \mathrm{Ar}-\mathrm{H}) ; 7.16$ (d, $J=8.4 \mathrm{~Hz}, 1 \mathrm{H}, \mathrm{Ar}-\mathrm{H}) ; 7.33-7.37$ $(\mathrm{m}, 2 \mathrm{H}, \mathrm{Ar}-\mathrm{H}) ; 7.52-7.55(\mathrm{~m}, 1 \mathrm{H}, \mathrm{Ar}-\mathrm{H}) ; 7.76(\mathrm{~d}, J=8.9 \mathrm{~Hz}, 1 \mathrm{H}$, $\mathrm{Ar}-\mathrm{H}) ; 7.96$ (s, $1 \mathrm{H}, \mathrm{Ar}-\mathrm{H}) ; 8.53$ (d, $J=5.3 \mathrm{~Hz}, 1 \mathrm{H}, \mathrm{Ar}-\mathrm{H}) ;{ }^{13} \mathrm{C} \mathrm{NMR}$ $\left(125 \mathrm{MHz}, \mathrm{CDCl}_{3}\right) \delta$ 24.0, 25.9, 26.2, 26.3, 28.3, 28.5, 37.3, 42.8, 52.7, 99.0, 114.7, 117.2, 117.7, 121.0, 123.1, 125.2, 128.7, 134.5, 134.7, 134.9, 149.1, 149.7, 150.9, 152.0, 168.1, 168.7. HRMS calcd for $\mathrm{C}_{28} \mathrm{H}_{31} \mathrm{ClN}_{4} \mathrm{O}_{2}[\mathrm{M}+\mathrm{H}]^{+} 491.2169$ found 491.2162 .

2-(2-((7-Chloroquinolin-4-yl)amino)ethyl)-5-(piperidin-1-yl) isoindoline-1,3-dione (4e). Yield 85\%; yellow solid; mp 180$181{ }^{\circ} \mathrm{C} ;{ }^{1} \mathrm{H}$ NMR $\left(500 \mathrm{MHz}, \mathrm{CDCl}_{3}\right) \delta 1.64-1.76\left(\mathrm{~m}, 6 \mathrm{H}, 3 \times-\mathbf{C H}_{2}-\right.$ ); 3.37-3.44 (m, 6H, 3×- $\left.\mathbf{C H}_{2}-\right)$; $3.79\left(\mathrm{t}, J=6.1 \mathrm{~Hz}, 2 \mathrm{H},-\mathbf{C H}_{2}{ }^{-}\right)$; $6.11\left(\mathrm{~s}, 1 \mathrm{H}, \mathrm{NH}\right.$-exchangeable with $\left.\mathrm{D}_{2} \mathrm{O}\right) ; 6.42(\mathrm{~d}, J=5.3 \mathrm{~Hz}, 1 \mathrm{H}$, $\mathrm{Ar}-\mathrm{H}) ; 7.03$ (d, J=8.0 Hz, 1H, Ar-H); 7.27 (s, 1H, Ar-H); 7.41 (d, $=9.0 \mathrm{~Hz}, 1 \mathrm{H}, \mathrm{Ar}-\mathrm{H}) ; 7.67(\mathrm{~d}, J=8.6 \mathrm{~Hz}, 1 \mathrm{H}, \mathrm{Ar}-\mathrm{H}) ; 7.92-7.97(\mathrm{~m}$, $2 \mathrm{H}, \mathrm{Ar}-\mathrm{H}) ; 8.51$ (d, $J=5.2 \mathrm{~Hz}, 1 \mathrm{H}, \mathrm{Ar}-\mathrm{H}) ;{ }^{13} \mathrm{C}$ NMR $(125 \mathrm{MHz}$, $\left.\mathrm{CDCl}_{3}\right) \delta 24.3,25.3,34.9,39.7,48.9$, 98.8, 108.3, 117.2, 117.4, $118.4,121.3,125.1,125.3,128.7,134.6,134.8,149.3,149.6$, 151.8, 155.4, 169.2, 169.7. HRMS calcd for $\mathrm{C}_{24} \mathrm{H}_{23} \mathrm{ClN}_{4} \mathrm{O}_{2}[\mathrm{M}+$ $\mathrm{H}]^{+} 435.1543$ found 435.1549 .

2-(3-((7-Chloroquinolin-4-yl)amino)propyl)-5-(piperidin-1-yl) isoindoline-1,3-dione (4f). Yield 88\%; yellow solid; mp $97-98{ }^{\circ} \mathrm{C}$; ${ }^{1} \mathrm{H}$ NMR $\left(500 \mathrm{MHz}, \mathrm{CDCl}_{3}\right) \delta 1.65-1.78\left(\mathrm{~m}, 6 \mathrm{H}, 3 \times-\mathbf{C H}_{2}-\right)$; $2.00-$

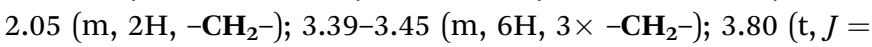
$\left.6.0 \mathrm{~Hz}, 2 \mathrm{H},-\mathbf{C H}_{2}-\right) ; 6.12\left(\mathrm{~s}, 1 \mathrm{H}, \mathrm{NH}\right.$-exchangeable with $\left.\mathrm{D}_{2} \mathrm{O}\right)$; $6.42(\mathrm{~d}, J=5.4 \mathrm{~Hz}, 1 \mathrm{H}, \mathrm{Ar}-\mathrm{H}) ; 7.01$ (d, $J=8.0 \mathrm{~Hz}, 1 \mathrm{H}, \mathrm{Ar}-\mathrm{H}) ; 7.26$ (s, $1 \mathrm{H}, \mathrm{Ar}-\mathrm{H}) ; 7.40$ (d, $J=8.9 \mathrm{~Hz}, 1 \mathrm{H}, \mathrm{Ar}-\mathrm{H}) ; 7.65(\mathrm{~d}, J=8.5 \mathrm{~Hz}$, $1 \mathrm{H}, \mathrm{Ar}-\mathrm{H})$; 7.90-7.95 (m, 2H, Ar-H); 8.51 (d, $J=5.3 \mathrm{~Hz}, 1 \mathrm{H}, \mathrm{Ar}-$ $\mathrm{H}) ;{ }^{13} \mathrm{C}$ NMR $\left(125 \mathrm{MHz}, \mathrm{CDCl}_{3}\right) \delta 24.2,25.2,26.7,34.6,39.2$, 48.8, 98.6, 108.2, 117.2, 117.4, 118.3, 121.4, 125.0, 125.3, 128.6, $134.5,134.8,149.2,149.5,151.9,155.4,169.1$, 169.6. HRMS calcd for $\mathrm{C}_{25} \mathrm{H}_{25} \mathrm{ClN}_{4} \mathrm{O}_{2}[\mathrm{M}+\mathrm{H}]^{+} 449.1700$ found 449.1712 .

2-(4-((7-Chloroquinolin-4-yl)amino)butyl)-5-(piperidin-1-yl) isoindoline-1,3-dione (4g). Yield 87\%; yellow solid; mp 91-92 ${ }^{\circ} \mathrm{C}$; ${ }^{1} \mathrm{H}$ NMR (500 MHz, $\mathrm{CDCl}_{3}$ ) $\delta$ 1.41-1.49 (m, 4H, $\left.2 \times-\mathbf{C H}_{2}^{-}\right)$), 1.64$1.77\left(\mathrm{~m}, 6 \mathrm{H}, 3 \times-\mathbf{C H}_{2}-\right)$; 3.37-3.44 (m, 6H, 3×- $\left.\mathbf{C H}_{2}-\right)$; $3.78(\mathrm{t}, \mathrm{J}=$ $\left.6.1 \mathrm{~Hz}, 2 \mathrm{H},-\mathbf{C H}_{2}-\right) ; 6.11\left(\mathrm{~s}, 1 \mathrm{H}, \mathrm{NH}\right.$-exchangeable with $\left.\mathrm{D}_{2} \mathrm{O}\right) ; 6.41$ $(\mathrm{d}, J=5.3 \mathrm{~Hz}, 1 \mathrm{H}, \mathrm{Ar}-\mathrm{H}) ; 7.00(\mathrm{~d}, J=8.1 \mathrm{~Hz}, 1 \mathrm{H}, \mathrm{Ar}-\mathrm{H}) ; 7.26(\mathrm{~s}$, $1 \mathrm{H}, \mathrm{Ar}-\mathrm{H}) ; 7.41$ (d, $J=9.0 \mathrm{~Hz}, 1 \mathrm{H}, \mathrm{Ar}-\mathrm{H}) ; 7.64(\mathrm{~d}, J=8.6 \mathrm{~Hz}, 1 \mathrm{H}$, $\mathrm{Ar}-\mathrm{H}$ ); 7.89-7.94 (m, 2H, Ar-H); 8.52 (d, $J=5.2 \mathrm{~Hz}, 1 \mathrm{H}, \mathrm{Ar}-\mathrm{H}) ;{ }^{13} \mathrm{C}$ NMR (125 MHz, $\mathrm{CDCl}_{3}$ ) $\delta$ 24.1, 25.2, 26.7, 26.9, 34.5, 39.2, 48.7, 98.4, 108.1, 117.2, 117.3, 118.2, 121.4, 125.1, 125.2, 128.7, 134.4,
134.7, 149.1, 149.5, 151.7, 155.3, 169.0, 169.5. HRMS calcd for $\mathrm{C}_{26} \mathrm{H}_{27} \mathrm{ClN}_{4} \mathrm{O}_{2}[\mathrm{M}+\mathrm{H}]^{+} 463.1856$ found 463.1874 .

2-(6-((7-Chloroquinolin-4-yl)amino)hexyl)-5-(piperidin-1-yl) isoindoline-1,3-dione $(\mathbf{4 h})$. Yield $89 \%$; yellow solid; $\mathrm{mp} 88-89^{\circ} \mathrm{C}$; ${ }^{1} \mathrm{H}$ NMR $\left(500 \mathrm{MHz}, \mathrm{CDCl}_{3}\right) \delta$ 1.31-1.35 (m, 4H, 2× - $\left.\mathbf{C H}_{2}^{-}\right), 1.52-$ $1.56\left(\mathrm{~m}, 2 \mathrm{H},-\mathbf{C H}_{2}{ }^{-}\right), 1.63-1.78\left(\mathrm{~m}, 8 \mathrm{H}, 4 \times-\mathbf{C H}_{2}-\right)$; 3.34-3.41 (m, $\left.6 \mathrm{H}, 3 \times-\mathbf{C H}_{2}-\right) ; 3.75\left(\mathrm{t}, J=6.2 \mathrm{~Hz}, 2 \mathrm{H},-\mathbf{C H}_{2}-\right) ; 6.10(\mathrm{~s}, 1 \mathrm{H}, \mathrm{NH}-$ exchangeable with $\left.\mathrm{D}_{2} \mathrm{O}\right) ; 6.40(\mathrm{~d}, J=5.3 \mathrm{~Hz}, 1 \mathrm{H}, \mathrm{Ar}-\mathrm{H}) ; 7.01$ (d, $J=8.0 \mathrm{~Hz}, 1 \mathrm{H}, \mathrm{Ar}-\mathrm{H}) ; 7.24(\mathrm{~s}, 1 \mathrm{H}, \mathrm{Ar}-\mathrm{H}) ; 7.40$ (d, $J=9.0 \mathrm{~Hz}, 1 \mathrm{H}$, $\mathrm{Ar}-\mathrm{H}) ; 7.64$ (d, $J=8.5 \mathrm{~Hz}, 1 \mathrm{H}, \mathrm{Ar}-\mathrm{H}) ; 7.88-7.94$ (m, 2H, $\mathrm{Ar}-\mathrm{H})$; $8.51(\mathrm{~d}, J=5.2 \mathrm{~Hz}, 1 \mathrm{H}, \mathrm{Ar}-\mathrm{H}) ;{ }^{13} \mathrm{C} \mathrm{NMR}\left(125 \mathrm{MHz}, \mathrm{CDCl}_{3}\right) \delta 24.2$, 25.1, 26.7, 26.7, 28.3, 28.7, 34.3, 39.2, 48.4, 98.2, 108.0, 117.0, 117.2, 118.0, 121.2, 125.0, 125.2, 128.6, 134.5, 134.7, 149.1, 149.3, 151.6, 155.3, 169.1, 169.2. HRMS calcd for $\mathrm{C}_{28} \mathrm{H}_{31} \mathrm{ClN}_{4} \mathrm{O}_{2}[\mathrm{M}+\mathrm{H}]^{+}$ 491.2169 found 491.2178.

2-(2-((7-Chloroquinolin-4-yl)amino)ethyl)-4-morpholinoisoindoline-1,3-dione (4i). Yield 92\%; yellow solid; mp $163-164{ }^{\circ} \mathrm{C}$; ${ }^{1} \mathrm{H}$ NMR (400 MHz, $\mathrm{CDCl}_{3}$ ) $\delta$ 3.36-3.40 (m, 6H, $\left.3 \times-\mathbf{C H}_{2}-\right) ; 3.74$ $\left(\mathrm{t}, J=6.4 \mathrm{~Hz}, 2 \mathrm{H},-\mathbf{C H}_{2}-\right) ; 3.95\left(\mathrm{t}, J=4.5 \mathrm{~Hz}, 4 \mathrm{H}, 2 \times-\mathbf{C H}_{2}-\right) ; 5.30$ (s, 1H, NH-exchangeable with $\left.\mathrm{D}_{2} \mathrm{O}\right) ; 6.36(\mathrm{~d}, J=5.2 \mathrm{~Hz}, 1 \mathrm{H}, \mathrm{Ar}-$ $\mathrm{H})$; 7.11 (d, $J=8.3 \mathrm{~Hz}, 1 \mathrm{H}, \mathrm{Ar}-\mathrm{H})$; 7.31-7.38 (m, 2H, Ar-H); 7.57$7.61(\mathrm{~m}, 1 \mathrm{H}, \mathrm{Ar}-\mathrm{H}) ; 7.75(\mathrm{~d}, J=9.0 \mathrm{~Hz}, 1 \mathrm{H}, \mathrm{Ar}-\mathrm{H}) ; 7.88(\mathrm{~d}, J=$ $2.0 \mathrm{~Hz}, 1 \mathrm{H}, \mathrm{Ar}-\mathrm{H}) ; 8.46$ (d, $J=5.2 \mathrm{~Hz}, 1 \mathrm{H}, \mathrm{Ar}-\mathrm{H}) ;{ }^{13} \mathrm{C}$ NMR $(100$ MHz) $\delta 37.5,43.3,51.7,66.9$, 99.0, 115.8, 117.1, 118.2, 121.4, $122.8,125.4,128.9,134.4,134.8,135.6,149.2,149.8,150.2$, 152.1, 168.3, 168.6. HRMS calcd for $\mathrm{C}_{23} \mathrm{H}_{21} \mathrm{ClN}_{4} \mathrm{O}_{3}[\mathrm{M}+\mathrm{H}]^{+}$ 437.1336 found 437.1344 .

2-(3-((7-Chloroquinolin-4-yl)amino)propyl)-4-morpholinoisoindoline-1,3-dione (4j). Yield 90\%; yellow solid; mp 141-142 ${ }^{\circ} \mathrm{C}$; ${ }^{1} \mathrm{H}$ NMR (400 MHz, $\mathrm{CDCl}_{3}$ ) $\delta$ 2.00-2.05 (m, 2H, - $\mathbf{C H}_{2}-$ ); 3.34-3.39 $\left(\mathrm{m}, 6 \mathrm{H}, 3 \times-\mathbf{C H}_{2}-\right) ; 3.71\left(\mathrm{t}, J=6.5 \mathrm{~Hz}, 2 \mathrm{H},-\mathbf{C H}_{2}-\right) ; 3.94(\mathrm{t}, J=$ $\left.4.3 \mathrm{~Hz}, 4 \mathrm{H}, 2 \times-\mathbf{C H}_{2}-\right)$; $5.28\left(\mathrm{~s}, 1 \mathrm{H}, \mathrm{NH}\right.$-exchangeable with $\left.\mathrm{D}_{2} \mathrm{O}\right)$; $6.35(\mathrm{~d}, J=5.3 \mathrm{~Hz}, 1 \mathrm{H}, \mathrm{Ar}-\mathrm{H}) ; 7.12$ (d, $J=8.4 \mathrm{~Hz}, 1 \mathrm{H}, \mathrm{Ar}-\mathrm{H}) ; 7.30-$ 7.37 (m, 2H, Ar-H); 7.56-7.59 (m, 1H, Ar-H); 7.75 (d, J=8.9 Hz, $1 \mathrm{H}, \mathrm{Ar}-\mathrm{H}) ; 7.89$ (d, $J=2.0 \mathrm{~Hz}, 1 \mathrm{H}, \mathrm{Ar}-\mathrm{H}) ; 8.45$ (d, $J=5.3 \mathrm{~Hz}, 1 \mathrm{H}$, $\mathrm{Ar}-\mathrm{H}) ;{ }^{13} \mathrm{C}$ NMR $(100 \mathrm{MHz}) \delta 28.4,37.3,43.1,51.6,66.8,99.0$, 115.9, 117.1, 118.1, 121.3, 122.8, 125.4, 128.8, 134.5, 134.9, 135.6, 149.1, 149.8, 150.1, 152.1, 168.2, 168.7. HRMS calcd for $\mathrm{C}_{24} \mathrm{H}_{23} \mathrm{ClN}_{4} \mathrm{O}_{3}[\mathrm{M}+\mathrm{H}]^{+} 451.1492$ found 451.1477 .

2-(4-((7-Chloroquinolin-4-yl)amino)butyl)-4-morpholinoisoindoline-1,3-dione (4k). Yield 89\%; yellow solid; mp $110-111^{\circ} \mathrm{C}$; ${ }^{1} \mathrm{H}$ NMR $\left(400 \mathrm{MHz}, \mathrm{CDCl}_{3}\right) \delta 1.74-1.87\left(\mathrm{~m}, 4 \mathrm{H}, 2 \times-\mathbf{C H}_{2}-\right)$; 3.30$3.37\left(\mathrm{~m}, 6 \mathrm{H}, 3 \times-\mathbf{C H}_{2}-\right) ; 3.73\left(\mathrm{t}, J=6.6 \mathrm{~Hz}, 2 \mathrm{H},-\mathbf{C H}_{2^{-}}\right) ; 3.91(\mathrm{t}, J$ $\left.=4.5 \mathrm{~Hz}, 4 \mathrm{H}, 2 \times-\mathbf{C H}_{2}-\right) ; 5.29(\mathrm{~s}, 1 \mathrm{H}, \mathrm{NH}-$ exchangeable with $\left.\mathrm{D}_{2} \mathrm{O}\right) ; 6.37$ (d, $\left.J=5.4 \mathrm{~Hz}, 1 \mathrm{H}, \mathrm{Ar}-\mathrm{H}\right) ; 7.12(\mathrm{~d}, J=8.4 \mathrm{~Hz}, 1 \mathrm{H}, \mathrm{Ar}-$ H); 7.31-7.39 (m, 2H, Ar-H); 7.54-7.58 (m, 1H, Ar-H); 7.73 (d, J $=9.0 \mathrm{~Hz}, 1 \mathrm{H}, \mathrm{Ar}-\mathrm{H}) ; 7.91(\mathrm{~d}, J=2.1 \mathrm{~Hz}, 1 \mathrm{H}, \mathrm{Ar}-\mathrm{H}) ; 8.47$ (d, $J=$ $5.4 \mathrm{~Hz}, 1 \mathrm{H}, \mathrm{Ar}-\mathrm{H}) ;{ }^{13} \mathrm{C}$ NMR $(100 \mathrm{MHz}) \delta 25.7,26.5,37.4,43.0$, 51.5, 66.9, 99.1, 115.9, 117.2, 118.1, 121.2, 122.8, 125.3, 128.7, 134.5 , 134.9, 135.5, 149.0, 149.8, 150.1, 152.0, 168.1, 168.6. HRMS calcd for $\mathrm{C}_{25} \mathrm{H}_{25} \mathrm{ClN}_{4} \mathrm{O}_{3}[\mathrm{M}+\mathrm{H}]^{+} 465.1649$ found 465.1665 .

2-(6-((7-Chloroquinolin-4-yl)amino)hexyl)-4-morpholinoisoindoline-1,3-dione (4l). Yield 88\%; yellow solid; mp $89-90{ }^{\circ} \mathrm{C} ;{ }^{1} \mathrm{H}$ NMR (400 MHz, $\left.\mathrm{CDCl}_{3}\right) \delta 1.35-1.39\left(\mathrm{~m}, 4 \mathrm{H}, 2 \times-\mathbf{C H}_{2}-\right)$; 1.50$1.54\left(\mathrm{~m}, 2 \mathrm{H},-\mathbf{C H}_{2}-\right)$; 1.64-1.77 (m, 4H, 2×- $\left.\mathbf{C H}_{2}-\right)$; 3.29-3.36 (m, $\left.6 \mathrm{H}, 3 \times-\mathbf{C H}_{2}-\right) ; 3.72\left(\mathrm{t}, J=6.5 \mathrm{~Hz}, 2 \mathrm{H},-\mathbf{C H}_{2}-\right) ; 3.90(\mathrm{t}, J=4.6 \mathrm{~Hz}$, 
$\left.4 \mathrm{H}, 2 \times-\mathbf{C H}_{2}-\right) ; 5.28\left(\mathrm{~s}, 1 \mathrm{H}, \mathrm{NH}\right.$-exchangeable with $\left.\mathrm{D}_{2} \mathrm{O}\right) ; 6.36(\mathrm{~d}$, $J=5.3 \mathrm{~Hz}, 1 \mathrm{H}, \mathrm{Ar}-\mathrm{H}) ; 7.11$ (d, $J=8.5 \mathrm{~Hz}, 1 \mathrm{H}, \mathrm{Ar}-\mathrm{H}) ; 7.30-7.38$ $(\mathrm{m}, 2 \mathrm{H}, \mathrm{Ar}-\mathrm{H}) ; 7.53-7.56(\mathrm{~m}, 1 \mathrm{H}, \mathrm{Ar}-\mathrm{H}) ; 7.71(\mathrm{~d}, J=8.9 \mathrm{~Hz}, 1 \mathrm{H}$, $\mathrm{Ar}-\mathrm{H}) ; 7.90$ (d, $J=2.0 \mathrm{~Hz}, 1 \mathrm{H}, \mathrm{Ar}-\mathrm{H}) ; 8.45$ (d, $J=5.4 \mathrm{~Hz}, 1 \mathrm{H}, \mathrm{Ar}-$ $\mathrm{H}) ;{ }^{13} \mathrm{C}$ NMR $(100 \mathrm{MHz}) \delta 25.3,26.6,28.4,28.8,37.2,43.2,51.2$, 66.7, 99.0, 115.8, 117.0, 118.0, 121.1, 122.6, 125.2, 128.7, 134.3, $134.7,135.3,149.1,149.6,150.2$, 152.1, 168.0, 168.4. HRMS calcd for $\mathrm{C}_{27} \mathrm{H}_{29} \mathrm{ClN}_{4} \mathrm{O}_{3}[\mathrm{M}+\mathrm{H}]^{+} 493.1962$ found 493.1971 .

2-(2-((7-Chloroquinolin-4-yl)amino)ethyl)-5-morpholinoisoindoline-1,3-dione (4m). Yield 89\%; dark brown solid; mp 192$193{ }^{\circ} \mathrm{C} ;{ }^{1} \mathrm{H}$ NMR $\left(500 \mathrm{MHz}, \mathrm{CDCl}_{3}\right) \delta 3.38(\mathrm{t}, J=4.8 \mathrm{~Hz}, 4 \mathrm{H}, 2 \times$ $\left.-\mathbf{C H}_{2}{ }^{-}\right)$; 3.52-3.55 (m, 2H, $\left.-\mathbf{C H}_{2}{ }^{-}\right) ; 3.88(\mathrm{t}, J=4.8 \mathrm{~Hz}, 4 \mathrm{H}, 2 \times$ $\left.-\mathbf{C H}_{2}{ }^{-}\right) ; 4.15\left(\mathrm{t}, J=5.2 \mathrm{~Hz}, 2 \mathrm{H},-\mathbf{C H}_{2}-\right) ; 6.13(\mathrm{~s}, 1 \mathrm{H}, \mathrm{NH}-$ exchangeable with $\left.\mathrm{D}_{2} \mathrm{O}\right) ; 6.36(\mathrm{~d}, J=5.3 \mathrm{~Hz}, 1 \mathrm{H}, \mathrm{Ar}-\mathrm{H}) ; 7.05$ $(\mathrm{d}, J=8.4 \mathrm{~Hz}, 1 \mathrm{H}, \mathrm{Ar}-\mathrm{H}) ; 7.30(\mathrm{~s}, 1 \mathrm{H}, \mathrm{Ar}-\mathrm{H}) ; 7.43(\mathrm{~d}, J=8.9 \mathrm{~Hz}$, $1 \mathrm{H}, \mathrm{Ar}-\mathrm{H}) ; 7.73$ (d, J=8.4 Hz, $1 \mathrm{H}, \mathrm{Ar}-\mathrm{H}) ; 7.80(\mathrm{~d}, J=8.9 \mathrm{~Hz}, 1 \mathrm{H}$, $\mathrm{Ar}-\mathrm{H}) ; 7.94$ (s, 1H, Ar-H); 8.52 (d, $J=5.3 \mathrm{~Hz}, 1 \mathrm{H}, \mathrm{Ar}-\mathrm{H}) ;{ }^{13} \mathrm{C}$ NMR (125 MHz, $\left.\mathrm{CDCl}_{3}\right) \delta 36.7,43.8,47.5,66.3,98.6,108.5$, $117.1,117.7,120.1,121.5,125.2$, 125.6, 128.5, 134.2, 134.9, $148.9,149.7,151.9,155.6,169.1,169.5$. HRMS calcd for $\mathrm{C}_{23} \mathrm{H}_{21} \mathrm{ClN}_{4} \mathrm{O}_{3}[\mathrm{M}+\mathrm{H}]^{+} 437.1336$ found 437.1349.

2-(3-((7-Chloroquinolin-4-yl)amino)propyl)-5-morpholinoisoindoline-1,3-dione (4n). Yield 85\%; dark brown solid; mp 185$186{ }^{\circ} \mathrm{C} ;{ }^{1} \mathrm{H}$ NMR $\left(500 \mathrm{MHz}, \mathrm{CDCl}_{3}\right) \delta 1.65-1.70\left(\mathrm{~m}, 2 \mathrm{H},-\mathbf{C H}_{2}-\right.$ ); 3.36-3.45 (m, 6H, 3×- $\left.\mathbf{C H}_{2}{ }^{-}\right) ; 3.80\left(\mathrm{t}, J=6.4 \mathrm{~Hz}, 2 \mathrm{H},-\mathbf{C H}_{2}{ }^{-}\right) ; 3.90$ $\left(\mathrm{t}, J=4.7 \mathrm{~Hz}, 4 \mathrm{H}, 2 \times-\mathbf{C H}_{2}-\right) ; 5.30(\mathrm{~s}, 1 \mathrm{H}, \mathrm{NH}$-exchangeable with $\left.\mathrm{D}_{2} \mathrm{O}\right) ; 6.40(\mathrm{~d}, J=5.4 \mathrm{~Hz}, 1 \mathrm{H}, \mathrm{Ar}-\mathrm{H}) ; 7.04(\mathrm{~d}, J=8.4 \mathrm{~Hz}, 1 \mathrm{H}, \mathrm{Ar}-\mathrm{H})$; 7.28 (s, 1H, Ar-H); $7.40(\mathrm{~d}, J=9.0 \mathrm{~Hz}, 1 \mathrm{H}, \operatorname{Ar}-\mathrm{H}) ; 7.70(\mathrm{~d}, J=$ $8.3 \mathrm{~Hz}, 1 \mathrm{H}, \mathrm{Ar}-\mathrm{H}) ; 7.78$ (d, $J=9.0 \mathrm{~Hz}, 1 \mathrm{H}, \mathrm{Ar}-\mathrm{H})$; 7.94 (s, 1H, Ar$\mathrm{H}) ; 8.52(\mathrm{~d}, J=5.4 \mathrm{~Hz}, 1 \mathrm{H}, \mathrm{Ar}-\mathrm{H}) ;{ }^{13} \mathrm{C} \mathrm{NMR}\left(125 \mathrm{MHz}, \mathrm{CDCl}_{3}\right.$ ) $\delta 26.8,37.5,43.0,47.8,66.2,99.0,108.4,117.0,117.6,120.5,121.4$, 124.9, 125.4, 128.6, 134.3, 134.8, 149.0, 149.6, 152.0, 155.5, 168.9, 169.3. HRMS calcd for $\mathrm{C}_{24} \mathrm{H}_{23} \mathrm{ClN}_{4} \mathrm{O}_{3}[\mathrm{M}+\mathrm{H}]^{+} 451.1492$ found 451.1486 .

2-(4-((7-Chloroquinolin-4-yl)amino)butyl)-5-morpholinoisoindoline-1,3-dione (4o). Yield 85\%; dark brown solid; mp 180$181{ }^{\circ} \mathrm{C} ;{ }^{1} \mathrm{H}$ NMR $\left(500 \mathrm{MHz}, \mathrm{CDCl}_{3}\right) \delta 1.85-1.90\left(\mathrm{~m}, 4 \mathrm{H}, 2 \times-\mathbf{C H}_{2}-\right.$ ); 3.36-3.41 (m, 6H, 3×- $\left.\mathbf{C H}_{2}-\right)$; $3.77\left(\mathrm{t}, J=6.5 \mathrm{~Hz}, 2 \mathrm{H},-\mathbf{C H}_{2}-\right)$; $3.89\left(\mathrm{t}, J=4.8 \mathrm{~Hz}, 4 \mathrm{H}, 2 \times-\mathbf{C H}_{2}-\right) ; 5.29(\mathrm{~s}, 1 \mathrm{H}, \mathrm{NH}-$ exchangeable with $\left.\mathrm{D}_{2} \mathrm{O}\right) ; 6.41(\mathrm{~d}, J=5.4 \mathrm{~Hz}, 1 \mathrm{H}, \mathrm{Ar}-\mathrm{H}) ; 7.04(\mathrm{~d}, J=8.4 \mathrm{~Hz}, 1 \mathrm{H}$, $\mathrm{Ar}-\mathrm{H}) ; 7.26$ (s, 1H, Ar-H); 7.37 (d, $J=8.9 \mathrm{~Hz}, 1 \mathrm{H}, \mathrm{Ar}-\mathrm{H}) ; 7.68$ (d, $=8.4 \mathrm{~Hz}, 1 \mathrm{H}, \mathrm{Ar}-\mathrm{H}) ; 7.76(\mathrm{~d}, J=9.0 \mathrm{~Hz}, 1 \mathrm{H}, \mathrm{Ar}-\mathrm{H}) ; 7.95(\mathrm{~s}, 1 \mathrm{H}$, $\mathrm{Ar}-\mathrm{H}) ; 8.52$ (d, $J=5.3 \mathrm{~Hz}, 1 \mathrm{H}, \mathrm{Ar}-\mathrm{H}) ;{ }^{13} \mathrm{C} \mathrm{NMR}\left(125 \mathrm{MHz}, \mathrm{CDCl}_{3}\right)$ $\delta$ 25.6, 26.5, 37.3, 42.9, 47.7, 66.3, 99.1, 108.3, 117.2, 117.6, $120.7,121.1,124.8,125.3,128.7,134.4,134.8,149.1,149.7$, 152.0, 155.4, 168.6, 169.0. HRMS calcd for $\mathrm{C}_{25} \mathrm{H}_{25} \mathrm{ClN}_{4} \mathrm{O}_{3}[\mathrm{M}+$ $\mathrm{H}]^{+} 465.1649$ found 465.1654 .

2-(6-((7-Chloroquinolin-4-yl)amino)hexyl)-5-morpholinoisoindoline-1,3-dione (4p). Yield 89\%; yellow solid; mp 177-178 ${ }^{\circ} \mathrm{C}$; ${ }^{1} \mathrm{H}$ NMR $\left(500 \mathrm{MHz}, \mathrm{CDCl}_{3}\right.$ ) $\delta 1.39-1.48$ (m, 4H, $\left.2 \times-\mathbf{C H}_{2}-\right)$; 1.60$1.69\left(\mathrm{~m}, 4 \mathrm{H}, 2 \times-\mathbf{C H}_{2}-\right) ; 3.35-3.42\left(\mathrm{~m}, 6 \mathrm{H}, 3 \times-\mathbf{C H}_{2}-\right) ; 3.76(\mathrm{t}, J$ $\left.=6.2 \mathrm{~Hz}, 2 \mathrm{H},-\mathbf{C H}_{2}-\right) ; 3.86\left(\mathrm{t}, J=4.5 \mathrm{~Hz}, 4 \mathrm{H}, 2 \times-\mathbf{C H}_{2}-\right) ; 5.28(\mathrm{~s}$, $1 \mathrm{H}, \mathrm{NH}$-exchangeable with $\left.\mathrm{D}_{2} \mathrm{O}\right) ; 6.40(\mathrm{~d}, J=5.3 \mathrm{~Hz}, 1 \mathrm{H}, \mathrm{Ar}-\mathrm{H})$; $7.02(\mathrm{~d}, J=8.3 \mathrm{~Hz}, 1 \mathrm{H}, \mathrm{Ar}-\mathrm{H}) ; 7.25$ (s, 1H, Ar-H); 7.35 (d, $J=$ $8.8 \mathrm{~Hz}, 1 \mathrm{H}, \mathrm{Ar}-\mathrm{H}) ; 7.66(\mathrm{~d}, J=8.3 \mathrm{~Hz}, 1 \mathrm{H}, \mathrm{Ar}-\mathrm{H}) ; 7.76(\mathrm{~d}, J=$ $8.8 \mathrm{~Hz}, 1 \mathrm{H}, \mathrm{Ar}-\mathrm{H}) ; 7.93$ (s, 1H, Ar-H); 8.53 (d, J=5.2 Hz, 1H, Ar$\mathrm{H}) ;{ }^{13} \mathrm{C} \mathrm{NMR}\left(125 \mathrm{MHz}, \mathrm{CDCl}_{3}\right) \delta 25.5,26.4,28.7,28.9,37.2$,
42.9, 47.6, 66.1, 99.0, 108.2, 117.2, 117.5, 120.8, 121.1, 124.7, 125.2 , 128.6, 134.4, 134.7, 149.0, 149.6, 152.1, 155.3, 168.5, 169.1. HRMS calcd for $\mathrm{C}_{27} \mathrm{H}_{29} \mathrm{ClN}_{4} \mathrm{O}_{3}[\mathrm{M}+\mathrm{H}]^{+} 493.1962$ found 493.1976.

2-(2-((7-Chloroquinolin-4-yl)amino)ethyl)-5-(4-(2-hydroxyethyl) piperazin-1-yl)isoindoline-1,3-dione (4q). Yield 88\%; dark brown solid; mp 211-212 ${ }^{\circ} \mathrm{C} ;{ }^{1} \mathrm{H}$ NMR (400 $\left.\mathrm{MHz}, \mathrm{CDCl}_{3}\right) \delta 2.65(\mathrm{t}, J=$ $\left.5.4 \mathrm{~Hz}, 2 \mathrm{H},-\mathbf{C H}_{2}\right) ; 2.69\left(\mathrm{t}, J=5.0 \mathrm{~Hz}, 4 \mathrm{H}, 2 \times-\mathbf{C H}_{2}-\right) ; 3.39(\mathrm{t}, J=$ $\left.6.4 \mathrm{~Hz}, 2 \mathrm{H},-\mathbf{C H}_{2}-\right) ; 3.45\left(\mathrm{t}, J=5.0 \mathrm{~Hz}, 4 \mathrm{H}, 2 \times-\mathbf{C H}_{2}-\right) ; 3.70(\mathrm{t}, J=$ $\left.5.3 \mathrm{~Hz}, 2 \mathrm{H},-\mathbf{C H}_{2}-\right) ; 3.77\left(\mathrm{t}, J=6.5 \mathrm{~Hz}, 2 \mathrm{H},-\mathbf{C H}_{2}-\right) ; 6.41(\mathrm{~d}, J=$ $5.5 \mathrm{~Hz}, 1 \mathrm{H}, \mathrm{Ar}-\mathrm{H}) ; 7.04$ (d, J=8.3 Hz, 1H, Ar-H); 7.23 (s, 1H, Ar-H); 7.35 (d, $J=9.0 \mathrm{~Hz}, 1 \mathrm{H}, \mathrm{Ar}-\mathrm{H}) ; 7.65$ (d, $J=8.2 \mathrm{~Hz}, 1 \mathrm{H}, \mathrm{Ar}-\mathrm{H}) ; 7.75$ $(\mathrm{d}, J=8.9 \mathrm{~Hz}, 1 \mathrm{H}, \mathrm{Ar}-\mathrm{H}) ; 7.93(\mathrm{~s}, 1 \mathrm{H}, \mathrm{Ar}-\mathrm{H}) ; 8.49(\mathrm{~d}, J=5.4 \mathrm{~Hz}, 1 \mathrm{H}$, $\mathrm{Ar}-\mathrm{H}) ;{ }^{13} \mathrm{C} \mathrm{NMR}\left(100 \mathrm{MHz}, \mathrm{CDCl}_{3}\right) \delta 37.4,42.9,47.8,52.5,57.9$, 59.5, 99.1, 108.5, 117.0, 117.5, 120.1, 121.0, 124.9, 125.3, 128.9, 134.6, 134.8, 149.1, 149.8, 152.0, 155.3, 168.7, 169.1. HRMS calcd for $\mathrm{C}_{25} \mathrm{H}_{26} \mathrm{ClN}_{5} \mathrm{O}_{3}[\mathrm{M}+\mathrm{H}]^{+} 480.1758$ found 480.1771 .

2-(3-((7-Chloroquinolin-4-yl)amino)propyl)-5-(4-(2-hydroxyethyl) piperazin-1-yl)isoindoline-1,3-dione (4r). Yield 89\%; dark brown solid; mp 197-198 ${ }^{\circ} \mathrm{C} ;{ }^{1} \mathrm{H}$ NMR (400 MHz, $\left.\mathrm{CDCl}_{3}\right) \delta$ 1.99-2.05 (m, $\left.2 \mathrm{H}, 2 \times-\mathbf{C H}_{2}-\right), 2.63\left(\mathrm{t}, J=5.3 \mathrm{~Hz}, 2 \mathrm{H},-\mathbf{C H}_{2}\right) ; 2.68(\mathrm{t}, J=5.0 \mathrm{~Hz}$, $\left.4 \mathrm{H}, 2 \times-\mathbf{C H}_{2}-\right) ; 3.36\left(\mathrm{t}, J=6.6 \mathrm{~Hz}, 2 \mathrm{H},-\mathbf{C H}_{2}-\right) ; 3.43(\mathrm{t}, J=5.1 \mathrm{~Hz}$, $\left.4 \mathrm{H}, 2 \times-\mathbf{C H}_{2}-\right) ; 3.68\left(\mathrm{t}, J=5.4 \mathrm{~Hz}, 2 \mathrm{H},-\mathbf{C H}_{2}-\right) ; 3.76(\mathrm{t}, J=6.4 \mathrm{~Hz}$, $\left.2 \mathrm{H},-\mathbf{C H}_{2}-\right)$; 6.39 (d, $\left.J=5.3 \mathrm{~Hz}, 1 \mathrm{H}, \mathrm{Ar}-\mathrm{H}\right) ; 7.03(\mathrm{~d}, J=8.3 \mathrm{~Hz}, 1 \mathrm{H}$, Ar-H); 7.22 (s, 1H, Ar-H); 7.33 (d, J=9.0 Hz, 1H, Ar-H); 7.63 (d, J= $8.3 \mathrm{~Hz}, 1 \mathrm{H}, \mathrm{Ar}-\mathrm{H})$; 7.74 (d, J=8.9 Hz, 1H, Ar-H); 7.93 (s, 1H, Ar-H); $8.48(\mathrm{~d}, J=5.3 \mathrm{~Hz}, 1 \mathrm{H}, \mathrm{Ar}-\mathrm{H}) ;{ }^{13} \mathrm{C} \mathrm{NMR}\left(100 \mathrm{MHz}, \mathrm{CDCl}_{3}\right) \delta 26.8$, 37.8, 42.7, 47.7, 52.6, 57.6, 59.3, 99.1, 108.3, 117.2, 117.8, 120.2, 121.3, 124.9, 125.5, 128.6, 134.6, 134.9, 149.2, 149.8, 151.7, 155.4, 168.6, 169.2. HRMS calcd for $\mathrm{C}_{26} \mathrm{H}_{28} \mathrm{ClN}_{5} \mathrm{O}_{3}[\mathrm{M}+\mathrm{H}]^{+}$494.1914, found 494.2160 .

2-(4-((7-Chloroquinolin-4-yl)amino)butyl)-5-(4-(2-hydroxyethyl) piperazin-1-yl)isoindoline-1,3-dione (4s). Yield 87\%; dark brown solid; mp 155-156 ${ }^{\circ} \mathrm{C} ;{ }^{1} \mathrm{H}$ NMR (400 MHz, $\left.\mathrm{CDCl}_{3}\right) \delta 1.76-1.86(\mathrm{~m}$, $\left.4 \mathrm{H}, 2 \times-\mathbf{C H}_{2}-\right) ; 2.61\left(\mathrm{t}, J=5.1 \mathrm{~Hz}, 2 \mathrm{H},-\mathbf{C H}_{2}\right) ; 2.66(\mathrm{t}, J=4.7 \mathrm{~Hz}$, $\left.4 \mathrm{H}, 2 \times-\mathbf{C H}_{2}-\right) ; 3.34\left(\mathrm{t}, J=6.6 \mathrm{~Hz}, 2 \mathrm{H},-\mathbf{C H}_{2}-\right) ; 3.40(\mathrm{t}, J=4.6 \mathrm{~Hz}$, $\left.4 \mathrm{H}, 2 \times-\mathbf{C H}_{2}-\right) ; 3.66\left(\mathrm{t}, J=5.1 \mathrm{~Hz}, 2 \mathrm{H},-\mathbf{C H}_{2}-\right) ; 3.73(\mathrm{t}, J=6.4 \mathrm{~Hz}$, $\left.2 \mathrm{H},-\mathbf{C H}_{2}-\right) ; 6.37$ (d, $\left.J=5.3 \mathrm{~Hz}, 1 \mathrm{H}, \mathrm{Ar}-\mathrm{H}\right) ; 7.00(\mathrm{~d}, J=8.4 \mathrm{~Hz}, 1 \mathrm{H}$, $\mathrm{Ar}-\mathrm{H}) ; 7.22$ (s, 1H, Ar-H); 7.34 (d, J=8.9 Hz, 1H, Ar-H); 7.63 (d, J= $8.3 \mathrm{~Hz}, 1 \mathrm{H}, \mathrm{Ar}-\mathrm{H}) ; 7.73$ (d, J=8.9 Hz, 1H, Ar-H); 7.91 (s, 1H, Ar-H); $8.47(\mathrm{~d}, J=5.4 \mathrm{~Hz}, 1 \mathrm{H}, \mathrm{Ar}-\mathrm{H}) ;{ }^{13} \mathrm{C} \mathrm{NMR}\left(100 \mathrm{MHz}, \mathrm{CDCl}_{3}\right) \delta 25.5$, 26.5, 37.2, 42.8, 47.6, 52.4, 57.7, 59.3, 99.0, 108.4, 117.1, 117.6, 120.1, 121.1, 124.8, 125.3, 128.6, 134.4, 134.8, 149.0, 149.6, 151.9, 155.2, 168.7, 169.1. HRMS calcd for $\mathrm{C}_{27} \mathrm{H}_{30} \mathrm{ClN}_{5} \mathrm{O}_{3}[\mathrm{M}+\mathrm{H}]^{+}$ 508.2071 found 508.2084.

2-(6-((7-Chloroquinolin-4-yl)amino)hexyl)-5-(4-(2-hydroxyethyl) piperazin-1-yl)isoindoline-1,3-dione (4t). Yield 85\%; dark brown solid; mp 93-94 ${ }^{\circ} \mathrm{C} ;{ }^{1} \mathrm{H}$ NMR (400 MHz, $\left.\mathrm{CDCl}_{3}\right) \delta 1.33-1.39(\mathrm{~m}, 4 \mathrm{H}$, $\left.2 \times-\mathbf{C H}_{2}-\right) ; 1.75-1.88\left(\mathrm{~m}, 4 \mathrm{H}, 2 \times-\mathbf{C H}_{2}-\right) ; 2.60(\mathrm{t}, J=5.3 \mathrm{~Hz}, 2 \mathrm{H}$, $\left.-\mathbf{C H}_{2}-\right) ; 2.65\left(\mathrm{t}, J=4.8 \mathrm{~Hz}, 4 \mathrm{H}, 2 \times-\mathbf{C H}_{2}-\right) ; 3.33(\mathrm{t}, J=6.5 \mathrm{~Hz}, 2 \mathrm{H}$, $\left.-\mathbf{C H}_{2}-\right) ; 3.40\left(\mathrm{t}, J=4.9 \mathrm{~Hz}, 4 \mathrm{H}, 2 \times-\mathbf{C H}_{2}-\right) ; 3.65(\mathrm{t}, J=5.3 \mathrm{~Hz}, 2 \mathrm{H}$, $\left.-\mathbf{C H}_{2}-\right) ; 3.72\left(\mathrm{t}, J=6.5 \mathrm{~Hz}, 2 \mathrm{H},-\mathbf{C H}_{2}-\right) ; 6.35(\mathrm{~d}, J=5.4 \mathrm{~Hz}, 1 \mathrm{H}, \mathrm{Ar}-$ $\mathrm{H}) ; 7.01$ (d, $8.4 \mathrm{~Hz}, 1 \mathrm{H}, \mathrm{Ar}-\mathrm{H}) ; 7.22(\mathrm{~s}, 1 \mathrm{H}, \mathrm{Ar}-\mathrm{H}) ; 7.32$ (d, J= $8.9 \mathrm{~Hz}$, $1 \mathrm{H}, \mathrm{Ar}-\mathrm{H}) ; 7.61$ (d, $J=8.4 \mathrm{~Hz}, 1 \mathrm{H}, \mathrm{Ar}-\mathrm{H}) ; 7.71$ (d, $J=9.0 \mathrm{~Hz}, 1 \mathrm{H}$, $\mathrm{Ar}-\mathrm{H}) ; 7.90$ (s, 1H, Ar-H); 8.45 (d, J=5.4 Hz, 1H, Ar-H); ${ }^{13} \mathrm{C}$ NMR $\left(100 \mathrm{MHz}, \mathrm{CDCl}_{3}\right) \delta 24.4,25.5,26.5,26.7,28.3,28.5,37.0,42.7,47.4$, 52.3, 57.5, 59.4, 99.0, 108.3, 117.0, 117.4, 120.1, 121.4, 124.6, 125.2, 
128.7, 134.4, 134.6, 149.0, 149.8, 152.0, 155.1, 168.4, 169.0. HRMS calcd for $\mathrm{C}_{29} \mathrm{H}_{34} \mathrm{ClN}_{5} \mathrm{O}_{3}[\mathrm{M}+\mathrm{H}]^{+} 536.2384$ found 536.2376.

\section{General procedure for synthesis of amide linked substituted} isoindoline-1,3-dione-4-aminoquinolines (7a-r, 8a-r)

Synthesis of C-5 substituted 2-(1,3-dioxoisoindolin-2-yl)acetic acid/3-(1,3-dioxoisoindolin-2-yl)propanoic acid/4-(1,3dioxoisoindolin-2-yl)butanoic acid (6): C-4 substituted phthalic anhydride (1 mmol), amino acids $(1.2 \mathrm{mmol})$ and triethylamine $\left(\mathrm{Et}_{3} \mathrm{~N}\right)(1.2 \mathrm{mmol})$ were mixed in toluene and the reaction mixture was refluxed for $6 \mathrm{~h}$. The progress of the reaction was monitored by thin layer chromatography (TLC). Toluene was evaporated under reduced pressure and the solid residue was stirred with 1 $\mathrm{N}-\mathrm{HCl}$ in ice-cold water. The resulted white powder was filtered, dried and used for subsequent step without any purification.

\section{Synthesis of C-5 substituted $N$-(2-((7-chloroquinolin-4-yl)amino)} alkyl)-2-(1,3-dioxoisoindolin-2-yl)alkylamides (7a-r)

$1.0 \mathrm{mmol}$ of C-5 substituted (1,3-dioxoisoindolin-2-yl)acetic acid, $N$-ethyl- $N$-dimethylaminopropyl carbodiimide (EDC) (1.1 mmol), hydroxybenzotriazole (HOBt) $(1.2 \mathrm{mmol})$ and $N, N$-diisopropylethylamine $(2.0 \mathrm{mmol})$ were mixed in minimum DMF and the obtained mixture was stirred for $5 \mathrm{~min}$. Then, 4aminoquinoline-diamines $(1.0 \mathrm{mmol})$ was added to the reaction mixture and the stirring was continued for $5 \mathrm{~h}$. The reaction end was proved by thin layer chromatography (TLC). Then, DMF was evaporated using rotary evaporator and cold water $(20 \mathrm{~mL})$ was added, and solid precipitates obtained were filtered and washed with cold water. The crude product was recrystallized in absolute ethanol.

$\mathrm{N}$-(2-((7-Chloroquinolin-4-yl)amino)ethyl)-2-(1,3-dioxoisoindolin2-yl)acetamide (7a). Yield 82\%; white solid; mp 189-190 ${ }^{\circ} \mathrm{C} ;{ }^{1} \mathrm{H}$ NMR $\left(400 \mathrm{MHz}, \mathrm{DMSO}_{6}\right) \delta 3.31\left(\mathrm{~s}, 4 \mathrm{H}, 2 \times-\mathbf{C H}_{2}-\right)$; $4.18\left(\mathrm{~s}, 2 \mathrm{H},-\mathbf{C H}_{2}-\right)$; $6.50(\mathrm{~d}, J=5.4 \mathrm{~Hz}, 1 \mathrm{H}, \operatorname{Ar}-\mathrm{H}) ; 7.33(\mathrm{t}, J=5.0 \mathrm{~Hz}, 1 \mathrm{H}, \mathrm{NH}-$ exchangeable with $\mathrm{D}_{2} \mathrm{O}$ ); 7.38 (dd, $\left.J=1.8,9.0 \mathrm{~Hz}, 1 \mathrm{H}, \mathrm{Ar}-\mathrm{H}\right) ; 7.74$ (d, $J=2.0 \mathrm{~Hz}, 1 \mathrm{H}, \mathrm{Ar}-\mathrm{H}) ; 7.82-7.88(\mathrm{~m}, 4 \mathrm{H}, \mathrm{Ar}-\mathrm{H}) ; 8.11$ (d, $J=$ $9.0 \mathrm{~Hz}, 1 \mathrm{H}, \mathrm{Ar}-\mathrm{H}) ; 8.36$ (d, $J=5.0 \mathrm{~Hz}, 1 \mathrm{H}, \mathrm{Ar}-\mathrm{H}) ; 8.45$ (t, $J=5.6 \mathrm{~Hz}$, $1 \mathrm{H}$, NH-exchangeable with $\left.\mathrm{D}_{2} \mathrm{O}\right) ;{ }^{13} \mathrm{C}$ NMR (100 MHz, DMSO-d $\left.\mathrm{d}_{6}\right)$ $\delta 37.9,40.7,42.3,99.1,117.9,123.7,124.4,124.6,128.0,132.2,133.9$, 135.1, 149.5, 150.5, 152.4, 167.2, 168.0. HRMS calcd for $\mathrm{C}_{21} \mathrm{H}_{17} \mathrm{ClN}_{4} \mathrm{O}_{3}[\mathrm{M}+\mathrm{H}]^{+} 409.1023$ found 409.1041.

$\mathrm{N}$-(4-((7-Chloroquinolin-4-yl)amino)butyl)-2-(1,3-dioxoisoindolin2-yl)acetamide (7b). Yield $81 \%$; white solid; mp $129-130{ }^{\circ} \mathrm{C} ;{ }^{1} \mathrm{H}$ NMR (400 MHz, DMSO-d $\left.{ }_{6}\right) \delta$ 0.96-1.29 (m, 4H, 2× - $\mathbf{C H}_{2}-$ ); 3.08$3.15\left(\mathrm{~m}, 2 \mathrm{H},-\mathbf{C H}_{2}-\right)$; 3.25-3.29 (m, 2H, $\left.-\mathbf{C H}_{2}-\right)$; $4.16\left(\mathrm{~s}, 2 \mathrm{H},-\mathbf{C H}_{2}-\right.$ ); $6.46(\mathrm{~d}, J=5.5 \mathrm{~Hz}, 1 \mathrm{H}, \mathrm{Ar}-\mathrm{H}) ; 7.33(\mathrm{t}, J=5.2 \mathrm{~Hz}, 1 \mathrm{H}, \mathrm{NH}-$ exchangeable with $\left.\mathrm{D}_{2} \mathrm{O}\right) ; 7.42(\mathrm{dd}, J=2.4,9.0 \mathrm{~Hz}, 1 \mathrm{H}, \mathrm{Ar}-\mathrm{H})$; $7.76(\mathrm{~d}, J=2.3 \mathrm{~Hz}, 1 \mathrm{H}, \mathrm{Ar}-\mathrm{H})$; 7.83-7.90 (m, 4H, Ar-H); 8.20-8.30 $\left(\mathrm{m}, 2 \mathrm{H}, \mathrm{Ar}-\mathrm{H}+\mathrm{NH}\right.$-exchangeable with $\left.\mathrm{D}_{2} \mathrm{O}\right) ; 8.37(\mathrm{~d}, J=5.4 \mathrm{~Hz}$, $1 \mathrm{H}, \mathrm{Ar}-\mathrm{H}) ;{ }^{13} \mathrm{C}$ NMR $\left(100 \mathrm{MHz}, \mathrm{DMSO}-\mathrm{d}_{6}\right) \delta 25.4,27.2,37.2,40.2$, 42.1, 99.2, 117.8, 123.7, 124.3, 124.7, 128.1, 132.2, 133.8, 135.2, 149.4, 150.4, 152.5, 167.0, 168.1. HRMS calcd for $\mathrm{C}_{23} \mathrm{H}_{21} \mathrm{ClN}_{4} \mathrm{O}_{3}$ $[\mathrm{M}+\mathrm{H}]^{+} 437.1336$ found 437.1323 .

$\mathrm{N}$-(6-((7-Chloroquinolin-4-yl)amino)hexyl)-2-(1,3-dioxoisoindolin2-yl)acetamide (7c). Yield 85\%; white solid; mp 110-111 ${ }^{\circ} \mathrm{C} ;{ }^{1} \mathrm{H}$ NMR $\left(400 \mathrm{MHz}, \mathrm{DMSO}-\mathrm{d}_{6}\right) \delta 1.32-1.41\left(\mathrm{~m}, 6 \mathrm{H}, 3 \times-\mathbf{C H}_{2}-\right) ; 1.57-1.64(\mathrm{~m}$,
2H, $\left.-\mathbf{C H}_{2}{ }^{-}\right) ; 3.00-3.05\left(\mathrm{~m}, 2 \mathrm{H},-\mathbf{C H}_{2}-\right)$; 3.20-3.25 (m, 2H, $\left.-\mathbf{C H}_{2}^{-}\right)$; $4.13\left(\mathrm{~s}, 2 \mathrm{H},-\mathbf{C H}_{2}-\right)$; $6.44(\mathrm{~d}, J=5.6 \mathrm{~Hz}, 1 \mathrm{H}, \mathrm{Ar}-\mathrm{H}) ; 7.38-7.42(\mathrm{~m}, 2 \mathrm{H}$, $\mathrm{Ar}-\mathrm{H}+\mathrm{NH}$-exchangeable with $\left.\mathrm{D}_{2} \mathrm{O}\right) ; 7.74(\mathrm{~d}, J=2.2 \mathrm{~Hz}, 1 \mathrm{H}, \mathrm{Ar}-\mathrm{H})$; 7.80-7.86 (m, 4H, Ar-H); 8.16 (t, $J=5.6 \mathrm{~Hz}, 1 \mathrm{H}, \mathrm{NH}$-exchangeable with $\mathrm{D}_{2} \mathrm{O}$ ); 8.25 (d, $\left.J=9.0 \mathrm{~Hz}, 1 \mathrm{H}, \mathrm{Ar}-\mathrm{H}\right) ; 8.34$ (d, $J=5.5 \mathrm{~Hz}, 1 \mathrm{H}$, $\mathrm{Ar}-\mathrm{H}) ;{ }^{13} \mathrm{C}$ NMR (100 MHz, DMSO-d 6 ) $\delta$ 26.5, 26.7, 28.2, 29.4, 39.1, 40.6, 42.9, 99.1, 117.8, 123.6, 124.7, 127.8, 132.3, 134.2, 135.0, 148.8, 150.9, 151.7, 166.3, 168.1. HRMS calcd for $\mathrm{C}_{25} \mathrm{H}_{25} \mathrm{ClN}_{4} \mathrm{O}_{3}[\mathrm{M}+\mathrm{H}]^{+}$ 465.1649 found 465.1629 .

$N$-(8-((7-Chloroquinolin-4-yl)amino)octyl)-2-(1,3-dioxoisoindolin2-yl)acetamide (7d). Yield 76\%; white solid; mp 101-102 ${ }^{\circ} \mathrm{C} ;{ }^{1} \mathrm{H}$ NMR (500 MHz, DMSO-d $\left.)_{6}\right) \delta 1.22-1.41\left(\mathrm{~m}, 12 \mathrm{H}, 6 \times-\mathbf{C H}_{2}-\right) ; 3.03-3.07(\mathrm{~m}$, $\left.2 \mathrm{H},-\mathbf{C H}_{2}{ }^{-}\right) ; 3.22-3.26\left(\mathrm{~m}, 2 \mathrm{H},-\mathbf{C H}_{2}-\right) ; 4.17$ (s, 2H, $\left.-\mathbf{C H}_{2}{ }^{-}\right) ; 6.45(\mathrm{~d}, J$ $=5.3 \mathrm{~Hz}, 1 \mathrm{H}, \mathrm{Ar}-\mathrm{H}) ; 7.29(\mathrm{t}, J=5.3 \mathrm{~Hz}, 1 \mathrm{H}, \mathrm{NH}$-exchangeable with $\left.\mathrm{D}_{2} \mathrm{O}\right) ; 7.43(\mathrm{dd}, J=2.3,8.9 \mathrm{~Hz}, 1 \mathrm{H}, \mathrm{Ar}-\mathrm{H}) ; 7.77$ (d, $J=2.3 \mathrm{~Hz}, 1 \mathrm{H}, \mathrm{Ar}-$ $\mathrm{H})$; $7.84-7.90(\mathrm{~m}, 4 \mathrm{H}, \mathrm{Ar}-\mathrm{H}) ; 8.18(\mathrm{t}, J=5.6 \mathrm{~Hz}, 1 \mathrm{H}, \mathrm{NH}-$ exchangeable with $\left.\mathrm{D}_{2} \mathrm{O}\right) ; 8.27(\mathrm{~d}, J=9.0 \mathrm{~Hz}, 1 \mathrm{H}, \mathrm{Ar}-\mathrm{H}) ; 8.38(\mathrm{~d}, J$ $=5.4 \mathrm{~Hz}, 1 \mathrm{H}, \mathrm{Ar}-\mathrm{H}) ;{ }^{13} \mathrm{C}$ NMR (125 MHz, DMSO-d $\left.{ }_{6}\right) \delta$ 26.4, 26.6, 28.2, 28.4, 29.3, 29.6, 37.8, 40.6, 42.8, 99.2, 117.9, 123.4, 124.3, 127.9, 132.1, 134.2, 135.2, 148.7, 150.6, 151.4, 166.1, 168.0. HRMS calcd for $\mathrm{C}_{27} \mathrm{H}_{29} \mathrm{ClN}_{4} \mathrm{O}_{3}[\mathrm{M}+\mathrm{H}]^{+} 493.1962$ found 493.1956.

$\mathrm{N}$-(2-((7-Chloroquinolin-4-yl)amino)ethyl)-3-(1,3-dioxoisoindolin2-yl)propanamide (7e). Yield 81\%; white solid; mp $182-183{ }^{\circ} \mathrm{C} ;{ }^{1} \mathrm{H}$ NMR (400 MHz, DMSO-d 6 ) $\delta 2.42\left(\mathrm{t}, J=7.2 \mathrm{~Hz}, 2 \mathrm{H},-\mathbf{C H}_{2}-\right)$ ) 2.25$2.30\left(\mathrm{~m}, 4 \mathrm{H}, 2 \times-\mathbf{C H}_{2}-\right) ; 3.75\left(\mathrm{t}, J=7.4 \mathrm{~Hz}, 2 \mathrm{H},-\mathbf{C H}_{2}-\right) ; 6.56(\mathrm{~d}, J$ $=5.8 \mathrm{~Hz}, 1 \mathrm{H}, \mathrm{Ar}-\mathrm{H}) ; 7.45(\mathrm{dd}, J=2.0,9.0 \mathrm{~Hz}, 1 \mathrm{H}, \mathrm{Ar}-\mathrm{H}) ; 7.70-$ $7.74(\mathrm{~m}, 4 \mathrm{H}, \mathrm{Ar}-\mathrm{H}) ; 7.79$ (d, $J=2.3 \mathrm{~Hz}, 1 \mathrm{H}, \mathrm{Ar}-\mathrm{H}) ; 7.93(\mathrm{t}, J=$ $5.6 \mathrm{~Hz}, 1 \mathrm{H}, \mathrm{NH}$-exchangeable with $\left.\mathrm{D}_{2} \mathrm{O}\right) ; 8.17(\mathrm{~d}, J=9.1 \mathrm{~Hz}, 1 \mathrm{H}$, $\mathrm{Ar}-\mathrm{H}) ; 8.29\left(\mathrm{t}, J=5.4 \mathrm{~Hz}, 1 \mathrm{H}, \mathrm{NH}\right.$-exchangeable with $\left.\mathrm{D}_{2} \mathrm{O}\right) ; 8.40(\mathrm{t}$, $J=5.8 \mathrm{~Hz}, 1 \mathrm{H}, \mathrm{Ar}-\mathrm{H}) ;{ }^{13} \mathrm{C} \mathrm{NMR}\left(100 \mathrm{MHz}, \mathrm{DMSO}^{-\mathrm{d}_{6}}\right) \delta 34.6,34.9$, 37.6, 42.9, 99.0, 117.2, 123.4, 124.8, 125.4, 126.7, 132.0, 134.7, 135.3, 146.2, 149.6, 152.2, 168.1, 170.9. HRMS calcd for $\mathrm{C}_{22} \mathrm{H}_{19} \mathrm{ClN}_{4} \mathrm{O}_{3}[\mathrm{M}+\mathrm{H}]^{+} 423.1179$ found 423.1161.

$\mathrm{N}$-(4-((7-Chloroquinolin-4-yl)amino)butyl)-3-(1,3-dioxoisoindolin2-yl)propanamide (7f). Yield 77\%; white solid; mp $172-173{ }^{\circ} \mathrm{C} ;{ }^{1} \mathrm{H}$ NMR (400 MHz, DMSO-d ${ }_{6}$ ) $\delta 1.23-1.33\left(\mathrm{~m}, 4 \mathrm{H}, 2 \times-\mathbf{C H}_{2}-\right) ; 2.41(\mathrm{t}, J$ $\left.=7.1 \mathrm{~Hz}, 2 \mathrm{H},-\mathbf{C H}_{2}-\right)$; 3.05-3.14 (m, 2H, $\left.-\mathbf{C H}_{2}-\right)$; 3.22-3.27 (m, $2 \mathrm{H}$, $\left.-\mathbf{C H}_{2}{ }^{-}\right) ; 3.73\left(\mathrm{t}, J=7.2 \mathrm{~Hz}, 2 \mathrm{H},-\mathbf{C H}_{2}-\right)$; $6.45(\mathrm{~d}, J=5.4 \mathrm{~Hz}, 1 \mathrm{H}, \mathrm{Ar}-\mathrm{H})$; $7.32\left(\mathrm{t}, J=5.2 \mathrm{~Hz}, 1 \mathrm{H}, \mathrm{NH}\right.$-exchangeable with $\left.\mathrm{D}_{2} \mathrm{O}\right) ; 7.43(\mathrm{dd}, J=2.2$, $8.9 \mathrm{~Hz}, 1 \mathrm{H}, \mathrm{Ar}-\mathrm{H}) ; 7.74$ (d, $J=2.2 \mathrm{~Hz}, 1 \mathrm{H}, \mathrm{Ar}-\mathrm{H}) ; 7.83-7.91(\mathrm{~m}, 4 \mathrm{H}$, Ar-H); 8.19-8.28 (m, 2H, Ar-H + NH-exchangeable with $\left.\mathrm{D}_{2} \mathrm{O}\right) ; 8.38$ $(\mathrm{d}, J=5.3 \mathrm{~Hz}, 1 \mathrm{H}, \mathrm{Ar}-\mathrm{H}) ;{ }^{13} \mathrm{C}$ NMR $\left(100 \mathrm{MHz}, \mathrm{DMSO}-\mathrm{d}_{6}\right) \delta 25.4,27.1$, 34.6, 38.2, 40.8, 42.2, 99.2, 117.5, 123.6, 124.3, 124.8, 128.3, 132.5, 133.7, 135.2, 149.6, 150.2, 152.6, 168.1, 170.8. HRMS calcd for $\mathrm{C}_{24} \mathrm{H}_{23} \mathrm{ClN}_{4} \mathrm{O}_{3}[\mathrm{M}+\mathrm{H}]^{+} 451.1492$ found 451.1466 .

$\mathrm{N}$-(6-((7-Chloroquinolin-4-yl)amino)hexyl)-3-(1,3-dioxoisoindolin2-yl)propanamide (7g). Yield 79\%; white solid; mp $122-123{ }^{\circ} \mathrm{C} ;{ }^{1} \mathrm{H}$ NMR (400 MHz, DMSO-d ${ }_{6}$ ) 1.29-1.40 (m, 6H, 3×- $\left.\mathbf{C H}_{2}-\right)$; 1.55-1.63 $\left(\mathrm{m}, 2 \mathrm{H},-\mathbf{C H}_{2}-\right) ; 2.40\left(\mathrm{t}, J=7.2 \mathrm{~Hz}, 2 \mathrm{H},-\mathbf{C H}_{2}-\right) ; 3.01-3.07(\mathrm{~m}, 2 \mathrm{H}$, $\left.-\mathbf{C H}_{2}-\right)$; 3.21-3.27 (m, 2H, $\left.-\mathbf{C H}_{2}-\right)$; $3.72\left(\mathrm{t}, J=7.2 \mathrm{~Hz}, 2 \mathrm{H},-\mathbf{C H}_{2}-\right)$; $6.44(\mathrm{~d}, J=5.3 \mathrm{~Hz}, 1 \mathrm{H}, \operatorname{Ar}-\mathrm{H}) ; 7.30(\mathrm{t}, J=5.2 \mathrm{~Hz}, 1 \mathrm{H}, \mathrm{NH}-$ exchangeable with $\mathrm{D}_{2} \mathrm{O}$ ); 7.42 (dd, $\left.J=2.2,9.0 \mathrm{~Hz}, 1 \mathrm{H}, \mathrm{Ar}-\mathrm{H}\right) ; 7.73$ $(\mathrm{d}, J=2.1 \mathrm{~Hz}, 1 \mathrm{H}, \mathrm{Ar}-\mathrm{H})$; 7.83-7.92 (m, 4H, Ar-H); 8.20-8.29 (m, 2H, $\mathrm{Ar}-\mathrm{H}+\mathrm{NH}$-exchangeable with $\left.\mathrm{D}_{2} \mathrm{O}\right) ; 8.35(\mathrm{~d}, J=5.2 \mathrm{~Hz}, 1 \mathrm{H}, \mathrm{Ar}-\mathrm{H})$; ${ }^{13} \mathrm{C}$ NMR (100 MHz, DMSO-d 6 ) $\delta$ 26.4, 26.7, 28.3, 29.1, 34.6, 39.4, 40.8, 42.2, 99.1, 117.7, 123.6, 124.2, 124.8, 128.4, 132.4, 133.7, 135.1, 
149.5, 150.1, 152.3, 168.1, 170.7. HRMS calcd for $\mathrm{C}_{26} \mathrm{H}_{27} \mathrm{ClN}_{4} \mathrm{O}_{3}[\mathrm{M}+$ $\mathrm{H}]^{+} 479.1805$ found 479.1814 .

$\mathrm{N}$-(8-((7-Chloroquinolin-4-yl)amino)octyl)-3-(1,3-dioxoisoindolin2-yl)propanamide (7h). Yield 70\%; white solid; mp 85-86 ${ }^{\circ} \mathrm{C} ;{ }^{1} \mathrm{H}$ NMR (400 MHz, DMSO-d ${ }_{6}$ ) 1.20-1.40 (m, 12H, 6×- $\left.\mathbf{C H}_{2}-\right) ; 2.41(\mathrm{t}, J$ $\left.=7.1 \mathrm{~Hz}, 2 \mathrm{H},-\mathbf{C H}_{2}-\right)$; 3.02-3.07 (m, $\left.2 \mathrm{H},-\mathbf{C H}_{2}-\right)$; 3.21-3.26 (m, $2 \mathrm{H}$, $\left.-\mathbf{C H}_{2}{ }^{-}\right) ; 3.71\left(\mathrm{t}, J=7.2 \mathrm{~Hz}, 2 \mathrm{H},-\mathbf{C H}_{2}-\right) ; 6.43(\mathrm{~d}, J=5.3 \mathrm{~Hz}, 1 \mathrm{H}, \mathrm{Ar}-\mathrm{H})$; $7.31\left(\mathrm{t}, J=5.4 \mathrm{~Hz}, 1 \mathrm{H}, \mathrm{NH}\right.$-exchangeable with $\left.\mathrm{D}_{2} \mathrm{O}\right) ; 7.41(\mathrm{dd}, J=2.1$, $9.0 \mathrm{~Hz}, 1 \mathrm{H}, \mathrm{Ar}-\mathrm{H}) ; 7.75$ (d, $J=2.0 \mathrm{~Hz}, 1 \mathrm{H}, \mathrm{Ar}-\mathrm{H}) ; 7.85-7.94(\mathrm{~m}, 4 \mathrm{H}$, Ar-H); 8.20-8.30 (m, 2H, Ar-H + NH-exchangeable with $\left.\mathrm{D}_{2} \mathrm{O}\right) ; 8.34$ $(\mathrm{d}, J=5.3 \mathrm{~Hz}, 1 \mathrm{H}, \mathrm{Ar}-\mathrm{H}) ;{ }^{13} \mathrm{C}$ NMR $\left(100 \mathrm{MHz}, \mathrm{DMSO}^{-\mathrm{d}_{6}}\right) \delta$ 26.2, 26.6, 28.2, 28.5, 29.1, 29.5, 34.6, 37.8, 40.5, 42.2, 99.2, 117.5, 123.8, 124.2, 124.9, 128.5, 132.4, 133.9, 135.0, 149.5, 150.0, 152.5, 168.3, 170.9. HRMS calcd for $\mathrm{C}_{28} \mathrm{H}_{31} \mathrm{ClN}_{4} \mathrm{O}_{3}[\mathrm{M}+\mathrm{H}]^{+} 507.2118$ found 507.2129.

$\mathrm{N}$-(2-((7-Chloroquinolin-4-yl)amino)ethyl)-4-(1,3-dioxoisoindolin2-yl)butanamide (7i). Yield 83\%; white solid; mp $177-178{ }^{\circ} \mathrm{C} ;{ }^{1} \mathrm{H}$ NMR (500 MHz, DMSO-d $\left.{ }_{6}\right) \delta$ 1.77-1.83 (m, 2H, - $\left.\mathbf{C H}_{2}-\right) ; 2.12(\mathrm{t}, J=$ $\left.7.5 \mathrm{~Hz}, 2 \mathrm{H},-\mathbf{C H}_{2}-\right)$; $3.32\left(\mathrm{t}, J=6.0 \mathrm{~Hz}, 2 \mathrm{H},-\mathbf{C H}_{2}-\right)$; 3.52-3.57 (m, $4 \mathrm{H}$, $\left.2 \times-\mathbf{C H}_{2}-\right) ; 6.89(\mathrm{~d}, J=7.1 \mathrm{~Hz}, 1 \mathrm{H}, \mathrm{Ar}-\mathrm{H}) ; 7.77(\mathrm{dd}, J=2.2,9.1 \mathrm{~Hz}$, $1 \mathrm{H}, \mathrm{Ar}-\mathrm{H})$; 7.81-7.86 (m, 4H, Ar-H); 8.00 (d, J=2.1 Hz, $1 \mathrm{H}, \mathrm{Ar}-\mathrm{H})$; $8.16\left(\mathrm{t}, J=5.3 \mathrm{~Hz}, 1 \mathrm{H}\right.$, NH-exchangeable with $\left.\mathrm{D}_{2} \mathrm{O}\right) ; 8.53-8.57(\mathrm{~m}$, $2 \mathrm{H}, \mathrm{Ar}-\mathrm{H}) ; 9.54\left(\mathrm{t}, J=5.9 \mathrm{~Hz}, 1 \mathrm{H}\right.$, NH-exchangeable with $\left.\mathrm{D}_{2} \mathrm{O}\right) ;{ }^{13} \mathrm{C}$ NMR (125 MHz, DMSO-d $\left.{ }_{6}\right) \delta 24.3,33.1,37.5,37.6,43.2,98.9,115.9$, 119.4, 123.4, 126.1, 127.3, 132.0, 134.8, 138.4, 138.9, 143.3, 156.1, 168.3, 172.6. HRMS calcd for $\mathrm{C}_{23} \mathrm{H}_{21} \mathrm{ClN}_{4} \mathrm{O}_{3}[\mathrm{M}+\mathrm{H}]^{+} 437.1336$ found 437.1321.

$\mathrm{N}$-(4-((7-Chloroquinolin-4-yl)amino)butyl)-4-(1,3-dioxoisoindolin2-yl)butanamide (7j). Yield 74\%; white solid; mp $145-146{ }^{\circ} \mathrm{C} ;{ }^{1} \mathrm{H}$ NMR (500 MHz, DMSO-d $\left.{ }_{6}\right) \delta 1.22-1.34\left(\mathrm{~m}, 4 \mathrm{H}, 2 \times-\mathbf{C H}_{2}-\right)$; 1.76-1.83 (m, 2H, - $\left.\mathbf{C H}_{2}-\right) ; 2.11$ (t, $\left.J=7.1 \mathrm{~Hz}, 2 \mathrm{H},-\mathbf{C H}_{2}-\right)$; 3.08-3.15 (m, 2H, $\left.-\mathbf{C H}_{2}{ }^{-}\right) ; 3.25-3.29\left(\mathrm{~m}, 2 \mathrm{H},-\mathbf{C H}_{2}{ }^{-}\right) ; 3.56\left(\mathrm{t}, J=7.2 \mathrm{~Hz}, 2 \mathrm{H},-\mathbf{C H}_{2}{ }^{-}\right)$; $6.85(\mathrm{~d}, J=7.1 \mathrm{~Hz}, 1 \mathrm{H}, \mathrm{Ar}-\mathrm{H}) ; 7.76(\mathrm{dd}, J=2.0,9.0 \mathrm{~Hz}, 1 \mathrm{H}, \mathrm{Ar}-\mathrm{H})$; 7.80-7.86 (m, 4H, Ar-H); 8.01 (d, J=2.1 Hz, 1H, Ar-H); 8.14 (t, $J=$ $5.4 \mathrm{~Hz}, 1 \mathrm{H}$, NH-exchangeable with $\left.\mathrm{D}_{2} \mathrm{O}\right)$; 8.54-8.59 (m, 2H, Ar-H); $8.85\left(\mathrm{t}, J=5.5 \mathrm{~Hz}, 1 \mathrm{H}, \mathrm{NH}\right.$-exchangeable with $\left.\mathrm{D}_{2} \mathrm{O}\right) ;{ }^{13} \mathrm{C}$ NMR $(125$ MHz, DMSO-d $\left.{ }_{6}\right) \delta 24.4,25.3,27.5,33.4,37.6,40.9,43.2,99.1,115.7$, 119.3, 123.4, 126.4, 127.3, 132.1, 134.8, 138.5, 138.8, 143.4, 156.1, 168.2, 172.4. HRMS calcd for $\mathrm{C}_{25} \mathrm{H}_{25} \mathrm{ClN}_{4} \mathrm{O}_{3}[\mathrm{M}+\mathrm{H}]^{+} 465.1649$ found 465.1633.

$\mathrm{N}$-(6-((7-Chloroquinolin-4-yl)amino)hexyl)-4-(1,3-dioxoisoindolin2-yl)butanamide (7k). Yield 75\%; white solid; mp $158-159{ }^{\circ} \mathrm{C} ;{ }^{1} \mathrm{H}$ NMR (500 MHz, DMSO-d $\left.{ }_{6}\right) \delta$ 1.18-1.25 (m, 2H, - $\left.\mathbf{C H}_{2}-\right)$; 1.27-1.40 (m, 4H, 2×- $\left.\mathbf{C H}_{2}-\right)$; 1.61-1.67 (m, 2H, $\left.-\mathbf{C H}_{2}-\right)$; 1.78-1.85 (m, 2H, - $\left.\mathbf{C H}_{2}{ }^{-}\right)$; 2.06-2.10 (m, 2H, - $\mathbf{C H}_{2}^{-}$); 2.91-2.99 (m, 2H, - $\left.\mathbf{C H}_{2}^{-}\right)$; 3.23$3.27\left(\mathrm{~m}, 2 \mathrm{H},-\mathbf{C H}_{2}-\right)$ ) $3.57\left(\mathrm{t}, J=7.1 \mathrm{~Hz}, 2 \mathrm{H},-\mathbf{C H}_{2}-\right)$ ); $6.46(\mathrm{~d}, J=$ $5.4 \mathrm{~Hz}, 1 \mathrm{H}, \mathrm{Ar}-\mathrm{H}) ; 7.32(\mathrm{t}, J=5.55 \mathrm{~Hz}, 1 \mathrm{H}, \mathrm{NH}$-exchangeable with $\left.\mathrm{D}_{2} \mathrm{O}\right) ; 7.44(\mathrm{dd}, J=2.1,8.9 \mathrm{~Hz}, 1 \mathrm{H}, \mathrm{Ar}-\mathrm{H}) ; 7.71$ (d, $J=5.5 \mathrm{~Hz}, 1 \mathrm{H}, \mathrm{Ar}-$ $\mathrm{H}) ; 7.76(\mathrm{~d}, J=2.3 \mathrm{~Hz}, 1 \mathrm{H}, \mathrm{Ar}-\mathrm{H}) ; 7.81-7.86$ (m, 4H, Ar-H); 8.28 (d, $=9.0 \mathrm{~Hz}, 1 \mathrm{H}, \mathrm{Ar}-\mathrm{H}) ; 8.38(\mathrm{t}, J=5.5 \mathrm{~Hz}, 1 \mathrm{H}, \mathrm{NH}$-exchangeable with $\mathrm{D}_{2} \mathrm{O}$ ); ${ }^{13} \mathrm{C}$ NMR (125 MHz, DMSO-d 6 ) $\delta$ 24.5, 26.4, 26.9, 28.2, 29.7, 33.5, 38.4, 40.4, 43.5, 99.2, 115.6, 119.3, 123.5, 126.4, 127.2, 132.0, 134.9, 138.5, 138.9, 143.3, 156.2, 168.1, 172.2. HRMS calcd for $\mathrm{C}_{27} \mathrm{H}_{29} \mathrm{ClN}_{4} \mathrm{O}_{3}[\mathrm{M}+\mathrm{H}]^{+} 493.1962$ found 4931951.

$\mathrm{N}$-(8-((7-Chloroquinolin-4-yl)amino)octyl)-4-(1,3-dioxoisoindolin2-yl)butanamide (7l). Yield 78\%; white solid; mp $152-153{ }^{\circ} \mathrm{C} ;{ }^{1} \mathrm{H}$ NMR (500 MHz, DMSO-d $\left.{ }_{6}\right) \delta 1.20-1.39$ (m, 12H, 6× - $\mathbf{C H}_{2}-$ ); 1.75$1.84\left(\mathrm{~m}, 2 \mathrm{H},-\mathbf{C H}_{2}-\right)$; 2.07-2.11 (m, 2H, $\left.-\mathbf{C H}_{2}-\right)$; 3.02-3.06 (m, 2H, $\left.{ }^{-} \mathbf{C H}_{2}{ }^{-}\right) ; 3.20-3.25\left(\mathrm{~m}, 2 \mathrm{H},-\mathbf{C H}_{2}-\right) ; 3.54\left(\mathrm{t}, J=7.2 \mathrm{~Hz}, 2 \mathrm{H},-\mathbf{C H}_{2}-\right)$; $6.44(\mathrm{~d}, J=5.2 \mathrm{~Hz}, 1 \mathrm{H}, \operatorname{Ar}-\mathrm{H}) ; 7.28(\mathrm{t}, J=5.3 \mathrm{~Hz}, 1 \mathrm{H}, \mathrm{NH}-$ exchangeable with $\mathrm{D}_{2} \mathrm{O}$ ); 7.44 (dd, $\left.J=2.2,8.9 \mathrm{~Hz}, 1 \mathrm{H}, \mathrm{Ar}-\mathrm{H}\right) ; 7.75$ (d, $J=2.3 \mathrm{~Hz}, 1 \mathrm{H}, \mathrm{Ar}-\mathrm{H}) ; 7.83-7.90(\mathrm{~m}, 4 \mathrm{H}, \mathrm{Ar}-\mathrm{H}) ; 8.19$ (d, $J=$ $5.4 \mathrm{~Hz}, 1 \mathrm{H}, \mathrm{Ar}-\mathrm{H}$ ); 8.27 (d, $J=8.9 \mathrm{~Hz}, 1 \mathrm{H}, \mathrm{Ar}-\mathrm{H}) ; 8.40$ (t, $J=5.3 \mathrm{~Hz}$, $1 \mathrm{H}$, NH-exchangeable with $\left.\mathrm{D}_{2} \mathrm{O}\right) ;{ }^{13} \mathrm{C}$ NMR (125 MHz, DMSO-d $\mathrm{d}_{6}$ ) $\delta$ 24.5, 26.4, 26.7, 28.1, 28.5, 29.4, 29.8, 33.3, 37.8, 40.5, 43.4, 99.1, 115.9, 119.34, 123.4, 126.6, 127.2, 132.1, 134.6, 138.7, 138.8, 143.3, 156.3, 168.2, 172.6. HRMS calcd for $\mathrm{C}_{29} \mathrm{H}_{33} \mathrm{ClN}_{4} \mathrm{O}_{3}[\mathrm{M}+\mathrm{H}]^{+} 521.2275$ found 521.2258 .

$\mathrm{N}$-(2-((7-Chloroquinolin-4-yl)amino)ethyl)-2-(5-fluoro-1,3dioxoisoindolin-2-yl)acetamide (7m). Yield $81 \%$; white solid; mp 192-193 ${ }^{\circ} \mathrm{C} ;{ }^{1} \mathrm{H}$ NMR (DMSO-d 6 , $500 \mathrm{MHz}$ ): 3.31 (s, 4H, $2 \times$ $\left.-\mathbf{C H}_{2}{ }^{-}\right)$; 4.17 (s, 2H, - $\left.\mathbf{C H}_{2}{ }^{-}\right) ; 6.51$ (d, $\left.J=5.5 \mathrm{~Hz}, 1 \mathrm{H}, \mathrm{Ar}-\mathrm{H}\right)$; 7.37$7.42\left(\mathrm{~m}, 2 \mathrm{H}, \mathrm{Ar}-\mathrm{H}+\mathrm{NH}\right.$-exchangeable with $\left.\mathrm{D}_{2} \mathrm{O}\right) ; 7.64-7.69(\mathrm{~m}$, $1 \mathrm{H}, \mathrm{Ar}-\mathrm{H}) ; 7.75$ (d, J = 2.2 Hz, 1H, Ar-H); 7.77-7.80 (m, 1H, Ar$\mathrm{H})$; 7.93-7.96 (m, 1H, Ar-H); 8.13 (d, $J=9.0 \mathrm{~Hz}, \mathrm{Ar}-\mathrm{H}) ; 8.37$ (d, $J$ $=5.5 \mathrm{~Hz}, \mathrm{Ar}-\mathrm{H}) ; 8.45(\mathrm{t}, J=5.6 \mathrm{~Hz}, 1 \mathrm{H}, \mathrm{NH}$-exchangeable with $\mathrm{D}_{2} \mathrm{O}$ ); ${ }^{13} \mathrm{C}$ NMR (125 MHz, DMSO-d $\left.{ }_{6}\right) \delta 36.7,41.3,42.5$, 99.1, $111.3(\mathrm{~d}, J=22.9 \mathrm{~Hz}), 117.8,121.5(\mathrm{~d}, J=23.7 \mathrm{~Hz}), 124.8,125.1$, $126.7(\mathrm{~d}, J=9.6 \mathrm{~Hz}), 127.9,128.5(\mathrm{~d}, J=1.9 \mathrm{~Hz}), 133.4,135.1(\mathrm{~d}, J$ $=9.4 \mathrm{~Hz}), 149.7,150.6,152.5,166.2(\mathrm{~d}, J=252.3 \mathrm{~Hz}), 166.7(\mathrm{~d}, J$ $=2.3 \mathrm{~Hz}), 167.3,169.7$. HRMS calcd for $\mathrm{C}_{2} 1 \mathrm{H}_{16} \mathrm{ClFN}_{4} \mathrm{O}_{3}[\mathrm{M}+\mathrm{H}]^{+}$ 427.0929 found 427.0935 .

$\mathrm{N}$-(4-((7-Chloroquinolin-4-yl)amino)butyl)-2-(5-fluoro-1,3dioxoisoindolin-2-yl)acetamide (7n). Yield 85\%; white solid; mp 140-141 ${ }^{\circ} \mathrm{C} ;{ }^{1} \mathrm{H}$ NMR (DMSO-d 6 , $\left.500 \mathrm{MHz}\right): 1.50-1.56(\mathrm{~m}, 2 \mathrm{H}$, $\left.-\mathbf{C H}_{2}{ }^{-}\right)$; $1.62-1.68\left(\mathrm{~m}, 2 \mathrm{H},-\mathbf{C H}_{2}{ }^{-}\right)$; 3.11-3.15 (m, 2H, $\left.-\mathbf{C H}_{2}{ }^{-}\right)$; 3.27-3.31 (m, 2H, - $\left.\mathbf{C H}_{2}-\right) ; 4.18\left(\mathrm{~s}, 2 \mathrm{H},-\mathbf{C H}_{2}-\right) ; 6.50(\mathrm{~d}, J=$ $5.6 \mathrm{~Hz}, 1 \mathrm{H}, \mathrm{Ar}-\mathrm{H})$; 7.45-7.47 (m, 2H, Ar-H + NH-exchangeable with $\left.\mathrm{D}_{2} \mathrm{O}\right) ; 7.68-7.72(\mathrm{~m}, 1 \mathrm{H}, \mathrm{Ar}-\mathrm{H}) ; 7.78(\mathrm{~d}, J=2.3 \mathrm{~Hz}, 1 \mathrm{H}$, Ar-H); 7.81-7.83 (m, 1H, Ar-H); 7.97-7.99 (m, 1H, Ar-H); 8.25 (t, $J=5.7 \mathrm{~Hz}$, NH-exchangeable with $\left.\mathrm{D}_{2} \mathrm{O}\right) ; 8.29$ (d, $J=9.0 \mathrm{~Hz}, \mathrm{Ar}-$ $\mathrm{H}) ; 8.39(\mathrm{~d}, J=5.5 \mathrm{~Hz}, 1 \mathrm{H}, \mathrm{Ar}-\mathrm{H}) ;{ }^{13} \mathrm{C} \mathrm{NMR}\left(125 \mathrm{MHz}, \mathrm{DMSO}_{6}\right.$ ) $\delta 25.7,26.8,35.2,39.3,42.9,99.0,111.7(\mathrm{~d}, J=23.3 \mathrm{~Hz}), 117.7$, $121.5(\mathrm{~d}, J=23.4 \mathrm{~Hz}), 124.4,124.8,126.6(\mathrm{~d}, J=9.6 \mathrm{~Hz}), 127.9$, $128.3(\mathrm{~d}, J=1.8 \mathrm{~Hz}), 133.9,135.2$ (d, $J=9.4 \mathrm{~Hz}), 149.1,150.4$, $152.2,166.1$ (d, $J=251.6 \mathrm{~Hz}), 166.9$ (d, $J=2.3 \mathrm{~Hz}), 167.4,169.8$. HRMS calcd for $\mathrm{C}_{23} \mathrm{H}_{20} \mathrm{ClFN}_{4} \mathrm{O}_{3}[\mathrm{M}+\mathrm{H}]^{+} 455.1242$ found 455.1265 .

$\mathrm{N}$-(6-((7-Chloroquinolin-4-yl)amino)hexyl)-2-(5-fluoro-1,3dioxoisoindolin-2-yl)acetamide (7o). Yield 84\%; white solid; mp 131-132 ${ }^{\circ} \mathrm{C} ;{ }^{1} \mathrm{H}$ NMR (DMSO-d 6 , $400 \mathrm{MHz}$ ): 1.36-1.44 (m, 4H, $2 \times$ $\left.-\mathbf{C H}_{2}{ }^{-}\right)$; 1.54-1.62 (m, 4H, $\left.2 \times-\mathbf{C H}_{2}{ }^{-}\right)$; 3.01-3.07 (m, 2H, $\left.-\mathbf{C H}_{2}^{-}\right)$; 3.22-3.25 (m, 2H, - $\left.\mathbf{C H}_{2}-\right) ; 4.17$ (s, 2H, $\left.-\mathbf{C H}_{2}-\right)$ ) 6.39 (d, $J=$ $5.3 \mathrm{~Hz}, 1 \mathrm{H}, \mathrm{Ar}-\mathrm{H}) ; 7.30(\mathrm{t}, J=5.4 \mathrm{~Hz}, \mathrm{NH}$-exchangeable with $\left.\mathrm{D}_{2} \mathrm{O}\right) ; 7.35$ (dd, $\left.J=2.1,9.0 \mathrm{~Hz}, 1 \mathrm{H}, \mathrm{Ar}-\mathrm{H}\right) ; 7.54-7.59$ (m, 1H, ArH); 7.69-7.74 (m, 2H, Ar-H); 7.88-7.90 (m, 1H, Ar-H); $7.96(\mathrm{t}, J=$ $5.5 \mathrm{~Hz}, \mathrm{NH}$-exchangeable with $\left.\mathrm{D}_{2} \mathrm{O}\right) ; 8.22(\mathrm{~d}, J=9.0 \mathrm{~Hz}, \mathrm{Ar}-\mathrm{H})$; $8.31(\mathrm{~d}, J=5.4 \mathrm{~Hz}, 1 \mathrm{H}, \mathrm{Ar}-\mathrm{H}) ;{ }^{13} \mathrm{C}$ NMR (100 MHz, DMSO-d $\left.{ }_{6}\right)$ $\delta 26.5,26.9,28.5,29.6,39.5,40.9,42.5,99.1,111.4$ (d, $J=23.7$ $\mathrm{Hz}), 117.7,121.9$ (d, $J=23.7 \mathrm{~Hz}), 124.9,125.4,126.5$ (d, $J=9.7$ $\mathrm{Hz}), 127.8,128.2(\mathrm{~d}, J=1.9 \mathrm{~Hz}), 133.7,135.1(\mathrm{~d}, J=9.7 \mathrm{~Hz})$, 149.6, 150.7, 152.3, 166.0 (d, $J=252.3 \mathrm{~Hz}), 166.8$ (d, $J=2.4 \mathrm{~Hz}$ ), 167.2, 169.6. HRMS calcd for $\mathrm{C}_{25} \mathrm{H}_{24} \mathrm{ClFN}_{4} \mathrm{O}_{3}[\mathrm{M}+\mathrm{H}]^{+} 483.1555$ found 483.1561 . 
$\mathrm{N}$-(2-((7-Chloroquinolin-4-yl)amino)ethyl)-3-(5-fluoro-1,3dioxoisoindolin-2-yl)propanamide (7p). Yield 81\%; white solid; mp 183-184 ${ }^{\circ} \mathrm{C} ;{ }^{1} \mathrm{H}$ NMR (DMSO-d $\left.6,400 \mathrm{MHz}\right): 2.40(\mathrm{t}, J=$ $\left.7.2 \mathrm{~Hz}, 2 \mathrm{H},-\mathbf{C H}_{2}-\right) ; 3.00-3.09\left(\mathrm{~m}, 4 \mathrm{H}, 2 \times-\mathbf{C H}_{2}-\right) ; 3.73(\mathrm{t}, J=$ $\left.7.1 \mathrm{~Hz}, 2 \mathrm{H},-\mathbf{C H}_{2}-\right) ; 6.41(\mathrm{~d}, J=5.3 \mathrm{~Hz}, 1 \mathrm{H}, \mathrm{Ar}-\mathrm{H}) ; 7.29(\mathrm{t}, J=$ $5.5 \mathrm{~Hz}, \mathrm{NH}$-exchangeable with $\left.\mathrm{D}_{2} \mathrm{O}\right) ; 7.41(\mathrm{dd}, J=2.1,9.0 \mathrm{~Hz}$, 1H, Ar-H); 7.56-7.62 (m, 1H, Ar-H); 7.70-7.74 (m, 2H, Ar-H); 7.84-7.88 (m, 1H, Ar-H); $7.99(\mathrm{t}, J=5.4 \mathrm{~Hz}$, NH-exchangeable with $\left.\mathrm{D}_{2} \mathrm{O}\right) ; 8.22(\mathrm{~d}, J=9.1 \mathrm{~Hz}, \mathrm{Ar}-\mathrm{H}) ; 8.35(\mathrm{~d}, J=5.5 \mathrm{~Hz}, 1 \mathrm{H}$, $\mathrm{Ar}-\mathrm{H}) ;{ }^{13} \mathrm{C}$ NMR (100 MHz, DMSO-d 6 ) $\delta 34.5,37.9,40.8,42.4$, 99.2, $111.3(\mathrm{~d}, J=23.2 \mathrm{~Hz}), 117.5,121.2(\mathrm{~d}, J=23.4 \mathrm{~Hz}), 124.4$, 124.8, 126.5 (d, $J=9.5 \mathrm{~Hz}), 127.8,128.2(\mathrm{~d}, J=1.8 \mathrm{~Hz}), 133.7$, $135.0(\mathrm{~d}, J=9.5 \mathrm{~Hz}), 149.6,150.3,152.2,166.1(\mathrm{~d}, J=251.9 \mathrm{~Hz})$, $166.5(\mathrm{~d}, J=2.3 \mathrm{~Hz}), 167.1,169.9$. HRMS calcd for $\mathrm{C}_{27} \mathrm{H}_{29} \mathrm{ClN}_{4} \mathrm{O}_{3}$ $[\mathrm{M}]^{+} 492.1928$ found 4921941. HRMS calcd for $\mathrm{C}_{22} \mathrm{H}_{18} \mathrm{ClFN}_{4} \mathrm{O}_{3}$ $[\mathrm{M}+\mathrm{H}]^{+} 441.1085$ found 441.1097 .

$\mathrm{N}$-(4-((7-Chloroquinolin-4-yl)amino)butyl)-3-(5-fluoro-1,3dioxoisoindolin-2-yl)propanamide (7q). Yield 76\%; white solid; mp 177-178 ${ }^{\circ} \mathrm{C}$; ${ }^{1} \mathrm{H}$ NMR (DMSO-d 6 , $400 \mathrm{MHz}$ ): 1.38-1.45 (m, $\left.2 \mathrm{H},-\mathbf{C H}_{2}{ }^{-}\right) ; 1.51-1.58\left(\mathrm{~m}, 2 \mathrm{H},-\mathbf{C H}_{2}^{-}\right) ; 2.38(\mathrm{t}, J=7.2 \mathrm{~Hz}, 2 \mathrm{H}$, $\left.-\mathbf{C H}_{2}{ }^{-}\right)$; 2.98-3.03 (m, 2H, $\left.-\mathbf{C H}_{2}-\right)$; 3.15-3.20 (m, 2H, $\left.-\mathbf{C H}_{2}-\right)$; $3.72\left(\mathrm{t}, J=7.3 \mathrm{~Hz}, 2 \mathrm{H},-\mathbf{C H}_{2}-\right) ; 6.39$ (d, $\left.J=5.4 \mathrm{~Hz}, 1 \mathrm{H}, \mathrm{Ar}-\mathrm{H}\right)$; $7.28\left(\mathrm{t}, J=5.4 \mathrm{~Hz}\right.$, NH-exchangeable with $\left.\mathrm{D}_{2} \mathrm{O}\right) ; 7.39(\mathrm{dd}, J=2.3$, $9.1 \mathrm{~Hz}, 1 \mathrm{H}, \mathrm{Ar}-\mathrm{H})$; 7.54-7.59 (m, 1H, Ar-H); 7.69-7.72 (m, 2H, $\mathrm{Ar}-\mathrm{H})$; 7.85-7.88 (m, 1H, Ar-H); 7.98 (t, $J=5.5 \mathrm{~Hz}, \mathrm{NH}-$ exchangeable with $\left.\mathrm{D}_{2} \mathrm{O}\right) ; 8.21$ (d, $\left.J=9.0 \mathrm{~Hz}, \mathrm{Ar}-\mathrm{H}\right) ; 8.33(\mathrm{~d}, J$ $=5.4 \mathrm{~Hz}, 1 \mathrm{H}, \mathrm{Ar}-\mathrm{H}) ;{ }^{13} \mathrm{C}$ NMR (100 MHz, DMSO-d $\left.\mathrm{d}_{6}\right) \delta 25.6,27.1$, 34.4, 35.1, 38.6, 42.5, 99.1, 111.4 (d, $J=23.5 \mathrm{~Hz}), 117.9,121.5$ (d, $J=23.5 \mathrm{~Hz}), 124.5,124.6,126.2(\mathrm{~d}, J=9.6 \mathrm{~Hz}), 127.8,128.3(\mathrm{~d}, J$ $=1.7 \mathrm{~Hz}), 133.9,135.1(\mathrm{~d}, J=9.5 \mathrm{~Hz}), 149.4,150.6,152.3,166.2$ $(\mathrm{d}, J=251.7 \mathrm{~Hz}), 166.8(\mathrm{~d}, J=2.4 \mathrm{~Hz}), 167.2$, 169.8. HRMS calcd for $\mathrm{C}_{24} \mathrm{H}_{22} \mathrm{ClFN}_{4} \mathrm{O}_{3}[\mathrm{M}+\mathrm{H}]^{+} 469.1398$ found 469.1387 .

$\mathrm{N}$-(6-((7-Chloroquinolin-4-yl)amino)hexyl)-3-(5-fluoro-1,3dioxoisoindolin-2-yl)propanamide (7r). Yield 77\%; white solid; mp 138-139 ${ }^{\circ} \mathrm{C} ;{ }^{1} \mathrm{H}$ NMR (DMSO-d $\left.6,400 \mathrm{MHz}\right): 1.32-1.39(\mathrm{~m}$, $\left.6 \mathrm{H}, 3 \times-\mathbf{C H}_{2}-\right)$; 1.54-1.63 (m, 2H, $\left.-\mathbf{C H}_{2}-\right)$; $2.39(\mathrm{t}, J=7.1 \mathrm{~Hz}, 2 \mathrm{H}$, $\left.-\mathbf{C H}_{2}{ }^{-}\right)$; 3.00-3.05 (m, 2H, $\left.-\mathbf{C H}_{2}-\right)$; 3.19-3.24 (m, 2H, $-\mathbf{C H}_{2}-$ ); $3.71\left(\mathrm{t}, J=7.2 \mathrm{~Hz}, 2 \mathrm{H},-\mathbf{C H}_{2}-\right)$; $6.38(\mathrm{~d}, J=5.3 \mathrm{~Hz}, 1 \mathrm{H}, \mathrm{Ar}-\mathrm{H})$; $7.29\left(\mathrm{t}, J=5.4 \mathrm{~Hz}, \mathrm{NH}\right.$-exchangeable with $\left.\mathrm{D}_{2} \mathrm{O}\right) ; 7.37(\mathrm{dd}, J=2.2$, $9.0 \mathrm{~Hz}, 1 \mathrm{H}, \mathrm{Ar}-\mathrm{H}) ; 7.53-7.59(\mathrm{~m}, 1 \mathrm{H}, \mathrm{Ar}-\mathrm{H}) ; 7.68-7.73(\mathrm{~m}, 2 \mathrm{H}$, $\mathrm{Ar}-\mathrm{H})$; 7.86-7.89 (m, 1H, Ar-H); $7.95(\mathrm{t}, J=5.4 \mathrm{~Hz}, \mathrm{NH}-$ exchangeable with $\left.\mathrm{D}_{2} \mathrm{O}\right) ; 8.20(\mathrm{~d}, J=9.1 \mathrm{~Hz}, \mathrm{Ar}-\mathrm{H}) ; 8.32(\mathrm{~d}, J$ $=5.3 \mathrm{~Hz}, 1 \mathrm{H}, \mathrm{Ar}-\mathrm{H}) ;{ }^{13} \mathrm{C}$ NMR $\left(100 \mathrm{MHz}, \mathrm{DMSO}^{-\mathrm{d}_{6}}\right) \delta 26.7,26.9$, 28.3, 29.5, 34.1, 39.3, 40.7, 42.4, 99.0, 111.5 (d, $J=23.4 \mathrm{~Hz}$ ), 117.5, 121.8 (d, $J=23.7 \mathrm{~Hz}), 124.8,125.3,126.1(\mathrm{~d}, J=9.7 \mathrm{~Hz})$, 127.9, 128.2 (d, $J=1.9 \mathrm{~Hz}), 133.8,135.0$ (d, $J=9.7 \mathrm{~Hz}), 149.5$, 150.5, 152.2, 166.1 (d, $J=251.6 \mathrm{~Hz}), 166.9$ (d, $J=2.5 \mathrm{~Hz}), 167.3$, 169.7. HRMS calcd for $\mathrm{C}_{26} \mathrm{H}_{26} \mathrm{ClFN}_{4} \mathrm{O}_{3}[\mathrm{M}+\mathrm{H}]^{+} 497.1711$ found 497.1723 .

General procedure for synthesis of $\mathrm{C}-5$ secondary amine substituted $N$-((7-chloroquinolin-4-yl)aminoalkyl)-2-(1,3dioxoisoindolin-2-yl)alkylamides 8a-r

In a microwave reaction vial was added a solution of C-5 fluoro substituted $N$-((7-chloroquinolin-4-yl)aminoalkyl)-2-(1,3-dioxoisoindolin-2-yl)alkylamides $(1.0 \mathrm{mmol})$ in $0.5 \mathrm{~mL}$ of NMP $(N$ - methylpyrrolidin-2-one) and secondary amines $(1.2 \mathrm{mmol})$. After sealing with a PTFE cap, the vessel was heated to $160^{\circ} \mathrm{C}$ for $5 \mathrm{~min}$ in the microwave reactor and the completion was ascertained using TLC. After completion, the contents were poured in water $(20 \mathrm{~mL})$ resulting in the precipitation of the desired product. The yellow product obtained was filtered and recrystallized using absolute ethanol.

$\boldsymbol{N}$-(2-((7-Chloroquinolin-4-yl)amino)ethyl)-2-(5-morpholino1,3-dioxoisoindolin-2-yl)acetamide (8a). Yield 76\%; yellow solid; mp 216-217 ${ }^{\circ} \mathrm{C} ;{ }^{1} \mathrm{H}$ NMR (500 MHz, DMSO-d 6 ) $\delta 3.30-3.32(\mathrm{~m}$, $\left.6 \mathrm{H}, 3 \times-\mathbf{C H}_{2}{ }^{-}\right)$; 3.59-3.63 (m, 2H, $\left.-\mathbf{C H}_{2}{ }^{-}\right)$; 3.74-3.76 (m, 4H, $2 \times$ $\left.-\mathbf{C H}_{2}{ }^{-}\right) ; 4.12\left(\mathrm{~s}, 2 \mathrm{H},-\mathbf{C H}_{2}{ }^{-}\right) ; 6.90(\mathrm{~d}, J=7.1 \mathrm{~Hz}, 1 \mathrm{H}, \mathrm{Ar}-\mathrm{H}) ; 7.25$ $(\mathrm{dd}, J=2.3,8.5 \mathrm{~Hz}, 1 \mathrm{H}, \mathrm{Ar}-\mathrm{H}) ; 7.32(\mathrm{~d}, J=2.2 \mathrm{~Hz}, 1 \mathrm{H}, \mathrm{Ar}-\mathrm{H})$; $7.66(\mathrm{~d}, J=8.4 \mathrm{~Hz}, 1 \mathrm{H}, \mathrm{Ar}-\mathrm{H}) ; 7.77$ (dd, $J=2.0,9.0 \mathrm{~Hz}, 1 \mathrm{H}, \mathrm{Ar}-$ $\mathrm{H}) ; 8.05$ (d, $J=2.1 \mathrm{~Hz}, 1 \mathrm{H}, \mathrm{Ar}-\mathrm{H})$; 8.55-8.57 (m, 3H, Ar-H); 9.55 $\left(\mathrm{t}, J=5.9 \mathrm{~Hz}, 1 \mathrm{H}, \mathrm{NH}\right.$-exchangeable with $\left.\mathrm{D}_{2} \mathrm{O}\right) ;{ }^{13} \mathrm{C}$ NMR $(125$ MHz, DMSO-d 6 ) $\delta 39.1,42.7,47.6,48.8,66.5,99.1,108.3,117.8$, $118.1,120.2$, 124.5, 124.6, 125.1, 127.9, 133.5, 134.6, 149.4, $150.5,152.3,155.7,166.4,167.7,168.4,174.1$. HRMS calcd for $\mathrm{C}_{25} \mathrm{H}_{24} \mathrm{ClN}_{5} \mathrm{O}_{4}[\mathrm{M}+\mathrm{H}]^{+} 494.1550$ found 494.1564 .

$\mathrm{N}$-(4-((7-Chloroquinolin-4-yl)amino)butyl)-2-(5-morpholino1,3-dioxoisoindolin-2-yl)acetamide (8b). Yield 79\%; yellow solid; mp 174-175 ${ }^{\circ} \mathrm{C} ;{ }^{1} \mathrm{H}$ NMR (500 MHz, DMSO-d $\left.{ }_{6}\right) \delta 1.51-1.56$ (m, 2H, $\left.-\mathbf{C H}_{2}{ }^{-}\right)$; 1.63-1.69 (m, 2H, $\left.-\mathbf{C H}_{2}{ }^{-}\right)$; 3.07-3.011 (m, 2H, - $\left.\mathbf{C H}_{2}{ }^{-}\right)$; 3.25-3.28 (m, 2H, $\left.-\mathbf{C H}_{2}{ }^{-}\right)$; 3.39-3.42 (m, 4H, $\left.2 \times-\mathbf{C H}_{2}{ }^{-}\right)$; 3.70-3.74 (m, $\left.4 \mathrm{H}, 2 \times-\mathbf{C H}_{2}-\right)$; 4.15 (s, 2H, $\left.-\mathbf{C H}_{2}{ }^{-}\right) ; 6.46(\mathrm{~d}, J=$ $5.3 \mathrm{~Hz}, 1 \mathrm{H}, \mathrm{Ar}-\mathrm{H}) ; 7.25(\mathrm{dd}, J=2.2,8.7 \mathrm{~Hz}, 1 \mathrm{H}, \mathrm{Ar}-\mathrm{H}) ; 7.28(\mathrm{t}, J=$ $5.4 \mathrm{~Hz}, 1 \mathrm{H}, \mathrm{NH}$-exchangeable with $\left.\mathrm{D}_{2} \mathrm{O}\right) ; 7.31(\mathrm{~d}, J=2.2 \mathrm{~Hz}, 1 \mathrm{H}$, $\mathrm{Ar}-\mathrm{H}) ; 7.45$ (dd, $J=2.0,9.0 \mathrm{~Hz}, 1 \mathrm{H}, \mathrm{Ar}-\mathrm{H}) ; 7.68$ (d, $J=8.8 \mathrm{~Hz}$, $1 \mathrm{H}, \mathrm{Ar}-\mathrm{H}) ; 7.79$ (d, $J=2.1 \mathrm{~Hz}, 1 \mathrm{H}, \mathrm{Ar}-\mathrm{H}) ; 8.16$ (t, $J=5.5 \mathrm{~Hz}, 1 \mathrm{H}$, $\mathrm{NH}$-exchangeable with $\mathrm{D}_{2} \mathrm{O}$ ); 8.27 (d, $\left.J=9.0 \mathrm{~Hz}, 1 \mathrm{H}, \mathrm{Ar}-\mathrm{H}\right) ; 8.39$ $(\mathrm{d}, J=5.3 \mathrm{~Hz}, 1 \mathrm{H}, \mathrm{Ar}-\mathrm{H}) ;{ }^{13} \mathrm{C}$ NMR $(125 \mathrm{MHz}$, DMSO-d 6 ) $\delta 25.4$, 27.6, 37.9, 40.6, 42.7, 47.4, 66.3, 99.1, 108.5, 117.7, 118.2, 120.3, $124.5,124.7,125.2$, 127.7, 133.9, 134.5, 149.6, 150.5, 152.7, 155.6, 166.4, 167.9, 168.2, 174.1. HRMS calcd for $\mathrm{C}_{27} \mathrm{H}_{28} \mathrm{ClN}_{5} \mathrm{O}_{4}$ $[\mathrm{M}+\mathrm{H}]^{+} 522.1863$ found 522.1878 .

$\mathrm{N}$-(6-((7-Chloroquinolin-4-yl)amino)hexyl)-2-(5-morpholino1,3-dioxoisoindolin-2-yl)acetamide (8c). Yield 81\%; yellow solid; mp 160-161 ${ }^{\circ} \mathrm{C} ;{ }^{1} \mathrm{H}$ NMR (500 MHz, DMSO-d 6 ) $\delta 1.30-1.45(\mathrm{~m}$, 6H, 3×- $\left.\mathbf{C H}_{2}-\right)$; 1.64-1.67 (m, 2H, $\left.-\mathbf{C H}_{2}-\right)$; 3.04-3.09 (m, 2H, $\left.-\mathbf{C H}_{2}{ }^{-}\right)$; 3.23-3.27 (m, 2H, $\left.-\mathbf{C H}_{2}{ }^{-}\right)$; 3.36-3.39 (m, 4H, 2×- $\mathbf{C H}_{2}{ }^{-}$);

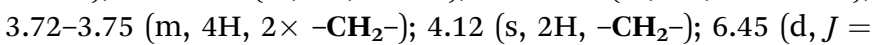
$5.4 \mathrm{~Hz}, 1 \mathrm{H}, \mathrm{Ar}-\mathrm{H}) ; 7.22(\mathrm{dd}, J=2.4,8.6 \mathrm{~Hz}, 1 \mathrm{H}, \mathrm{Ar}-\mathrm{H}) ; 7.27(\mathrm{t}, J=$ $5.5 \mathrm{~Hz}, 1 \mathrm{H}$, NH-exchangeable with $\left.\mathrm{D}_{2} \mathrm{O}\right) ; 7.32(\mathrm{~d}, J=2.3 \mathrm{~Hz}, 1 \mathrm{H}$, $\mathrm{Ar}-\mathrm{H}) ; 7.42$ (dd, $J=2.3,8.9 \mathrm{~Hz}, 1 \mathrm{H}, \mathrm{Ar}-\mathrm{H}) ; 7.66$ (d, $J=8.6 \mathrm{~Hz}$, $1 \mathrm{H}, \mathrm{Ar}-\mathrm{H}) ; 7.77$ (d, J=2.2 Hz, $1 \mathrm{H}, \mathrm{Ar}-\mathrm{H}) ; 8.15$ (t, $J=5.6 \mathrm{~Hz}, 1 \mathrm{H}$, NH-exchangeable with $\left.\mathrm{D}_{2} \mathrm{O}\right) ; 8.26(\mathrm{~d}, J=9.0 \mathrm{~Hz}, 1 \mathrm{H}, \mathrm{Ar}-\mathrm{H}) ; 8.38$ $(\mathrm{d}, J=5.4 \mathrm{~Hz}, 1 \mathrm{H}, \mathrm{Ar}-\mathrm{H}) ;{ }^{13} \mathrm{C}$ NMR $(125 \mathrm{MHz}$, DMSO-d 6 ) $\delta 26.4$, 26.7, 28.1, 29.4, 39.0, 42.7, 47.5, 48.9, 66.2, 99.0, 108.2, 117.9, $118.0,120.1,124.4,124.5,125.0,127.9,133.7,134.7,149.5$, $150.5,152.4,155.7,166.5,167.8,168.3,174.2$. HRMS calcd for $\mathrm{C}_{29} \mathrm{H}_{32} \mathrm{ClN}_{5} \mathrm{O}_{4}[\mathrm{M}+\mathrm{H}]^{+} 550.2176$ found 550.2188 .

$\mathrm{N}$-(2-((7-Chloroquinolin-4-yl)amino)ethyl)-3-(5-morpholino1,3-dioxoisoindolin-2-yl)propanamide (8d). Yield 76\%; yellow solid; mp 208-209 ${ }^{\circ} \mathrm{C} ;{ }^{1} \mathrm{H}$ NMR (400 MHz, DMSO-d 6 ) $\delta 2.38(\mathrm{t}, J$ $\left.=7.3 \mathrm{~Hz}, 2 \mathrm{H},-\mathbf{C H}_{2}{ }^{-}\right) ; 3.20-3.28\left(\mathrm{~m}, 8 \mathrm{H}, 4 \times-\mathbf{C H}_{2}-\right) ; 3.67-3.73$ $\left(\mathrm{m}, 6 \mathrm{H}, 3 \times-\mathbf{C H}_{2}-\right) ; 6.44(\mathrm{~d}, J=5.6 \mathrm{~Hz}, 1 \mathrm{H}, \mathrm{Ar}-\mathrm{H}) ; 7.06(\mathrm{dd}, J=$ 
2.3, $8.4 \mathrm{~Hz}, 1 \mathrm{H}, \mathrm{Ar}-\mathrm{H}) ; 7.16(\mathrm{~d}, J=2.2 \mathrm{~Hz}, 1 \mathrm{H}, \mathrm{Ar}-\mathrm{H}) ; 7.25(\mathrm{t}, J=$ $5.1 \mathrm{~Hz}, 1 \mathrm{H}, \mathrm{N}-\mathrm{H}$-exchangeable with $\left.\mathrm{D}_{2} \mathrm{O}\right) ; 7.36(\mathrm{dd}, J=2.3$, $9.0 \mathrm{~Hz}, 1 \mathrm{H}, \mathrm{Ar}-\mathrm{H}) ; 7.50(\mathrm{~d}, J=8.6 \mathrm{~Hz}, 1 \mathrm{H}, \mathrm{Ar}-\mathrm{H}) ; 7.73(\mathrm{~d}, J=$ $2.3 \mathrm{~Hz}, 1 \mathrm{H}, \mathrm{Ar}-\mathrm{H}) ; 8.02(\mathrm{~d}, J=9.0 \mathrm{~Hz}, 1 \mathrm{H}, \mathrm{Ar}-\mathrm{H}) ; 8.24(\mathrm{t}, J=$ $5.5 \mathrm{~Hz}, 1 \mathrm{H}, \mathrm{N}-\mathrm{H}$-exchangeable with $\left.\mathrm{D}_{2} \mathrm{O}\right) ; 8.35(\mathrm{~d}, J=5.1 \mathrm{~Hz}, 1 \mathrm{H}$, $\mathrm{Ar}-\mathrm{H}) ;{ }^{13} \mathrm{C}$ NMR (100 MHz, DMSO-d 6 ) $\delta$ 34.7, 34.8, 37.7, 42.8, 47.4, 66.2, 99.0, 108.0, 117.7, 117.8, 119.9, 124.2, 124.5, 124.7, $127.9,133.8,134.4,149.4,150.4,152.3,155.5,168.0,168.3$, 170.9. HRMS calcd for $\mathrm{C}_{26} \mathrm{H}_{26} \mathrm{ClN}_{5} \mathrm{O}_{4}[\mathrm{M}+\mathrm{H}]^{+} 508.1707$ found 508.1716 .

$\mathrm{N}$-(4-((7-Chloroquinolin-4-yl)amino)butyl)-3-(5-morpholino1,3-dioxoisoindolin-2-yl)propanamide (8e). Yield 82\%; Yellow solid; mp $158-159{ }^{\circ} \mathrm{C} ;{ }^{1} \mathrm{H}$ NMR (400 MHz, DMSO-d 6 ) $\delta 1.52-1.57$ $\left(\mathrm{m}, 2 \mathrm{H},-\mathbf{C H}_{2}{ }^{-}\right) ; 1.61-1.67\left(\mathrm{~m}, 2 \mathrm{H},-\mathbf{C H}_{2}{ }^{-}\right) ; 2.36(\mathrm{t}, J=7.1 \mathrm{~Hz}, 2 \mathrm{H}$, $\left.-\mathbf{C H}_{2}{ }^{-}\right)$; 3.19-3.28 (m, 8H, $\left.4 \times-\mathbf{C H}_{2}{ }^{-}\right) ; 3.65-3.71(\mathrm{~m}, 6 \mathrm{H}, 3 \times$ $\left.-\mathbf{C H}_{2}-\right) ; 6.42(\mathrm{~d}, J=5.4 \mathrm{~Hz}, 1 \mathrm{H}, \mathrm{Ar}-\mathrm{H}) ; 7.04(\mathrm{dd}, J=2.2,8.7 \mathrm{~Hz}$, $1 \mathrm{H}, \mathrm{Ar}-\mathrm{H}) ; 7.14$ (d, J=2.2 Hz, $1 \mathrm{H}, \mathrm{Ar}-\mathrm{H}) ; 7.23(\mathrm{t}, J=5.3 \mathrm{~Hz}, 1 \mathrm{H}$, $\mathrm{N}-\mathrm{H}$-exchangeable with $\left.\mathrm{D}_{2} \mathrm{O}\right) ; 7.32(\mathrm{dd}, J=2.2,8.9 \mathrm{~Hz}, 1 \mathrm{H}, \mathrm{Ar}-$ $\mathrm{H})$; $7.51(\mathrm{~d}, J=8.7 \mathrm{~Hz}, 1 \mathrm{H}, \mathrm{Ar}-\mathrm{H}) ; 7.71(\mathrm{~d}, J=2.2 \mathrm{~Hz}, 1 \mathrm{H}, \mathrm{Ar}-\mathrm{H})$; $8.01(\mathrm{~d}, J=9.0 \mathrm{~Hz}, 1 \mathrm{H}, \mathrm{Ar}-\mathrm{H}) ; 8.25(\mathrm{t}, J=5.4 \mathrm{~Hz}, 1 \mathrm{H}, \mathrm{N}-\mathrm{H}-$ exchangeable with $\left.\mathrm{D}_{2} \mathrm{O}\right) ; 8.33(\mathrm{~d}, J=5.2 \mathrm{~Hz}, 1 \mathrm{H}, \mathrm{Ar}-\mathrm{H}) ;{ }^{13} \mathrm{C}$ NMR (100 MHz, DMSO-d $\left.{ }_{6}\right) \delta$ 25.5, 27.4, 34.6, 34.9, 37.9, 42.9, 47.7, 66.1, 99.1, 108.2, 117.5, 117.9, 119.4, 124.1, 124.6, 124.8, $127.7,133.6$, 134.2, 149.1, 150.2, 152.1, 155.6, 168.1, 168.2, 170.7. HRMS calcd for $\mathrm{C}_{28} \mathrm{H}_{30} \mathrm{ClN}_{5} \mathrm{O}_{4}[\mathrm{M}+\mathrm{H}]^{+} 536.2020$ found 536.2009 .

$\mathrm{N}$-(6-((7-Chloroquinolin-4-yl)amino)hexyl)-3-(5-morpholino1,3-dioxoisoindolin-2-yl)propanamide (8f). Yield 78\%; yellow solid; mp $126-127{ }^{\circ} \mathrm{C} ;{ }^{1} \mathrm{H}$ NMR (400 MHz, DMSO-d 6 ) $\delta 1.31-1.46$ $\left(\mathrm{m}, 6 \mathrm{H}, 3 \times-\mathbf{C H}_{2}-\right)$; 1.53-1.56 (m, 2H, $\left.-\mathbf{C H}_{2}{ }^{-}\right) ; 2.35(\mathrm{t}, J=7.1 \mathrm{~Hz}$, 2H, $\left.-\mathbf{C H}_{2}{ }^{-}\right)$; 3.05-3.09 (m, 2H, $\left.-\mathbf{C H}_{2}{ }^{-}\right)$; 3.23-3.27 (m, 2H, $-\mathbf{C H}_{2}-$

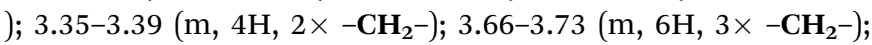
$6.41(\mathrm{~d}, J=5.3 \mathrm{~Hz}, 1 \mathrm{H}, \mathrm{Ar}-\mathrm{H}) ; 7.03(\mathrm{dd}, J=2.1,8.6 \mathrm{~Hz}, 1 \mathrm{H}, \mathrm{Ar}-$ $\mathrm{H}) ; 7.15(\mathrm{~d}, J=2.1 \mathrm{~Hz}, 1 \mathrm{H}, \mathrm{Ar}-\mathrm{H}) ; 7.25$ (t, $J=5.2 \mathrm{~Hz}, 1 \mathrm{H}, \mathrm{N}-\mathrm{H}-$ exchangeable with $\left.\mathrm{D}_{2} \mathrm{O}\right) ; 7.33(\mathrm{dd}, J=2.0,8.9 \mathrm{~Hz}, 1 \mathrm{H}, \mathrm{Ar}-\mathrm{H})$; $7.53(\mathrm{~d}, J=8.8 \mathrm{~Hz}, 1 \mathrm{H}, \mathrm{Ar}-\mathrm{H}) ; 7.73(\mathrm{~d}, J=2.1 \mathrm{~Hz}, 1 \mathrm{H}, \mathrm{Ar}-\mathrm{H}) ; 8.03$ $(\mathrm{d}, J=9.0 \mathrm{~Hz}, 1 \mathrm{H}, \mathrm{Ar}-\mathrm{H}) ; 8.26(\mathrm{t}, J=5.3 \mathrm{~Hz}, 1 \mathrm{H}, \mathrm{N}-\mathrm{H}-$ exchangeable with $\left.\mathrm{D}_{2} \mathrm{O}\right) ; 8.34(\mathrm{~d}, J=5.3 \mathrm{~Hz}, 1 \mathrm{H}, \mathrm{Ar}-\mathrm{H}) ;{ }^{13} \mathrm{C}$ NMR (100 MHz, DMSO-d $)_{6} \delta$ 26.5, 26.9, 28.1, 29.5, 34.6, 38.2, $40.1,42.8,47.6$, 66.2, 99.2, 108.1, 117.6, 117.8, 119.3, 124.2, $124.7,124.8,127.6,133.7,134.1,149.3,150.1,152.4,155.5$, 168.1, 168.3, 170.5 HRMS calcd for $\mathrm{C}_{30} \mathrm{H}_{34} \mathrm{ClN}_{5} \mathrm{O}_{4}[\mathrm{M}+\mathrm{H}]^{+}$ 564.2333 found 564.2326 .

$N$-(2-((7-Chloroquinolin-4-yl)amino)ethyl)-2-(5-(diethylamino)1,3-dioxoisoindolin-2-yl)acetamide (8g). Yield 79\%; yellow solid; mp 197-198 ${ }^{\circ} \mathrm{C} ;{ }^{1} \mathrm{H}$ NMR (400 MHz, DMSO-d $\left.{ }_{6}\right) \delta 1.10(\mathrm{t}, 6 \mathrm{H}, 2 \times$ - $\left.\mathbf{C H}_{3}\right)$; 3.22-3.27 (m, 4H, $2 \times-\mathbf{C H}_{2}-$ ); 3.36-3.41 (m, 4H, $2 \times-\mathbf{C H}_{2}-$ ); $4.11\left(\mathrm{~s}, 2 \mathrm{H},-\mathbf{C H}_{2}-\right) ; 6.52(\mathrm{~d}, J=5.5 \mathrm{~Hz}, 1 \mathrm{H}, \mathrm{Ar}-\mathrm{H}) ; 6.91(\mathrm{~d}, J=$ $8.8 \mathrm{~Hz}, 1 \mathrm{H}, \mathrm{Ar}-\mathrm{H})$; 6.97 (s, 1H, Ar-H), 7.46-7.50 (m, 2H, Ar-H, NHexchangeable with $\left.\mathrm{D}_{2} \mathrm{O}\right) ; 7.56(\mathrm{~d}, J=8.6 \mathrm{~Hz}, 1 \mathrm{H}, \mathrm{Ar}-\mathrm{H}) ; 7.77(\mathrm{~s}, 1 \mathrm{H}$, $\mathrm{Ar}-\mathrm{H}), 8.16\left(\mathrm{t}, J=5.2 \mathrm{~Hz}, 1 \mathrm{H}, \mathrm{NH}\right.$-exchangeable with $\left.\mathrm{D}_{2} \mathrm{O}\right) ; 8.28$ (d, $J=8.9 \mathrm{~Hz}, 1 \mathrm{H}, \mathrm{Ar}-\mathrm{H}) ; 8.38(\mathrm{~d}, J=5.6 \mathrm{~Hz}, 1 \mathrm{H}, \mathrm{Ar}-\mathrm{H}) ;{ }^{13} \mathrm{C}$ NMR $(100$ MHz, DMSO-d $\left.{ }_{6}\right) \delta 12.4,37.6,40.8,42.6,44.7,99.0,105.3,114.7$, 116.2, 117.8, 124.4, 124.6, 125.5, 127.2, 127.7, 134.1, 135.5, 150.7, 151.7, 152.2, 166.6, 167.6, 168.9 HRMS calcd for $\mathrm{C}_{25} \mathrm{H}_{26} \mathrm{ClN}_{5} \mathrm{O}_{3}[\mathrm{M}$ $+\mathrm{H}]^{+} 480.1758$ found 480.1743 .
$\mathrm{N}$-(4-((7-Chloroquinolin-4-yl)amino)butyl)-2-(5-(diethylamino)1,3-dioxoisoindolin-2-yl)acetamide (8h). Yield 78\%; yellow solid; mp 173-174 ${ }^{\circ} \mathrm{C} ;{ }^{1} \mathrm{H}$ NMR (400 MHz, DMSO-d 6 ) $\delta 1.13(\mathrm{t}, 6 \mathrm{H}, 2 \times$ - $\mathbf{C H}_{3}$ ); 1.50-1.57 (m, 2H, - $\mathbf{C H}_{2}-$ ); 1.62-1.68 (m, 2H, - $\mathbf{C H}_{2}-$ ); 3.10$3.14\left(\mathrm{~m}, 2 \mathrm{H},-\mathbf{C H}_{2}-\right)$; 3.27-3.31 (m, 2H, 2× $\left.-\mathbf{C H}_{2}-\right)$; 3.39-3.43 (m, $\left.4 \mathrm{H}, 2 \times-\mathbf{C H}_{2}-\right) ; 4.10\left(\mathrm{~s}, 2 \mathrm{H},-\mathbf{C H}_{2}-\right) ; 6.51(\mathrm{~d}, J=5.6 \mathrm{~Hz}, 1 \mathrm{H}, \mathrm{Ar}-\mathrm{H})$; $6.92(\mathrm{~d}, J=8.7 \mathrm{~Hz}, 1 \mathrm{H}, \mathrm{Ar}-\mathrm{H}) ; 6.99(\mathrm{~s}, 1 \mathrm{H}, \mathrm{Ar}-\mathrm{H}), 7.44-7.50(\mathrm{~m}, 2 \mathrm{H}$, $\mathrm{Ar}-\mathrm{H}+\mathrm{NH}$-exchangeable with $\left.\mathrm{D}_{2} \mathrm{O}\right) ; 7.59$ (d, $\left.J=8.5 \mathrm{~Hz}, 1 \mathrm{H}, \mathrm{Ar}-\mathrm{H}\right)$; $7.78(\mathrm{~s}, 1 \mathrm{H}, \mathrm{Ar}-\mathrm{H}), 8.18(\mathrm{t}, J=5.2 \mathrm{~Hz}, 1 \mathrm{H}, \mathrm{NH}-$ exchangeable with $\mathrm{D}_{2} \mathrm{O}$ ); 8.29 (d, $\left.J=9.0 \mathrm{~Hz}, 1 \mathrm{H}, \mathrm{Ar}-\mathrm{H}\right) ; 8.39$ (d, $\left.J=5.7 \mathrm{~Hz}, 1 \mathrm{H}, \mathrm{Ar}-\mathrm{H}\right)$; ${ }^{13} \mathrm{C}$ NMR (100 MHz, DMSO-d ${ }_{6}$ ) $\delta$ 12.5, 25.5, 27.1, 38.8, 41.5, 42.5, 44.8, 99.1, 105.2, 114.8, 116.3, 117.7, 124.5, 124.6, 125.4, 127.1, 127.4, 134.2, 135.3, 150.9, 151.6, 152.3, 166.7, 167.9, 168.6 HRMS calcd for $\mathrm{C}_{27} \mathrm{H}_{30} \mathrm{ClN}_{5} \mathrm{O}_{3}[\mathrm{M}+\mathrm{H}]^{+}$508.2071 found 508.2079.

$\boldsymbol{N}$-(6-((7-Chloroquinolin-4-yl)amino)hexyl)-2-(5-(diethylamino)1,3-dioxoisoindolin-2-yl)acetamide (8i). Yield 79\%; yellow solid; mp 158-159 ${ }^{\circ} \mathrm{C} ;{ }^{1} \mathrm{H}$ NMR (400 MHz, DMSO-d 6 ) $\delta 1.12(\mathrm{t}, 6 \mathrm{H}, 2 \times$ $\left.-\mathbf{C H}_{3}\right)$; 1.32-1.44 (m, 6H, 3× $\left.-\mathbf{C H}_{2}-\right)$; $1.63-1.67$ (m, 2H, $-\mathbf{C H}_{2}-$ ); 3.07-3.10 (m, 2H, - $\mathbf{C H}_{2}-$ ); 3.25-3.30 (m, 2H, 2× - $\mathbf{C H}_{2}-$ ); 3.37-3.41 (m, $\left.4 \mathrm{H}, 2 \times-\mathbf{C H}_{2}{ }^{-}\right) ; 4.11\left(\mathrm{~s}, 2 \mathrm{H},-\mathbf{C H}_{2}{ }^{-}\right) ; 6.50$ (d, $J=5.4 \mathrm{~Hz}, 1 \mathrm{H}, \mathrm{Ar}-$ $\mathrm{H}) ; 6.90(\mathrm{dd}, J=2.2,8.8 \mathrm{~Hz}, 1 \mathrm{H}, \mathrm{Ar}-\mathrm{H}) ; 6.98$ (d, $J=2.3 \mathrm{~Hz}, 1 \mathrm{H}, \mathrm{Ar}-$ $\mathrm{H})$, 7.43-7.50 (m, 2H, Ar-H + NH-exchangeable with $\left.\mathrm{D}_{2} \mathrm{O}\right) ; 7.54(\mathrm{~d}, J$ $=8.6 \mathrm{~Hz}, 1 \mathrm{H}, \mathrm{Ar}-\mathrm{H}) ; 7.75(\mathrm{~d}, J=2.2 \mathrm{~Hz} 1 \mathrm{H}, \mathrm{Ar}-\mathrm{H}), 8.20(\mathrm{t}, J=$ $5.3 \mathrm{~Hz}, 1 \mathrm{H}, \mathrm{NH}$-exchangeable with $\left.\mathrm{D}_{2} \mathrm{O}\right) ; 8.27(\mathrm{~d}, J=9.0 \mathrm{~Hz}, 1 \mathrm{H}, \mathrm{Ar}-$ $\mathrm{H}) ; 8.37(\mathrm{~d}, J=5.4 \mathrm{~Hz}, 1 \mathrm{H}, \mathrm{Ar}-\mathrm{H}) ;{ }^{13} \mathrm{C}$ NMR (100 MHz, DMSO-d $\left.{ }_{6}\right)$ $\delta 12.4,26.3,26.9,28.2,29.5,39.2,41.3,42.9,44.6,99.2,105.1,114.8$, 116.3, 117.6, 124.7, 124.9, 125.4, 127.3, 127.7, 134.3, 135.3, 150.8, 151.6, 152.4, 166.6, 167.8, 168.7 HRMS calcd for $\mathrm{C}_{29} \mathrm{H}_{34} \mathrm{ClN}_{5} \mathrm{O}_{3}[\mathrm{M}$ $+\mathrm{H}]^{+} 536.2384$ found 536.2371 .

$\mathrm{N}$-(2-((7-Chloroquinolin-4-yl)amino)ethyl)-3-(5-(diethylamino)1,3-dioxoisoindolin-2-yl)propanamide (8j). Yield 70\%; yellow solid; mp 189-190 ${ }^{\circ} \mathrm{C} ;{ }^{1} \mathrm{H}$ NMR (400 MHz, DMSO-d $\left.{ }_{6}\right) \delta 1.05(\mathrm{t}, J=7.0 \mathrm{~Hz}$, $\left.6 \mathrm{H}, 2 \times-\mathbf{C H}_{3}\right) ; 2.37\left(\mathrm{t}, J=7.3 \mathrm{~Hz}, 2 \mathrm{H},-\mathbf{C H}_{2}\right) ; 3.22-3.26(\mathrm{~m}, 4 \mathrm{H}, 2 \times$ $\left.-\mathbf{C H}_{2}-\right)$; 3.38-3.42 (m, 4H, $\left.2 \times-\mathbf{C H}_{2}-\right)$; $3.69\left(\mathrm{t}, J=7.3 \mathrm{~Hz}, 2 \mathrm{H},-\mathbf{C H}_{3}\right)$; $6.45(\mathrm{~d}, J=5.4 \mathrm{~Hz}, 1 \mathrm{H}, \mathrm{Ar}-\mathrm{H}) ; 6.76(\mathrm{dd}, J=2.6,8.8 \mathrm{~Hz}, 1 \mathrm{H}, \mathrm{Ar}-\mathrm{H})$; $6.85(\mathrm{~d}, J=2.6 \mathrm{~Hz}, 1 \mathrm{H}, \operatorname{Ar}-\mathrm{H}), 7.29(\mathrm{t}, J=5.2 \mathrm{~Hz}, 1 \mathrm{H}, \mathrm{NH}-$ exchangeable with $\mathrm{D}_{2} \mathrm{O}$ ); 7.37 (dd, $J=2.2,9.0 \mathrm{~Hz}, 1 \mathrm{H}, \mathrm{Ar}-\mathrm{H}$ ); $7.44(\mathrm{~d}, J=8.6 \mathrm{~Hz}, 1 \mathrm{H}, \mathrm{Ar}-\mathrm{H}) ; 7.73$ (d, $J=2.4 \mathrm{~Hz} 1 \mathrm{H}, \mathrm{Ar}-\mathrm{H}), 8.05$ (d, $J=9.0 \mathrm{~Hz}, 1 \mathrm{H}, \mathrm{Ar}-\mathrm{H}) ; 8.23(\mathrm{t}, J=5.3 \mathrm{~Hz}, 1 \mathrm{H}$, NH-exchangeable with $\left.\mathrm{D}_{2} \mathrm{O}\right) ; 8.35$ (d, $\left.J=5.0 \mathrm{~Hz}, 1 \mathrm{H}, \mathrm{Ar}-\mathrm{H}\right) ;{ }^{13} \mathrm{C}$ NMR $(100 \mathrm{MHz}$, DMSO- $\left._{6}\right) \delta 12.6$, 34.6, 37.7, 41.1, 42.7, 44.8, 99.0, 105.0, 114.6, 116.2, 117.8, 124.3, 124.5, 124.6, 125.2, 127.8, 133.9, 135.0, 149.3, 150.5, 152.2, 168.1, 168.6, 170.9 HRMS calcd for $\mathrm{C}_{26} \mathrm{H}_{28} \mathrm{ClN}_{5} \mathrm{O}_{3}[\mathrm{M}$ $+\mathrm{H}]^{+} 494.1914$ found 494.1902 .

N-(4-((7-Chloroquinolin-4-yl)amino)butyl)-3-(5-(diethylamino)1,3-dioxoisoindolin-2-yl)propanamide (8k). Yield 72\%; yellow solid; mp 161-162 ${ }^{\circ} \mathrm{C} ;{ }^{1} \mathrm{H}$ NMR (400 MHz, DMSO-d $\left.{ }_{6}\right) \delta 1.04(\mathrm{t}, J=$ $\left.7.1 \mathrm{~Hz}, 6 \mathrm{H}, 2 \times-\mathbf{C H}_{3}\right) ; 1.52-1.57\left(\mathrm{~m}, 2 \mathrm{H},-\mathbf{C H}_{2}-\right)$; 1.60-1.67 (m, 2H, $\left.-\mathbf{C H}_{2}-\right) ; 2.35\left(\mathrm{t}, J=7.2 \mathrm{~Hz}, 2 \mathrm{H},-\mathbf{C H}_{3}\right) ; 3.11-3.15\left(\mathrm{~m}, 2 \mathrm{H},-\mathbf{C H}_{2}-\right)$; 3.25-3.30 (m, 2H, - $\left.\mathbf{C H}_{2}-\right)$; 3.37-3.41 (m, 4H, 2×- $\left.\mathbf{C H}_{2}-\right)$; $3.67(\mathrm{t}, J=$ $\left.7.2 \mathrm{~Hz}, 2 \mathrm{H},-\mathbf{C H}_{3}\right) ; 6.43(\mathrm{~d}, J=5.3 \mathrm{~Hz}, 1 \mathrm{H}, \mathrm{Ar}-\mathrm{H}) ; 6.77(\mathrm{dd}, J=2.4$, $8.7 \mathrm{~Hz}, 1 \mathrm{H}, \mathrm{Ar}-\mathrm{H}) ; 6.84$ (d, $J=2.4 \mathrm{~Hz}, 1 \mathrm{H}, \mathrm{Ar}-\mathrm{H}), 7.26$ (t, $J=5.4 \mathrm{~Hz}$, $1 \mathrm{H}, \mathrm{NH}$-exchangeable with $\mathrm{D}_{2} \mathrm{O}$ ); 7.37 (dd, $J=2.1,9.0 \mathrm{~Hz}, 1 \mathrm{H}, \mathrm{Ar}-$ $\mathrm{H}) ; 7.45$ (d, $J=8.7 \mathrm{~Hz}, 1 \mathrm{H}, \mathrm{Ar}-\mathrm{H}) ; 7.75$ (d, $J=2.2 \mathrm{~Hz} 1 \mathrm{H}, \mathrm{Ar}-\mathrm{H}), 8.07$ $(\mathrm{d}, J=9.0 \mathrm{~Hz}, 1 \mathrm{H}, \mathrm{Ar}-\mathrm{H}) ; 8.25$ (t, $J=5.3 \mathrm{~Hz}, 1 \mathrm{H}, \mathrm{NH}$-exchangeable with $\left.\mathrm{D}_{2} \mathrm{O}\right) ; 8.36(\mathrm{~d}, J=5.2 \mathrm{~Hz}, 1 \mathrm{H}, \mathrm{Ar}-\mathrm{H}) ;{ }^{13} \mathrm{C}$ NMR $(100 \mathrm{MHz}$, 
DMSO-d 6 ) $\delta 12.6,25.4,27.5,34.6,37.7,39.7,42.7,44.7,99.1,105.2$, 114.3, 116.1, 117.8, 124.2, 124.5, 124.7, 125.4, 127.9, 133.7, 135.1, 149.3, 150.6, 152.4, 168.1, 168.5, 170.7 HRMS calcd for $\mathrm{C}_{28} \mathrm{H}_{32} \mathrm{ClN}_{5} \mathrm{O}_{3}[\mathrm{M}+\mathrm{H}]^{+} 522.2227$ found 522.2239.

$\mathrm{N}$-(6-((7-Chloroquinolin-4-yl)amino)hexyl)-3-(5-(diethylamino)1,3-dioxoisoindolin-2-yl)propanamide (81). Yield 68\%; yellow solid; mp 142-143 ${ }^{\circ} \mathrm{C} ;{ }^{1} \mathrm{H}$ NMR (400 MHz, DMSO-d 6 ) $\delta 1.08(\mathrm{t}, J=7.3 \mathrm{~Hz}$, 6H, 2× $\left.-\mathbf{C H}_{3}\right) ; 1.35-1.45\left(\mathrm{~m}, 6 \mathrm{H}, 3 \times-\mathbf{C H}_{2}-\right)$; 1.61-1.66 (m, 2H, $\left.-\mathbf{C H}_{2}-\right)$; 2.37 (t, $\left.J=7.2 \mathrm{~Hz}, 2 \mathrm{H},-\mathbf{C H}_{3}\right) ; 3.10-3.14\left(\mathrm{~m}, 2 \mathrm{H},-\mathbf{C H}_{2}-\right.$ ); 3.24-3.30 (m, 2H, - $\left.\mathbf{C H}_{2}-\right)$; 3.36-3.41 (m, 4H, 2×- $\left.\mathbf{C H}_{2}-\right)$; 3.68 (t, $J=$ $\left.7.2 \mathrm{~Hz}, 2 \mathrm{H},-\mathbf{C H}_{3}\right) ; 6.42(\mathrm{~d}, J=5.2 \mathrm{~Hz}, 1 \mathrm{H}, \mathrm{Ar}-\mathrm{H}) ; 6.75(\mathrm{dd}, J=2.2$, $8.6 \mathrm{~Hz}, 1 \mathrm{H}, \mathrm{Ar}-\mathrm{H}) ; 6.85$ (d, $J=2.4 \mathrm{~Hz}, 1 \mathrm{H}, \mathrm{Ar}-\mathrm{H}), 7.26(\mathrm{t}, J=5.3 \mathrm{~Hz}$, $1 \mathrm{H}, \mathrm{NH}$-exchangeable with $\mathrm{D}_{2} \mathrm{O}$ ); 7.37 (dd, $J=2.0,9.0 \mathrm{~Hz}, 1 \mathrm{H}, \mathrm{Ar}-$ $\mathrm{H}) ; 7.47$ (d, $J=8.7 \mathrm{~Hz}, 1 \mathrm{H}, \mathrm{Ar}-\mathrm{H}) ; 7.77$ (d, $J=2.2 \mathrm{~Hz} 1 \mathrm{H}, \mathrm{Ar}-\mathrm{H}), 8.06$ $(\mathrm{d}, J=9.0 \mathrm{~Hz}, 1 \mathrm{H}, \mathrm{Ar}-\mathrm{H}) ; 8.26(\mathrm{t}, J=5.3 \mathrm{~Hz}, 1 \mathrm{H}, \mathrm{NH}$-exchangeable with $\left.\mathrm{D}_{2} \mathrm{O}\right) ; 8.38(\mathrm{~d}, J=5.2 \mathrm{~Hz}, 1 \mathrm{H}, \mathrm{Ar}-\mathrm{H}) ;{ }^{13} \mathrm{C}$ NMR $(100 \mathrm{MHz}$, DMSO-d $\left._{6}\right) \delta 12.6,26.4,26.9,28.5,29.8,34.6,39.5$, 41.1, 42.7, 44.5, 99.1, 105.3, 114.4, 116.1, 117.9, 124.2, 124.6, 124.8, 125.4, 127.8, 133.8, 135.2, 149.4, 150.7, 152.5, 168.1, 168.7, 170.6 HRMS calcd for $\mathrm{C}_{30} \mathrm{H}_{36} \mathrm{ClN}_{5} \mathrm{O}_{3}[\mathrm{M}+\mathrm{H}]^{+} 550.2540$ found 550.2521.

$\mathrm{N}$-(2-((7-Chloroquinolin-4-yl)amino)ethyl)-2-(5-(4-(2-hydroxyethyl) piperazin-1-yl)-1,3-dioxoisoindolin-2-yl)acetamide (8m). Yield 75\%; yellow solid; mp 218-219 ${ }^{\circ} \mathrm{C} ;{ }^{1} \mathrm{H}$ NMR (500 MHz, DMSO-d $\left.{ }_{6}\right) \delta 2.45(\mathrm{t}$, $\left.J=6.1 \mathrm{~Hz}, 2 \mathrm{H},-\mathbf{C H}_{2}-\right) ; 2.54\left(\mathrm{t}, J=4.8 \mathrm{~Hz}, 4 \mathrm{H}, 2 \times-\mathbf{C H}_{2}-\right)$; 3.11-3.15 $\left(\mathrm{m}, 2 \mathrm{H},-\mathbf{C H}_{2}-\right) ; 3.26-3.29\left(\mathrm{~m}, 2 \mathrm{H},-\mathbf{C H}_{2}-\right) ; 3.42(\mathrm{t}, J=4.5 \mathrm{~Hz}, 4 \mathrm{H}, 2 \times$ $\left.-\mathbf{C H}_{2}-\right) ; 3.53\left(\mathrm{t}, J=6.1 \mathrm{~Hz}, 2 \mathrm{H},-\mathbf{C H}_{2}-\right) ; 4.10\left(\mathrm{~s}, 2 \mathrm{H},-\mathbf{C H}_{2}-\right) ; 4.48$ (s, $1 \mathrm{H},-\mathrm{OH}) ; 6.47(\mathrm{~d}, J=5.4 \mathrm{~Hz}, 1 \mathrm{H}, \mathrm{Ar}-\mathrm{H}) ; 7.21(\mathrm{dd}, J=1.5,8.6 \mathrm{~Hz}, 1 \mathrm{H}$, $\mathrm{Ar}-\mathrm{H}$ ); 7.30 (d, $J=1.4 \mathrm{~Hz}, 1 \mathrm{H}, \mathrm{Ar}-\mathrm{H}) ; 7.35$ (t, $J=5.6 \mathrm{~Hz}, 1 \mathrm{H}, \mathrm{NH}-$ exchangeable with $\left.\mathrm{D}_{2} \mathrm{O}\right) ; 7.45(\mathrm{dd}, J=2.1,9.0 \mathrm{~Hz}, 1 \mathrm{H}, \mathrm{Ar}-\mathrm{H}) ; 7.66$ $(\mathrm{d}, J=8.6 \mathrm{~Hz}, 1 \mathrm{H}, \mathrm{Ar}-\mathrm{H}) ; 7.78$ (d, $J=2.0 \mathrm{~Hz}, 1 \mathrm{H}, \mathrm{Ar}-\mathrm{H}) ; 8.18$ (t, $J=$ $5.7 \mathrm{~Hz}, 1 \mathrm{H}$, NH-exchangeable with $\left.\mathrm{D}_{2} \mathrm{O}\right) ; 8.29(\mathrm{~d}, J=9.0 \mathrm{~Hz}, 1 \mathrm{H}, \mathrm{Ar}-$ $\mathrm{H}) ; 8.39$ (d, $J=5.4 \mathrm{~Hz}, 1 \mathrm{H}, \mathrm{Ar}-\mathrm{H}) ;{ }^{13} \mathrm{C}$ NMR (125 MHz, DMSO-d 6 ) $\delta 38.7,42.4,47.5,49.1,53.3,59.1,60.6,99.0,108.1,117.3,117.8$, 119.4, 124.3, 124.6, 125.1, 127.9, 133.7, 134.7, 149.5, 150.6, 152.2, 155.5, 166.7, 167.8, 168.2 HRMS calcd for $\mathrm{C}_{27} \mathrm{H}_{29} \mathrm{ClN}_{6} \mathrm{O}_{4}[\mathrm{M}+\mathrm{H}]^{+}$ 537.1972 found 537.1961 .

$\mathrm{N}$-(4-((7-Chloroquinolin-4-yl)amino)butyl)-2-(5-(4-(2-hydroxyethyl) piperazin-1-yl)-1,3-dioxoisoindolin-2-yl)acetamide (8n). Yield 83\%; yellow solid; mp 151-152 ${ }^{\circ} \mathrm{C} ;{ }^{1} \mathrm{H}$ NMR (500 MHz, DMSO-d $\left.{ }_{6}\right) \delta 1.50-$ $1.55\left(\mathrm{~m}, 2 \mathrm{H},-\mathbf{C H}_{2}-\right) ; 1.62-1.68\left(\mathrm{~m}, 2 \mathrm{H},-\mathbf{C H}_{2}-\right) ; 2.44(\mathrm{t}, J=6.1 \mathrm{~Hz} 2 \mathrm{H}$, $\left.-\mathbf{C H}_{2}-\right) ; 2.55\left(\mathrm{t}, J=4.9 \mathrm{~Hz}, 4 \mathrm{H}, 2 \times-\mathbf{C H}_{2}-\right) ; 3.10-3.14\left(\mathrm{~m}, 2 \mathrm{H},-\mathbf{C H}_{2}-\right)$; 3.25-3.29 (m, 2H, - $\left.\mathbf{C H}_{2}-\right) ; 3.41\left(\mathrm{t}, J=4.5 \mathrm{~Hz}, 4 \mathrm{H}, 2 \times-\mathbf{C H}_{2}-\right) ; 3.54(\mathrm{t}, J$ $\left.\left.=6.1 \mathrm{~Hz}, 2 \mathrm{H},-\mathbf{C H}_{2}\right)^{-}\right) ; 4.11\left(\mathrm{~s}, 2 \mathrm{H},-\mathbf{C H}_{2}-\right) ; 4.49(\mathrm{~s}, 1 \mathrm{H},-\mathrm{OH}) ; 6.48(\mathrm{~d}, J$ $=5.5 \mathrm{~Hz}, 1 \mathrm{H}, \mathrm{Ar}-\mathrm{H}) ; 7.22(\mathrm{dd}, J=1.5,8.5 \mathrm{~Hz}, 1 \mathrm{H}, \mathrm{Ar}-\mathrm{H}) ; 7.31$ (d, $J=$ $1.4 \mathrm{~Hz}, 1 \mathrm{H}, \mathrm{Ar}-\mathrm{H}) ; 7.34(\mathrm{t}, J=5.6 \mathrm{~Hz}, 1 \mathrm{H}, \mathrm{NH}$-exchangeable with $\left.\mathrm{D}_{2} \mathrm{O}\right) ; 7.43(\mathrm{dd}, J=2.2,9.0 \mathrm{~Hz}, 1 \mathrm{H}, \mathrm{Ar}-\mathrm{H}) ; 7.65(\mathrm{~d}, J=8.5 \mathrm{~Hz}, 1 \mathrm{H}, \mathrm{Ar}-$ $\mathrm{H}) ; 7.77$ (d, $J=2.0 \mathrm{~Hz}, 1 \mathrm{H}, \mathrm{Ar}-\mathrm{H}) ; 8.19$ (t, $J=5.7 \mathrm{~Hz}, 1 \mathrm{H}, \mathrm{NH}-$ exchangeable with $\mathrm{D}_{2} \mathrm{O}$ ); 8.27 (d, $\left.J=9.0 \mathrm{~Hz}, 1 \mathrm{H}, \mathrm{Ar}-\mathrm{H}\right) ; 8.38$ (d, $J$ $=5.4 \mathrm{~Hz}, 1 \mathrm{H}, \mathrm{Ar}-\mathrm{H}) ;{ }^{13} \mathrm{C} \mathrm{NMR}\left(125 \mathrm{MHz}, \mathrm{DMSO}-\mathrm{d}_{6}\right) \delta$ 25.5, 27.1, 38.8, 42.5, 47.3, 49.0, 53.2, 59.0, 60.5, 99.1, 108.2, 117.8, 117.9, 119.4, 124.4, 124.5, 125.0, 127.8, 133.8, 134.7, 149.4, 150.5, 152.2, 155.5, 166.6, 167.8, 168.3 HRMS calcd for $\mathrm{C}_{29} \mathrm{H}_{33} \mathrm{ClN}_{6} \mathrm{O}_{4}[\mathrm{M}+\mathrm{H}]^{+} 565.2285$ found 565.2268 .

$\mathrm{N}$-(6-((7-Chloroquinolin-4-yl)amino)hexyl)-2-(5-(4-(2-hydroxyethyl) piperazin-1-yl)-1,3-dioxoisoindolin-2-yl)acetamide (8o). Yield 75\%; yellow solid; mp $118-119{ }^{\circ} \mathrm{C} ;{ }^{1} \mathrm{H}$ NMR (500 MHz, DMSO-d $\left.{ }_{6}\right) \delta 1.31-$ $1.45\left(\mathrm{~m}, 6 \mathrm{H}, 3 \times-\mathbf{C H}_{2}-\right)$; $1.62-1.67\left(\mathrm{~m}, 2 \mathrm{H},-\mathbf{C H}_{2}-\right) ; 2.46(\mathrm{t}, J=6.2 \mathrm{~Hz}$, $\left.2 \mathrm{H},-\mathbf{C H}_{2}-\right) ; 2.54\left(\mathrm{t}, J=4.8 \mathrm{~Hz}, 4 \mathrm{H}, 2 \times-\mathbf{C H}_{2}-\right) ; 3.07-3.11(\mathrm{~m}, 2 \mathrm{H}$, $\left.-\mathbf{C H}_{2}-\right)$; 3.20-3.27 (m, 2H, $\left.-\mathbf{C H}_{2}-\right)$; $3.40\left(\mathrm{t}, J=4.7 \mathrm{~Hz}, 4 \mathrm{H}, 2 \times-\mathbf{C H}_{2}-\right)$; $3.55\left(\mathrm{t}, J=6.2 \mathrm{~Hz}, 2 \mathrm{H},-\mathbf{C H}_{2}-\right) ; 4.10\left(\mathrm{~s}, 2 \mathrm{H},-\mathbf{C H}_{2}-\right) ; 4.48(\mathrm{~s}, 1 \mathrm{H},-\mathrm{OH})$; $6.47(\mathrm{~d}, J=5.4 \mathrm{~Hz}, 1 \mathrm{H}, \mathrm{Ar}-\mathrm{H}) ; 7.20$ (dd, $J=1.6,8.6 \mathrm{~Hz}, 1 \mathrm{H}, \mathrm{Ar}-\mathrm{H})$; $7.30(\mathrm{~d}, J=1.5 \mathrm{~Hz}, 1 \mathrm{H}, \operatorname{Ar}-\mathrm{H}) ; 7.34(\mathrm{t}, J=5.5 \mathrm{~Hz}, 1 \mathrm{H}, \mathrm{NH}-$ exchangeable with $\mathrm{D}_{2} \mathrm{O}$ ); 7.44 (dd, $J=2.1,9.0 \mathrm{~Hz}, 1 \mathrm{H}, \mathrm{Ar}-\mathrm{H}$ ); 7.64 $(\mathrm{d}, J=8.4 \mathrm{~Hz}, 1 \mathrm{H}, \mathrm{Ar}-\mathrm{H}) ; 7.75$ (d, $J=2.0 \mathrm{~Hz}, 1 \mathrm{H}, \mathrm{Ar}-\mathrm{H}) ; 8.16$ (t, $J=$ $5.5 \mathrm{~Hz}, 1 \mathrm{H}, \mathrm{NH}$-exchangeable with $\left.\mathrm{D}_{2} \mathrm{O}\right) ; 8.25(\mathrm{~d}, J=9.0 \mathrm{~Hz}, 1 \mathrm{H}, \mathrm{Ar}-$ $\mathrm{H}) ; 8.36$ (d, $J=5.3 \mathrm{~Hz}, 1 \mathrm{H}, \mathrm{Ar}-\mathrm{H}) ;{ }^{13} \mathrm{C}$ NMR (125 MHz, DMSO-d $\left.{ }_{6}\right)$ $\delta$ 26.1, 26.8, 28.1, 29.4, 39.5, 42.9, 47.5, 49.1, 53.5, 59.1, 60.4, 99.0, 108.1, 117.9, 118.1, 119.3, 124.5, 124.8, 125.1, 127.9, 133.7, 134.6, 149.3, 150.6, 152.1, 155.7, 166.6, 167.7, 168.2 HRMS calcd for $\mathrm{C}_{3} 1 \mathrm{H}_{37} \mathrm{ClN}_{6} \mathrm{O}_{4}[\mathrm{M}+\mathrm{H}]^{+} 593.2598$ found 593.2604.

$\mathrm{N}$-(2-((7-Chloroquinolin-4-yl)amino)ethyl)-3-(5-(4-(2-hydroxyethyl) piperazin-1-yl)-1,3-dioxoisoindolin-2-yl)propanamide (8p). Yield 69\%; yellow solid; mp 211-212 ${ }^{\circ} \mathrm{C}$; ${ }^{1} \mathrm{H}$ NMR (500 MHz, DMSO-d ${ }_{6}$ ) $\delta$ 2.42-2.45 (m, 4H, 2× - $\left.\mathbf{C H}_{2}-\right)$; $2.53\left(\mathrm{t}, J=5.1 \mathrm{~Hz}, 4 \mathrm{H}, 2 \times-\mathbf{C H}_{2}-\right)$; 3.26-3.31 (m, 4H, 2×- $\mathbf{C H}_{2}-$ ); 3.33-3.35 (m, 4H, $\left.2 \times-\mathbf{C H}_{2}-\right)$ ); 3.52$3.55\left(\mathrm{~m}, 2 \mathrm{H},-\mathbf{C H}_{2}-\right)$; $3.76\left(\mathrm{t}, J=7.1 \mathrm{~Hz}, 2 \mathrm{H},-\mathbf{C H}_{2}-\right)$; $4.47(\mathrm{~s}, 1 \mathrm{H}, \mathrm{OH})$; 6.49 (d, $J=5.4 \mathrm{~Hz}, 1 \mathrm{H}, \mathrm{Ar}-\mathrm{H}) ; 7.11$ (dd, $J=2.3,8.5 \mathrm{~Hz}, 1 \mathrm{H}, \mathrm{Ar}-\mathrm{H}$ ); $7.19(\mathrm{~d}, J=2.3 \mathrm{~Hz}, 1 \mathrm{H}, \operatorname{Ar}-\mathrm{H}) ; 7.28(\mathrm{t}, J=5.2 \mathrm{~Hz}, 1 \mathrm{H}, \mathrm{NH}-$ exchangeable with $\left.\mathrm{D}_{2} \mathrm{O}\right) ; 7.40(\mathrm{dd}, J=2.2,9.0 \mathrm{~Hz}, 1 \mathrm{H}, \mathrm{Ar}-\mathrm{H}) ; 7.53$ (d, $J=8.4 \mathrm{~Hz}, 1 \mathrm{H}, \mathrm{Ar}-\mathrm{H}) ; 7.77$ (d, $J=2.3 \mathrm{~Hz}, 1 \mathrm{H}, \mathrm{Ar}-\mathrm{H}) ; 8.08$ (d, $J=$ $8.9 \mathrm{~Hz}, 1 \mathrm{H}, \mathrm{Ar}-\mathrm{H}) ; 8.25$ (t, $J=5.4 \mathrm{~Hz}, 1 \mathrm{H}, \mathrm{NH}$-exchangeable with $\left.\mathrm{D}_{2} \mathrm{O}\right) ; 8.39(\mathrm{~d}, J=5.4 \mathrm{~Hz}, 1 \mathrm{H}, \mathrm{Ar}-\mathrm{H}) ;{ }^{13} \mathrm{C}$ NMR $\left(125 \mathrm{MHz}, \mathrm{DMSO}_{6}\right.$ ) $\delta 34.7,34.8,37.7,42.7,47.2,53.2,59.0,60.5$, 99.0, 107.9, 117.7, 117.8, 119.2 , 124.2, 124.5, 124.8, 127.9, 133.8, 134.5, 149.4, 150.4, 152.3, 153.3, 168.0, 168.4, 170.9. HRMS calcd for $\mathrm{C}_{28} \mathrm{H}_{31} \mathrm{ClN}_{6} \mathrm{O}_{4}[\mathrm{M}+\mathrm{H}]^{+}$ 551.2129 found 551.2141 .

N-(4-((7-Chloroquinolin-4-yl)amino)butyl)-3-(5-(4-(2-hydroxyethyl) piperazin-1-yl)-1,3-dioxoisoindolin-2-yl)propanamide (8q). Yield 68\%; yellow solid; mp 162-163 ${ }^{\circ} \mathrm{C} ;{ }^{1} \mathrm{H}$ NMR (500 MHz, DMSO-d ${ }_{6}$ ) $\delta$ 1.50-1.55 (m, 2H, - $\left.\mathbf{C H}_{2}-\right)$; 1.62-1.68 (m, 2H, - $\left.\mathbf{C H}_{2}-\right)$; 2.41-2.47 (m, $\left.4 \mathrm{H}, 2 \times-\mathbf{C H}_{2}-\right) ; 2.55\left(\mathrm{t}, J=5.0 \mathrm{~Hz}, 4 \mathrm{H}, 2 \times-\mathbf{C H}_{2}-\right) ; 3.13-3.16(\mathrm{~m}, 2 \mathrm{H}$, $\left.-\mathbf{C H}_{2}-\right)$; 3.27-3.31 (m, 2H, $\left.-\mathbf{C H}_{2}-\right)$; $3.41\left(\mathrm{t}, J=4.5 \mathrm{~Hz}, 4 \mathrm{H}, 2 \times-\mathbf{C H}_{2}-\right)$; $3.54\left(\mathrm{t}, J=6.1 \mathrm{~Hz}, 2 \mathrm{H},-\mathbf{C H}_{2}-\right) ; 3.75\left(\mathrm{t}, J=7.1 \mathrm{~Hz}, 2 \mathrm{H},-\mathbf{C H}_{2}-\right)$; $4.48(\mathrm{~s}$, $1 \mathrm{H}, \mathrm{OH}) ; 6.47(\mathrm{~d}, J=5.5 \mathrm{~Hz}, 1 \mathrm{H}, \mathrm{Ar}-\mathrm{H}) ; 7.10(\mathrm{dd}, J=2.2,8.6 \mathrm{~Hz}, 1 \mathrm{H}$, $\mathrm{Ar}-\mathrm{H}) ; 7.18$ (d, $J=2.2 \mathrm{~Hz}, 1 \mathrm{H}, \mathrm{Ar}-\mathrm{H}) ; 7.27$ (t, $J=5.3 \mathrm{~Hz}, 1 \mathrm{H}, \mathrm{NH}-$ exchangeable with $\mathrm{D}_{2} \mathrm{O}$ ); 7.41 (dd, $\left.J=2.1,9.0 \mathrm{~Hz}, 1 \mathrm{H}, \mathrm{Ar}-\mathrm{H}\right) ; 7.52$ $(\mathrm{d}, J=8.5 \mathrm{~Hz}, 1 \mathrm{H}, \mathrm{Ar}-\mathrm{H}) ; 7.78(\mathrm{~d}, J=2.2 \mathrm{~Hz}, 1 \mathrm{H}, \mathrm{Ar}-\mathrm{H}) ; 8.05$ (d, $J=$ $9.0 \mathrm{~Hz}, 1 \mathrm{H}, \mathrm{Ar}-\mathrm{H}) ; 8.27$ (t, $J=5.4 \mathrm{~Hz}, 1 \mathrm{H}, \mathrm{NH}$-exchangeable with $\left.\mathrm{D}_{2} \mathrm{O}\right) ; 8.40(\mathrm{~d}, J=5.3 \mathrm{~Hz}, 1 \mathrm{H}, \mathrm{Ar}-\mathrm{H}) ;{ }^{13} \mathrm{C}$ NMR (125 MHz, DMSO-d $\left.{ }_{6}\right)$ $\delta$ 25.4, 27.9, 34.6, 37.9, 39.1, 42.7, 47.8, 53.1, 59.1, 60.6, 99.1, 107.8, $117.4,117.9,119.1,124.3,124.5,124.9,127.8,133.9,134.6,149.6$, $150.3,152.5,153.5,168.1,168.7,170.6$. HRMS calcd for $\mathrm{C}_{30} \mathrm{H}_{35} \mathrm{ClN}_{6} \mathrm{O}_{4}[\mathrm{M}+\mathrm{H}]^{+} 579.2442$ found 579.2457 .

$\mathrm{N}$-(6-((7-Chloroquinolin-4-yl)amino)hexyl)-3-(5-(4-(2-hydroxyethyl) piperazin-1-yl)-1,3-dioxoisoindolin-2-yl)propanamide (8r). Yield 64\%; yellow solid; mp 102-103 ${ }^{\circ} \mathrm{C} ;{ }^{1} \mathrm{H}$ NMR (500 MHz, DMSO-d $\mathrm{d}_{6}$ ) $\delta$ 1.32-1.44 (m, 6H, 3× - $\mathbf{C H}_{2}-$ ); 1.63-1.68 (m, 2H, - $\mathbf{C H}_{2}-$ ); 2.42-2.48 $\left(\mathrm{m}, 4 \mathrm{H}, 2 \times-\mathbf{C H}_{2}-\right) ; 2.54\left(\mathrm{t}, J=5.0 \mathrm{~Hz}, 4 \mathrm{H}, 2 \times-\mathbf{C H}_{2}-\right) ; 3.11-3.15(\mathrm{~m}$, $\left.2 \mathrm{H},-\mathbf{C H}_{2}-\right)$; 3.24-3.30 (m, 2H, $\left.-\mathbf{C H}_{2}-\right) ; 3.43$ (t, $J=4.8 \mathrm{~Hz}, 4 \mathrm{H}, 2 \times$ $\left.-\mathbf{C H}_{2}-\right) ; 3.57\left(\mathrm{t}, J=6.1 \mathrm{~Hz}, 2 \mathrm{H},-\mathbf{C H}_{2}-\right) ; 3.75\left(\mathrm{t}, J=7.1 \mathrm{~Hz}, 2 \mathrm{H},-\mathbf{C H}_{2}-\right.$ ); 4.47 (s, 1H, OH); 6.45 (d, J=5.4 Hz, 1H, Ar-H); 7.09 (dd, $J=2.1$, $8.7 \mathrm{~Hz}, 1 \mathrm{H}, \mathrm{Ar}-\mathrm{H}) ; 7.16$ (d, J=2.1 Hz, $1 \mathrm{H}, \mathrm{Ar}-\mathrm{H}) ; 7.28(\mathrm{t}, J=5.1 \mathrm{~Hz}$, $1 \mathrm{H}, \mathrm{NH}$-exchangeable with $\left.\mathrm{D}_{2} \mathrm{O}\right) ; 7.40(\mathrm{dd}, J=2.0,9.0 \mathrm{~Hz}, 1 \mathrm{H}, \mathrm{Ar}-\mathrm{H})$; 7.51 (d, $J=8.4 \mathrm{~Hz}, 1 \mathrm{H}, \mathrm{Ar}-\mathrm{H}) ; 7.79$ (d, $J=2.1 \mathrm{~Hz}, 1 \mathrm{H}, \mathrm{Ar}-\mathrm{H}) ; 8.07$ (d, $J$ 
$=9.0 \mathrm{~Hz}, 1 \mathrm{H}, \mathrm{Ar}-\mathrm{H}) ; 8.29(\mathrm{t}, J=5.5 \mathrm{~Hz}, 1 \mathrm{H}, \mathrm{NH}$-exchangeable with $\left.\mathrm{D}_{2} \mathrm{O}\right) ; 8.41$ (d, $\left.J=5.3 \mathrm{~Hz}, 1 \mathrm{H}, \mathrm{Ar}-\mathrm{H}\right) ;{ }^{13} \mathrm{C}$ NMR (125 MHz, DMSO-d 6 ) $\delta$ 26.3, 26.9, 28.4, 29.6, 34.5, 39.7, 42.8, 47.4, 49.3, 53.7, 59.3, 60.6, 99.0, 107.7, 117.5, 117.9, 119.3, 124.4, 124.8, 124.8, 127.9, 133.8, 134.7, 149.5, 150.5, 152.8, 153.8, 168.2, 168.9, 170.5. HRMS calcd for $\mathrm{C}_{32} \mathrm{H}_{39} \mathrm{ClN}_{6} \mathrm{O}_{4}[\mathrm{M}+\mathrm{H}]^{+} 607.2755$ found 607.2769.

\section{Materials and methods}

\section{Bacterial strains and growth conditions}

M. tuberculosis $\mathrm{mc}^{2} 6230$ (ref. 29) was grown at $37{ }^{\circ} \mathrm{C}$ in Middlebrook 7H9 supplemented with oleic-albumin-dextrosecatalase enrichment (OADC) and $109 \mu \mathrm{M}$ of pantothenic acid (complete 7H9).

\section{Drug susceptibility testing}

The vulnerability of $M$. tuberculosis $\mathrm{mc}^{2} 6230$ to the synthesized compounds was determined as reported previously. ${ }^{30}$ Briefly, an exponentially growing culture was diluted in complete $7 \mathrm{H} 9$ to and $\mathrm{OD}_{600}=0.01$. The bacteria were then seeded in $100 \mu \mathrm{L}$ volumes in all the wells of a 96-well plate except the first column of wells which contained $200 \mu \mathrm{L}$ of bacterial suspension. Compounds (stock concentration $10 \mathrm{mg} \mathrm{mL}^{-1}$ ) were directly added to the wells of the first column so as to achieve a concentration of $200 \mu \mathrm{g} \mathrm{mL}^{-1}$ (or $100 \mu \mathrm{g} \mathrm{mL}^{-1}$ in cases where precipitation at the higher concentration was observed). Twofold serial dilutions were then carried out by transferring 100 $\mu \mathrm{L}$ of bacterial suspension from the first column of wells to the second column, mixing, and repeating this procedure for each consecutive column. The plates were then placed in sealed plastic bags and incubated at $37^{\circ} \mathrm{C}$. After 7 days of incubation, plates were visually inspected to determine the MIC, which was defined as the minimal concentration of compound at which no growth of bacteria was observed. Drug susceptibility testing was completed twice, with each compound tested in duplicate. Isoniazid was included as a positive control.

\section{Cytotoxicity assay}

Cell viability was determined using Vero cells (ATCC, Sigma, Germany) grown in RPMI medium (Gibco, USA), supplemented with $10 \%$ decomplemented fetal calf serum, under a $5 \% \mathrm{CO}_{2}$ atmosphere. Cells were seeded in 96-well plates at a density of 2 $\times 10^{4}$ cells per well in $160 \mu \mathrm{L}$ medium and incubated overnight at $37{ }^{\circ} \mathrm{C}$ to allow cells to adhere. Compounds (dissolved in DMSO) were freshly diluted to appropriate concentrations in RPMI, so as to allow addition of $20 \mu \mathrm{L}$ volumes of the diluted compounds to the cells that resulted in final compound concentrations ranging from $100 \mu \mathrm{g} \mathrm{mL}^{-1}$ to $0.78 \mu \mathrm{g} \mathrm{mL}{ }^{-1}$. The maximum final concentration of DMSO was $1 \%(\mathrm{v} / \mathrm{v})$ and no cytotoxic effect of DMSO was observed at this concentration. After $24 \mathrm{~h}$ incubation at $37^{\circ} \mathrm{C}, 20 \mu \mathrm{L}$ of $1 \mathrm{mg} \mathrm{mL}{ }^{-1}$ resazurin (Sigma, Germany) was added to each well and the cells were incubated for an additional 3 hours at $37{ }^{\circ} \mathrm{C}$. Fluorescence was measured in a Polarstar Omega fluorometer using appropriate filters (540 $\mathrm{nm}$ excitation and $590 \mathrm{~nm}$ emission wave length). Percentage survival was determined by dividing fluorescence values obtained in the compound containing wells by values obtained for control wells containing cells incubated with a dilution series of DMSO and multiplying this value by 100 . SDS $(20 \%)$ was included as a positive control. Cytotoxic evaluation was completed twice, with each compound tested in duplicate. The $\mathrm{IC}_{50}$ is defined as the lowest concentration of compound tested at which exactly $50 \%$ cell viability was observed and was calculated using a non-linear regression curve using Graphpad Prism 5. The SI values were determined as a function of $\mathrm{IC}_{50} / \mathrm{MIC}_{99}$.

\section{Conflicts of interest}

The authors declare no conflict of interest.

\section{Abbreviations}

$\begin{array}{ll}\text { MIC }_{990} & 99 \% \text { minimum inhibitory concentration } \\ \text { MW } & \text { microwave } \\ + \text { SAR } & \text { Structure activity relationship } \\ \text { NMP } & N \text {-Methyl-2-pyrrolidone } \\ \text { DMF } & \text { Dimethylformamide } \\ \text { DMSO } & \text { Dimethyl sulfoxide } \\ \text { SI value } & \text { Selectivity index } \\ \text { IC }_{50} & 50 \% \text { inhibitory concentration }\end{array}$

\section{Acknowledgements}

Council of Scientific and Industrial Research (CSIR), New Delhi, India was acknowledged by AR for CSIR-JRF Fellowship (A.R.) with Ref. No. 09/254(0269)/2017-EMR-1. Science and Engineering Research Board (SERB), New Delhi was acknowledged by VK for financial assistance with grant no. EMR/2015/001687. LK acknowledges the support by the Fondation pour la Recherche Médicale (FRM) (DEQ20150331719) and the Labex EpiGenMed under the program "Investissements d'avenir » (ANR-10-LABX-12-01).

\section{References}

1 S. Chetty, M. Ramesh, A. S. Pillay and M. E. S. Soliman, Bioorg. Med. Chem. Lett., 2017, 27, 370-386.

2 World Health Organization (WHO), Global tuberculosis report, 2016, available from: http:/www.apps.who.int/iris/ bitstream/10665/250441/1/9789241565394-eng.pdf?ua=1, 2016, accessed 3 October 2017.

3 Revised National Tuberculosis Control Program, Training manual on intensified TB/HIV package, Ministry of Health and Family Welfare, New Delhi, 2017.

4 X. Lu, J. Tang, S. Cui, B. Wan, S. G. Franzblauc, T. Zhang, X. Zhang and K. Ding, Eur. J. Med. Chem., 2017, 125, 41.

5 WHO Multidrug and extensively drug-resistant TB 2010 Global report on surveillance and response (http:/www.apps.who.int/ iris/bitstream/10665/44286/1/9789241599191_eng.pdf). 
6 H. Janmanchi, A. Raju, M. S. Degani, M. K. Ray and M. G. R. Rajan, S. Afr. J. Bot., 2017, 113, 421.

7 A. H. Diacon, A. Pym, M. Grobusch, R. Patientia, R. Rustomjee, L. Page-Shipp, C. Pistorius, R. Krause, M. Bogoshi, G. Churchyard, A. Venter, J. Allen, J. C. Palomino, T. De Marez, R. P. van Heeswijk, N. Lounis, P. Meyvisch, J. Verbeeck, W. Parys, K. de Beule, K. Andries and D. F. Mc Neeley, N. Engl. J. Med., 2009, 360, 2397.

8 N. Veziris, M. Ibrahim, N. Lounis, T. Andries and V. Jarlier, PLoS One, 2011, 6, 17556.

9 J. Cohen, Science, 2013, 339, 130.

10 A. H. Diacon, A. Pym, M. P. Grobusch, J. M. de los Rios, E. Gotuzzo, I. Vasilyeva, V. Leimane, K. Andries, N. Bakare, T. De Marez, M. Haxaire-Theeuwes, N. Lounis, P. Meyvisch, E. De Paepe, R. P. G. van Heeswijk and B. Dannemann, $N$. Engl. J. Med., 2014, 371, 723.

11 S. Umamatheswari and C. Sankar, Bioorg. Med. Chem. Lett., 2017, 27, 695.

12 S. Jayaprakash, Y. Iso, B. Wan, S. G. Franzblau and A. P. Kozikowski, ChemMedChem, 2006, 1, 593.

13 L. E. Bermudez, P. Kolonoski, M. Wu, P. A. Aralar, C. B. Inderlied and L. S. Young, Antimicrob. Agents Chemother., 1999, 43, 1870.

14 L. E. Bermudez, P. Kolonoski, L. E. Seitz, M. Petrofsky, R. Reynolds and M. Wu, Antimicrob. Agents Chemother., 2004, 48, 3556.

15 L. E. Bermudez, P. Kolonoski, M. Petrofsky, M. Wu, C. B. Inderlied and L. S. Young, J. Infect. Dis., 2003, 187, 1977.

16 J. Mao, H. Yuan, Y. Wang, B. Wan, D. Pak, R. He and S. G. Franzblau, Bioorg. Med. Chem. Lett., 2010, 20, 1263.

17 J. Mao, Y. Wang, B. Wan, A. P. Kozikowski and S. G. Franzblau, ChemMedChem, 2007, 2, 1624.

18 U. Sharma, P. Kumar and B. Kumar, Mini-Rev. Med. Chem., 2010, 10, 678.

19 S. M. Capitosti, T. P. Hansen and M. L. Brown, Bioorg. Med. Chem. Lett., 2004, 12, 327.
20 S. G. Stewart, C. J. Braun, S. L. Ng, M. E. Polomska, M. Karimi and L. J. Abraham, Bioorg. Med. Chem., 2010, 18, 650.

21 S. H. L. Kok, R. Gambari, C. H. Chu, M. C. W. Yuen, E. Lin, R. S. M. Wong, F. Y. Lau, G. Y. M. Cheng, W. S. Lam, S. H. Chan, K. H. Lam, C. H. Cheng, P. B. S. Lai, M. W. Y. Yu, F. Cheung, J. C. O. Tang and A. S. C. Chan, Bioorg. Med. Chem., 2008, 16, 3626.

22 S. M. Sami, R. T. Dorr, D. S. Alberts, A. M. Solyom and W. A. Remers, J. Med. Chem., 2000, 43, 3067.

23 R. Dahlbom, B. Karlen, R. George and D. J. Jenden, J. Med. Chem., 1966, 9, 843-846.

24 H. Akgun, I. Karamelekoglu, B. Berk, I. Kurnaz, G. Saribiyik, S. Oktem and T. Kocagoz, Bioorg. Med. Chem., 2012, 20, 4149.

25 (a) J. L. Santos, P. R. Yamasaki, C. M. Chin, C. H. Takashi, F. R. Pavan and C. Q. F. Leite, Bioorg. Med. Chem., 2009, 17, 3795; (b) A. Kamal, A. HariBabu, A. V. Ramana, R. Sinha, J. S. Yadava and S. K. Arorab, Bioorg. Med. Chem. Lett., 2005, 15, 1923.

26 A. Rani, A. Viljoen, Sumanjit, L. Kremer and V. Kumar, ChemistrySelect, 2017, 2, 10782.

27 (a) A. Singh, A. Viljoen, L. Kremer and V. Kumar, Future Med. Chem., 2017, 9, 1701; (b) A. Singh, C. Biot, A. Viljoen, C. Dupont, L. Kremer, K. Kumar and V. Kumar, Chem. Biol. Drug Des., 2017, 89, 856; (c) A. Singh, J. Gut, P. J. Rosenthal and V. Kumar, Eur. J. Med. Chem., 2017, 5, 269; (d) S. Kumar, A. Saini, J. Gut, P. J. Rosenthal, R. Raj and V. Kumar, Eur. J. Med. Chem., 2017, 138, 993.

28 D. Di, F. M. Krogstad, L. D. Byers and D. J. Krogstad, J. Med. Chem., 1998, 41, 4918.

29 V. K. Sambandamurthy, S. C. Derrick, T. Hsu, B. Chen, M. H. Larsen, K. V. Jalapathy, M. Chen, J. Kim, S. A. Porcelli, J. Chan, S. L. Morris and W. R. Jacobs Jr, Vaccine, 2006, 24, 6309.

30 J. Ollinger, M. A. Bailey, G. C. Moraski, A. Casey, S. Florio, T. Alling, M. J. Miller and T. Parish, PLoS One, 2013, 8, e60531. 